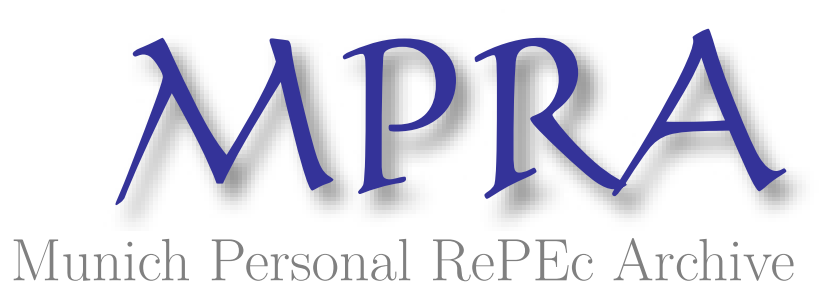

\title{
Tranched Value Securities
}

Zvezdin, Nikolay

19 February 2019

Online at https://mpra.ub.uni-muenchen.de/92302/

MPRA Paper No. 92302, posted 22 Feb 2019 04:34 UTC 


\title{
Tranched Value Securities
}

\author{
by
}

\author{
Nikolay Zvezdin ${ }^{1}$
}

February 19, 2019

\begin{abstract}
Structured financial products and derivatives were one of the major financial innovations since 18th century, which improve market completeness by transforming risk-sharing mechanisms. Since then, thousands of derivative types were created, and its market has grown to over six-times greater than global GDP, but capital markets still exhibit efficiency only to a limited extent. This paper assesses the potential performance of Tranched Value Securities (patent pending) - a new financial instrument that transforms a single underlying to asymmetrically paying derivative, and has a potential to further improve capital markets by facilitating risk sharing, and satisfy a wide range of investment objectives.
\end{abstract}

Keywords: tranched value securities; value tranching; derivatives; securitization; risk transfer; financial instrument; structured products; securities; alternative investments; financial innovation

JEL Classification: G, G1, G10, G12, G13, G19

\footnotetext{
${ }^{1}$ Corresponding author e-mail: nikolay.zvezdin@ yahoo.com.
} 


\section{Introduction}

Since the mid-18th century one of the most significant innovations in the financial world was creation of asset-backed securities (ABS), which were represented by mortgage-backed securities (MBS) in the United States where farm railroad mortgage bonds were issued ${ }^{2}$. Since then many other types of derivative products were created in an attempt to enhance risk transfer between market participants by securitizing assets or cash-flows. As a result of the advancements in structured products, global OTC derivatives market (Figure 1) has grown from nearly US\$ 80 trillion in 1998 to almost US\$ 700 trillion at the peak in 2011, and slightly over US\$ 500 trillion in 2017, which is 6x times greater than global GDP according to IMF (January 2019).

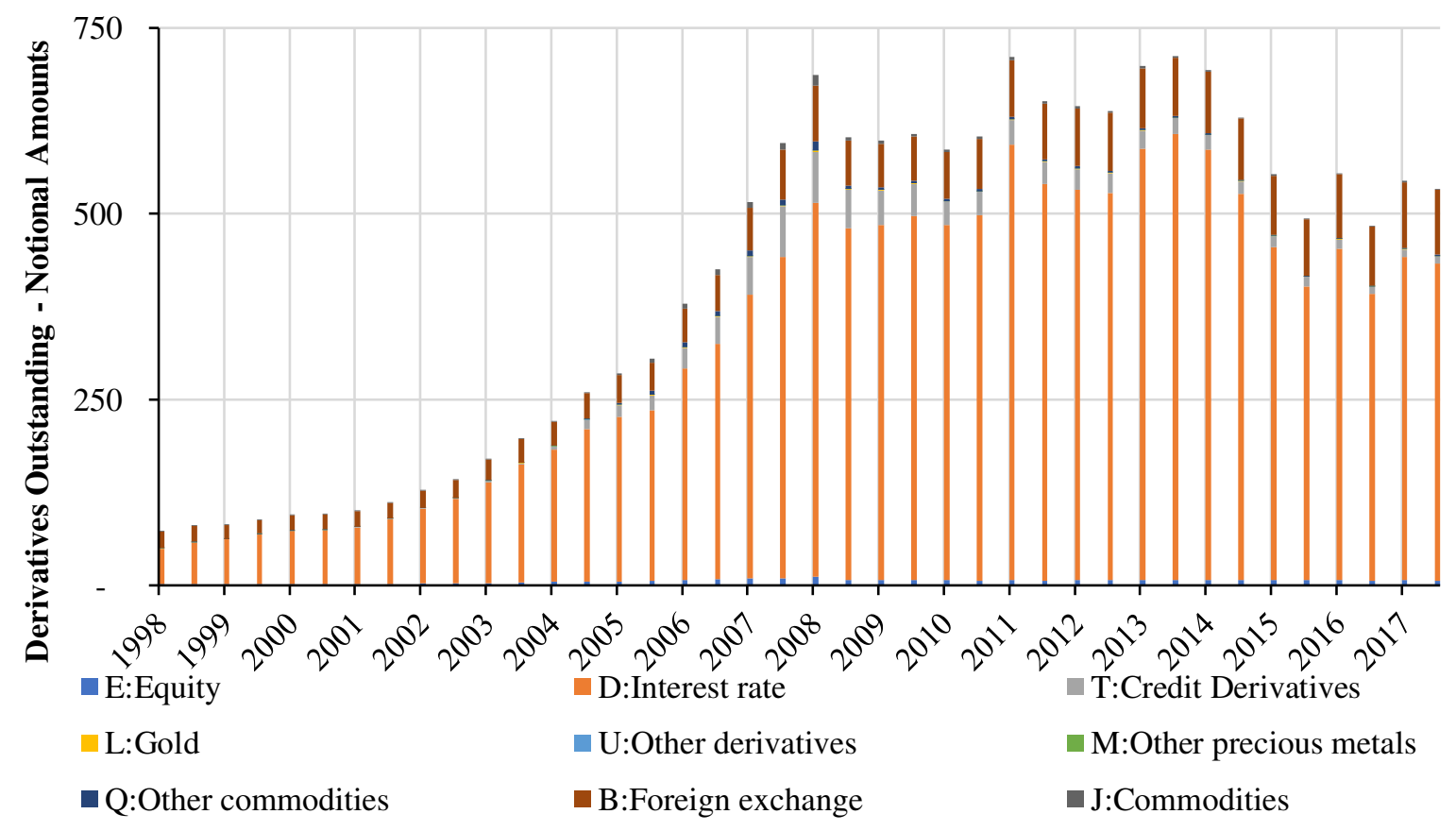

Source: Bank for International Settlements (BIS)

Figure 1: Global OTC Derivatives Market (US\$ trn).

Despite the importance and size of global derivatives market, and continuous developments, there has been little change to the actual structure of derivatives, as most of them either split various pooled assets or pooled cash-flows from the groups of assets

\footnotetext{
${ }^{2}$ See Riddiough, Timothy J. and Thompson, Howard E. (18/04/2012).
} 
using different types of combination of forward commitments or contingent claims with slightly modified parameters.

However, with the currently evolved technological environment it is possible to create a new type of financial instrument, that would tranch value of a single asset or a single cash-flow, resulting in creation of multiple instruments of various risk profiles all within the same asset or cash-flow, which would satisfy different types of investors from sovereign wealth and pension funds who invest only in the safest instruments (or tranches), to speculative hedge funds aiming for high risk, high return investment opportunities. This instrument that effectively tranches a value of a single asset or cashflow - Tranched Value Security (TVS), is expected to facilitate further improvement of risk-transfer practice, and evolution of financial system.

\section{Related Literature}

As shown by the various examples by Robert L. Kosowski and Salih N. Neftci (2015), current financial market accommodates different types of structured financial instruments, ranging from traditional futures and options contracts, to Quantos, volatility swaps, swaptions, and other types of hybrid instruments. Don M. Chance, PhD, CFA and Don M. Chance, PhD, CFA (2013) generalize derivative instruments to be either forward commitments, where parties fulfil an obligation in some point in future, or contingent claims which have a value in the future if a specified event occurs or given conditions are met (such as reaching a specific price by an asset). As a result of financial innovation and market development, securitization became a norm of financial practice, when multiple assets or cash-flows are pooled together, tranched and sold as different securities with various risk-return characteristics to multiple investors. Thus, different financial products have emerged, such as asset-backed securities (ABS), cash-flow backed securities, and even future flows securities ${ }^{3}$.

Moreover, there has been a number of attempts to create innovative financial instruments or include specific contractual provisions that would change the nature of

\footnotetext{
${ }^{3}$ See Vinod Kothari (2006).
} 
instruments. Some examples of such are presented by Katarzyna Jakimowicz, David Osimo, and others (2017) that discuss use of co-investment schemes defined as public equity investment in private companies alongside a partner organization; blending instruments, which combine grants with either loans, soft loans, guarantees, or equity; and royalty-based financing instruments, also referred to as revenue-based financing.

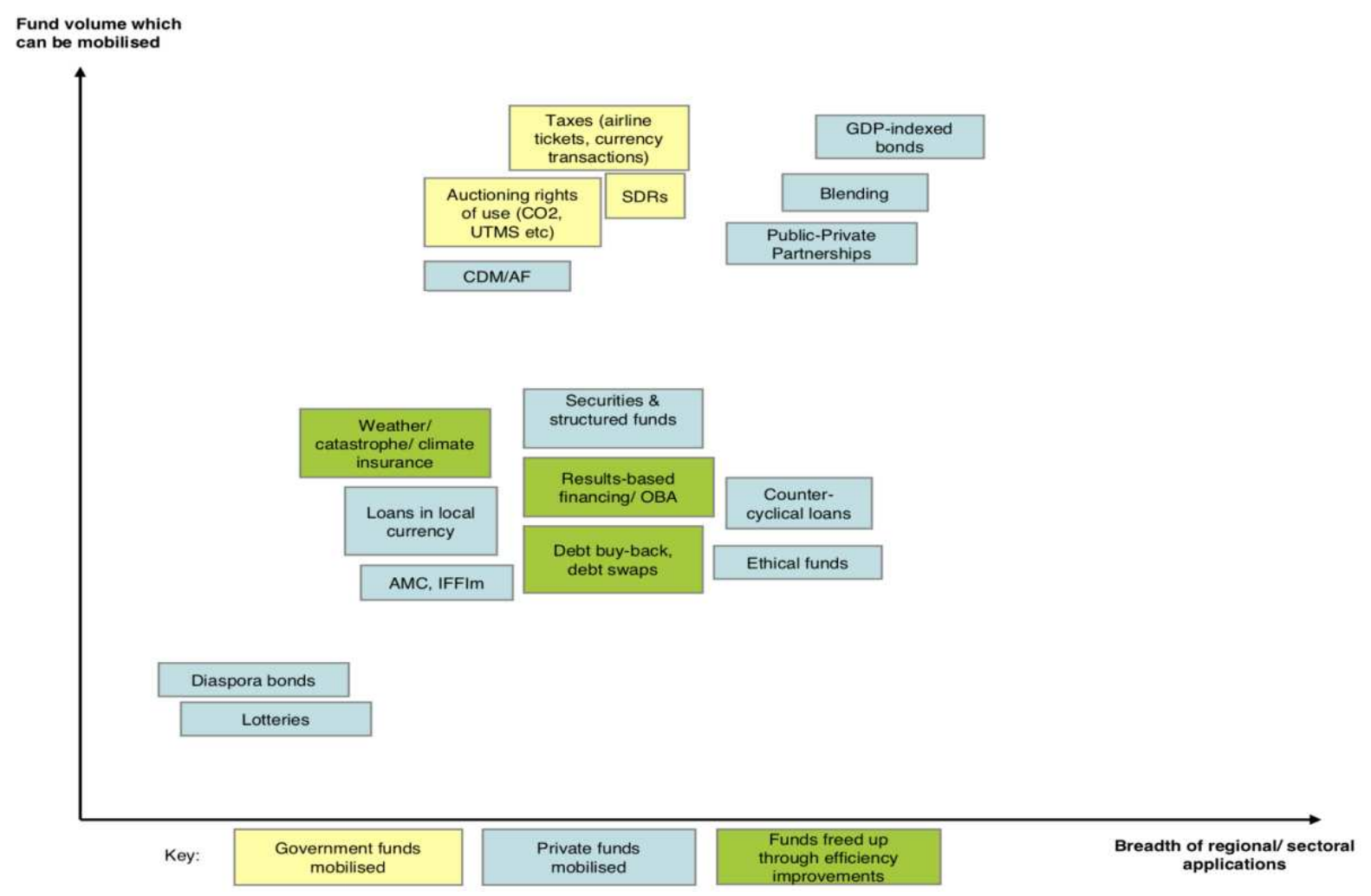

Source: Dr. Helke Waelde. KWF

Figure 2: Innovative Financial Instruments.

Another overview of new financial instruments is provided by Dr. Helke Waelde (2013), where instruments can be of three types: additional public funds, which implement taxes and levies on specific activities, government auctions on rights of use, and allocation of International Monetary Fund's (IMF) Special Drawing Rights (SDR); additional private funds that include Public Private Partnerships (PPPs), government guarantees, blended instruments, performance-dependent debt instruments, ethical loans, and diaspora funds; and efficiency improvement and debt conversion instruments, that include result-based financing instruments, weather insurance, conditional debt 
forgiveness mechanisms and debt-for-development swaps. These instruments are summarized on Figure 2, and as can be seen, they are typically modifications of existing instruments or contractual agreements, with hybrid or specialized characteristics and underlying assets. However, such instruments are mostly non-standardized, and are not easily accessible by general investment public, even though they do serve the purpose of risk-transfer when used for narrow purposes.

Besides the above instruments, there are various other equity and debt derivatives and structured products, among which Barriers, Cliquets, Autocallable, Volatility-linked, Equity-linked CDs, Baskets and Rainbow derivatives, and multiple others, all of which modify some of the more common derivative parameters and combine various products or assets under one security with diverse payment and obligation structures. This allows satisfying various risk-return appetites of different investment groups, however, none of currently available instruments is able to do so within a single asset that could serve as underlying for the same class of instrument with various risk-return profile.

This results in market incompleteness and only partial efficiency ${ }^{4}$, allowing for asset mispricing, instruments misuse and arbitrage profits for sophisticated investors. At the same time, while return pattern from a securities or derivatives can be either symmetric or asymmetric 5 , whereas symmetric implies returns that move proportionally in response to price changes of underlying, and asymmetric being such instrument that does not directly translate returns of underlying into a continuous linear profit-loss pattern of derivative instrument; there is a continuous increase in the demand for financial instruments with asymmetric return patterns, and the currently presented Tranched Value Security (TVS) is one of possible types of such instrument.

\section{Tranched Value Securities}

This section lays out some of the basic principles and parameters of the proposed new financial instrument - Tranched Value Security. First, general construction model is

\footnotetext{
${ }^{4}$ See Saad E.W., Prokhorov D.V., and Wunsch D.C. (November 1998).

${ }^{5}$ See Gary L. Gastineau and Louis I. Margolis (1994).
} 
presented with some key attributes of TVS, with later economic valuation model and its advantages and further work required depiction.

\section{A. TVS General Form}

In perfect capital markets, TVS, similar to other derivatives would serve no purpose; as the costs of constructing and marketing it would inhibit its creation. However, market perfectness is highly questionable given the currently worsening economic conditions, and various evidences shown by Jegadeesh, N, and Titman, S. (2001), which demonstrated that some investment strategies, such as momentum in particular do produce positive risk-adjusted average returns; by multiple market anomalies, such as Calendar effects (Sell in May principle ${ }^{6}$, January effect ${ }^{7}$, January barometer ${ }^{8}$, Mark Twain effect $^{9}$, Weekend effect ${ }^{10}$, and several others), various asset bubbles ${ }^{11}$, stock market crashes, and flash crushes ${ }^{12}$; and by existence of investors that succeed to continually outperform markets ${ }^{13}$. While some of these anomalies do fade away over time, sometimes they appear again on the market, while others continually persist ${ }^{14}$, illustrating that financial markets are not of strong form efficiency, and if not of weak form efficiency they are at least semi-strong efficient ${ }^{15}$.

All of this supports a need for further enhancement of market efficiency, which is partially possible with new financial instruments that would improve market completeness, risk transfer practice and sensitivity to new information, and Tranched Value Security is a possible candidate for this role.

\footnotetext{
${ }^{6}$ See Maberly, Edwin D., and Raylene M. Pierce (April 2004).

${ }^{7}$ See Haugen, R. A., \& Lakonishok, J. (1988).

${ }^{8}$ See Christian Felde (January 2011).

${ }^{9}$ See Teresa Meek (February 2017).

${ }^{10}$ See Kenneth R. French (March 1980).

${ }^{11}$ See Michael Simkovic (2009).

12 See Dragos Bozdog, Ionut Florescu, Khaldoun Khashanah, and Jim Wang (October 2018).

${ }^{13}$ See John Reeves (May 2009).

${ }^{14}$ See Eugene F. Fama and Kenneth R. French (2008).

${ }^{15}$ See Saad E.W., Prokhorov D.V., and Wunsch D.C. (November 1998).
} 
In addition to the above, recent period of low interest rates ${ }^{16}$, creates a need for new instruments that would allow to amplify risk-return profiles of various assets by artificially creating different risk-return levels within the same security, which can satisfy diverse investment groups, without necessarily packaging and repackaging a number of other securities, and increasing use of leverage, as it is currently usually done.

As such, TVS presents an opportunity for market improvement, while combining some of the properties of other currently existing structured products.

The author defines Tranched Value Security (TVS) as: a security whose income payments, and hence value is derived from and collateralized (or "backed") by the value of a single asset, group of assets, stream of cash-flows or any other entity or product possibly having a determinable value (and / or price). Value of TVS is derived either from a value share of a specific underlying, or from a minimum contract value, which can equal to the value share of a specific underlying at the contract initiation, given that a higherlevel (or "prior") TVSs are satisfied.

Tranching the value of a single asset and creating different products allows TVS to be sold through securitization process, while diversifying underlying-specific risks by creating value tranches of various orders. This is similar to the sequential-pay collateralized mortgage obligations (CMOs), which are structured so that each tranche retires in sequence, where the payment rules for principal payment distribution are known but the exact amounts to be paid are not. TVS offers similar rules for value exercise, where first, all senior value tranches must be paid if requested (similar to exercising a call option contract), followed by the less senior tranches if anything left. Other instruments are also similar in concept to TVS that allow for credit tranching, time tranching, cash-flow tranching, asset pool tranching, with a major distinction, that with the use of TVS, the underlying does not need to be necessarily a pool of assets or a stream of various cash flows - it can be rather anything, what has a value.

The main principles of TVS are depicted on Figure 3, which is a modification of IMF's illustration of CDO principles (2008), as TVS effectively possesses similar characteristics

\footnotetext{
${ }^{16}$ See Ardeshir Sepehri, and Saeed Moshiri (January 2007).
} 
to any other ABS (and CDO), but instead of using pooled assets or cash-flows as underlying, is using asset's value, which is further subordinated.

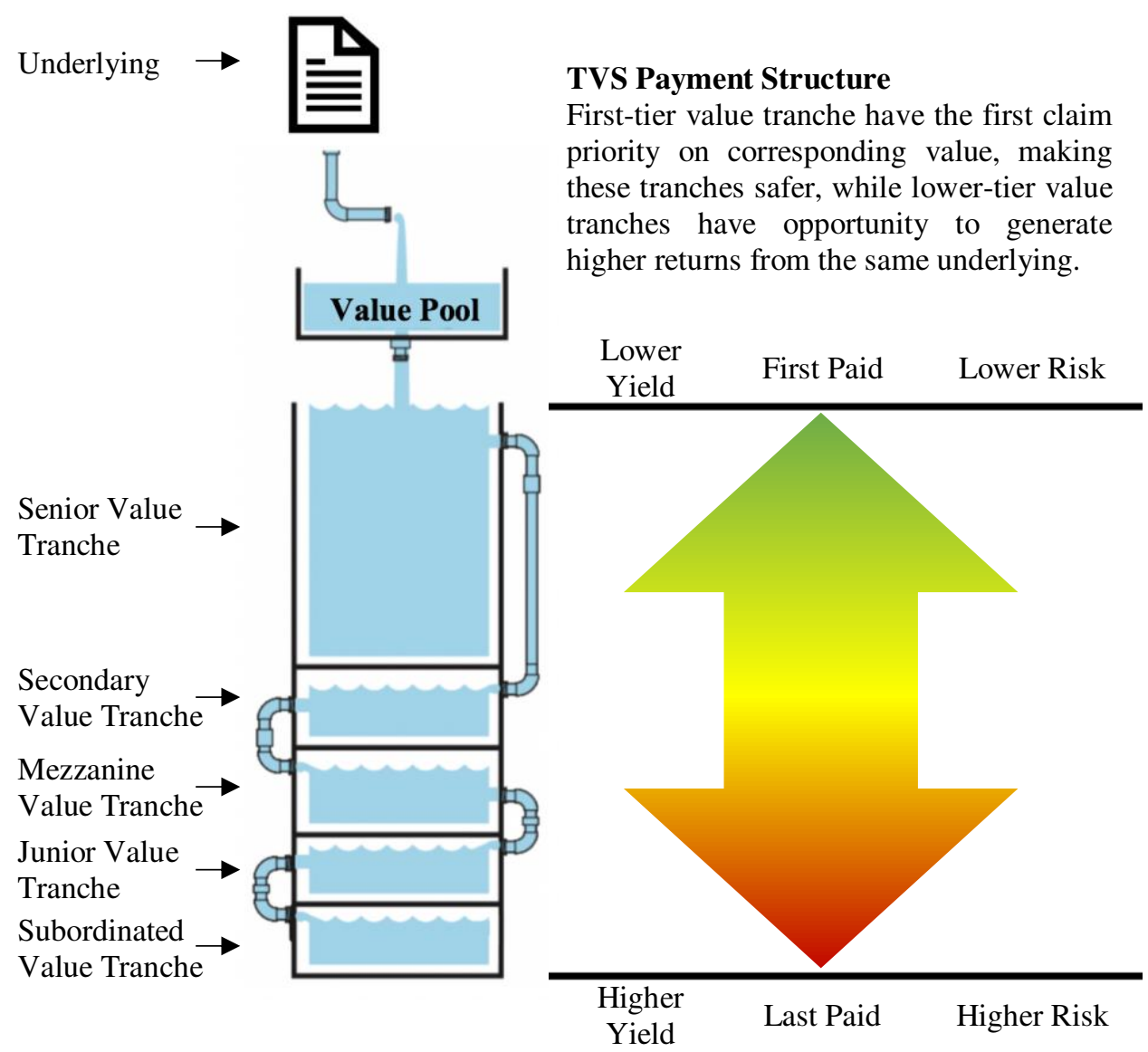

Source: Modified according to IMF (2008).

Figure 3: TVS General Principle.

In such structure, the highest value tranches are similar to the Planned Amortization Class (PAC) tranche securities, while in the case of TVS, it is rather a Planned Value Class (PVC) tranche securities, which is designed to protect investors from sharp declines of value of their portfolios, allowing to effectively manage idiosyncratic risks. On the other hand, the lowest value tranches can be viewed as support value tranches (SVT), which exhibit the highest risks and highest expected returns. As long as the market value of underlying does not fluctuate significantly from the initial one, values of PVCs and SVTs will remain relatively stable, reducing the risk that investors' portfolio value will deteriorate significantly, thus allowing all investors to earn relatively same return from 
the TVSs that are based on the same underlying. However, once the underlying's value starts to exhibit significant volatility, different tranches of TVS backed by the same underlying start to display very different returns, as will be shown further.

While the main proposed structure of TVS is of perpetual nature in the case of equity instruments (with indefinite life and no expiration date), TVS issued for maturing fixed income instruments or contracts with expiration date, can also have an expiration date.

\section{B. TVS Contractual Relations}

A generic example of the contractual relationships involved in TVS are shown on Figure 4, which is modified from Schorin, C. and S. Weinreich (1998).

The trustee of the TVS is responsible for monitoring the contractual provisions of the TVS and their execution. Manager of the underlying is responsible for selection and purchase of underlying for special purpose vehicle (SPV), with subsequent tranching the value of underlying, creating multiple securities, that are held by SPV. Special purpose vehicle issues multiple securities (TVSs) that correspond to various levels of seniority of the value pool, which are sold to investors. Other roles required in TVS issuance include underwriters that acts as the structurers and arrangers, accountants that would perform a cash-flow tie-out in which the transaction's waterfall is modeled per the priority of value set forth in the transaction documents, and attorneys that ensure compliance with applicable laws and regulations and draft the transaction documents.

Moreover, in order to further improve a particular value tranche of the TVS issuance, external or internal value enhancement methods can be used by involving lending or insurance organizations. As a part of internal value enhancement, the issuer of TVS might overcollateralize the particular issuance by pledging supportive risk-free securities, or providing the underlying of the greater value than a particular value of TVS at issuance or a specific issuance tranche only. Additionally, a reserve account can be used that would be reimbursing a value tranche of a particular TVS up to the amount allocated for the reserve. As a part of external value enhancement, traditional credit enhancement 
mechanisms can be used, such as surety bonds, wrapped securities, and letters of credit, in order to further decrease risks of senior value tranches of TVS security.

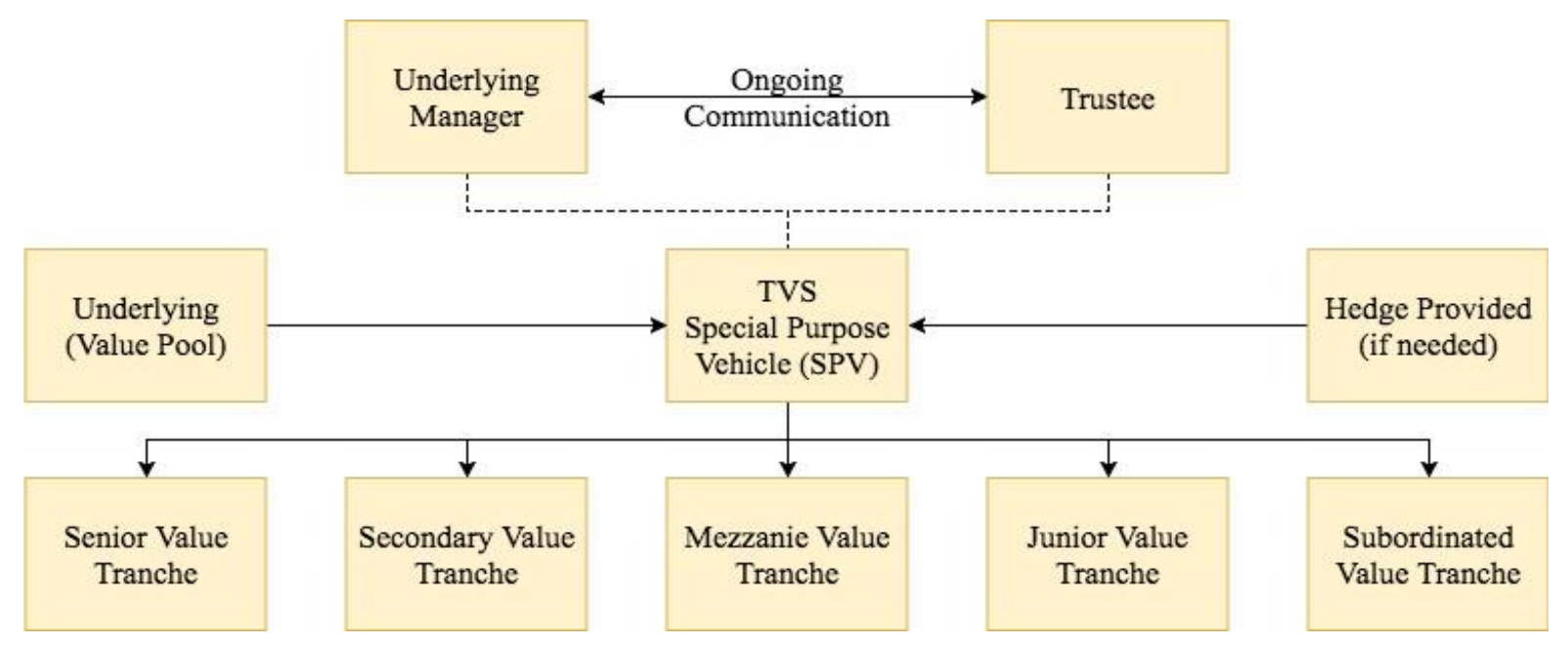

Source: Modified according to Schorin, C. and S. Weinreich (1998).

Figure 4: TVS Contractual Relationships.

All above, allows for efficient risk transfer and performance transformation, creating from a single instrument a series of different instruments with the same or different (depending on a particular issuance) risks from a single issue.

\section{TVS Economics and Valuation}

Based on the earlier presented definition and general structure of Tranched Value Securities, unconditional value of each individual TVS unit to investor is displayed by equation ( 1 )

$$
T V S_{i_{t}}=\max \left(w_{i} S_{t}, X_{i}\right)
$$

Where $T V S_{i_{t}}$ is the value of Tranched Value Security $\left(T V S_{i}\right)$, i.e. $i$-th value tranche at time $t=n$ of underlying $\left(S_{t}\right) ; S_{t}$ is the price of underlying at time $t=n ; w_{i}$ is the fixed weight of $i$-th value share corresponding to the specific underlying $\left(S_{t}\right)$ at the contract initiation $(t=0) ; X_{i}$ is the minimum corresponding value of $T V S_{i}$ share at any time, which is set fixed and equals to $w_{i} S_{t}$ during the contract initiation at $t=0$. 
However, the nature of TVS conditionally tranched on the level of seniority of specific value shares implies that before the current unit of TVS can be satisfied, the previous level (more senior-level) of TVS must be satisfied, implying the model ( 2 )

$$
T V S_{i_{t}}=\min \left(S_{t}-T V S_{i-1_{t}}, \max \left(w_{i} S_{t}, X_{i}\right)\right)
$$

Where $T V S_{i_{t}}$ is the value of Tranched Value Security $\left(T V S_{i}\right)$, i.e. $i$-th value tranche at time $t=n$ of underlying $\left(S_{t}\right) ; S_{t}$ is the price of underlying at time $t=n ; w_{i}$ is the fixed weight of $i$-th value share corresponding to the specific underlying $\left(S_{t}\right)$ at the contract initiation $(t=0) ; X_{i}$ is the minimum corresponding value of $T V S_{i}$ share at any time, which is set fixed and equals to $w_{i} S_{t}$ during the contract initiation at $t=0 ; T V S_{i-1_{t}}$ is the value of higher-ranked Tranched Value Security $\left(T V S_{i}\right)$, i.e. $i-1$-th value tranche at time $t=n$ of underlying $\left(S_{t}\right)$, which must be satisfied before any subsequent Tranched Value Security $\left(T V S_{i+1}\right)$ can be fulfilled.

Based on this simplistic model, it is possible to illustrate price behavior of such instrument. It can be assumed that value of underlying $\left(S_{t=0}\right)$ is US $\$ 100.00$, for which senior value tranche security, and secondary value securities were issued. Senior value tranche security $\left(T V S_{S E N}\right)$ corresponds to $60.00 \%$ value of underlying $\left(w_{S E N}=60.00 \%\right)$, which is fixed and equals to $w_{S E N} S_{t=0}=X_{S E N}=U S \$ 60.00$ minimum value, or more specifically $T V S_{S E N}=\max \left(60.00 \% \times S_{t}, U S \$ 60.00\right)$; while the secondary value tranche security $\left(T V S_{S E C}\right)$ corresponds to $1-w_{S E N}=w_{S E C}=40.00 \%$ value of underlying, which is fixed and equals to US\$ 40.00 minimum value, or more specifically $T V S_{S E C}=$ $\max \left(40.00 \% \times S_{t}, U S \$ 40.00\right)$, and can be paid only if the senior value security (TVS $\left.S_{S E N}\right)$ has been fully satisfied.

Based on ( 2 ), and specified initial parameters, during the contract initiation $(t=0)$, three securities have such values as: $S_{t=0}=100.00, T V S_{S E N_{t=0}}=60.00, T V S_{S E C_{t=0}}=$ 40.00. However, once market movements occur and change the price of $S_{t}$ to any price different from $S_{t=0}$, the two $T V S_{i_{t}}$ change their value in a different manner. Assuming the sample rates of return of $S_{t=n}:+0.0 \%,+50.0 \%,+50.0 \%,-50.0 \%,-50.0 \%,+50.0 \%,+50.0 \%$, during $t=n+0 \ldots+6, S_{t}, T V S_{S E N}$, and $T V S_{S E C}$ exhibit price and return rates as displayed on Figure 5. 

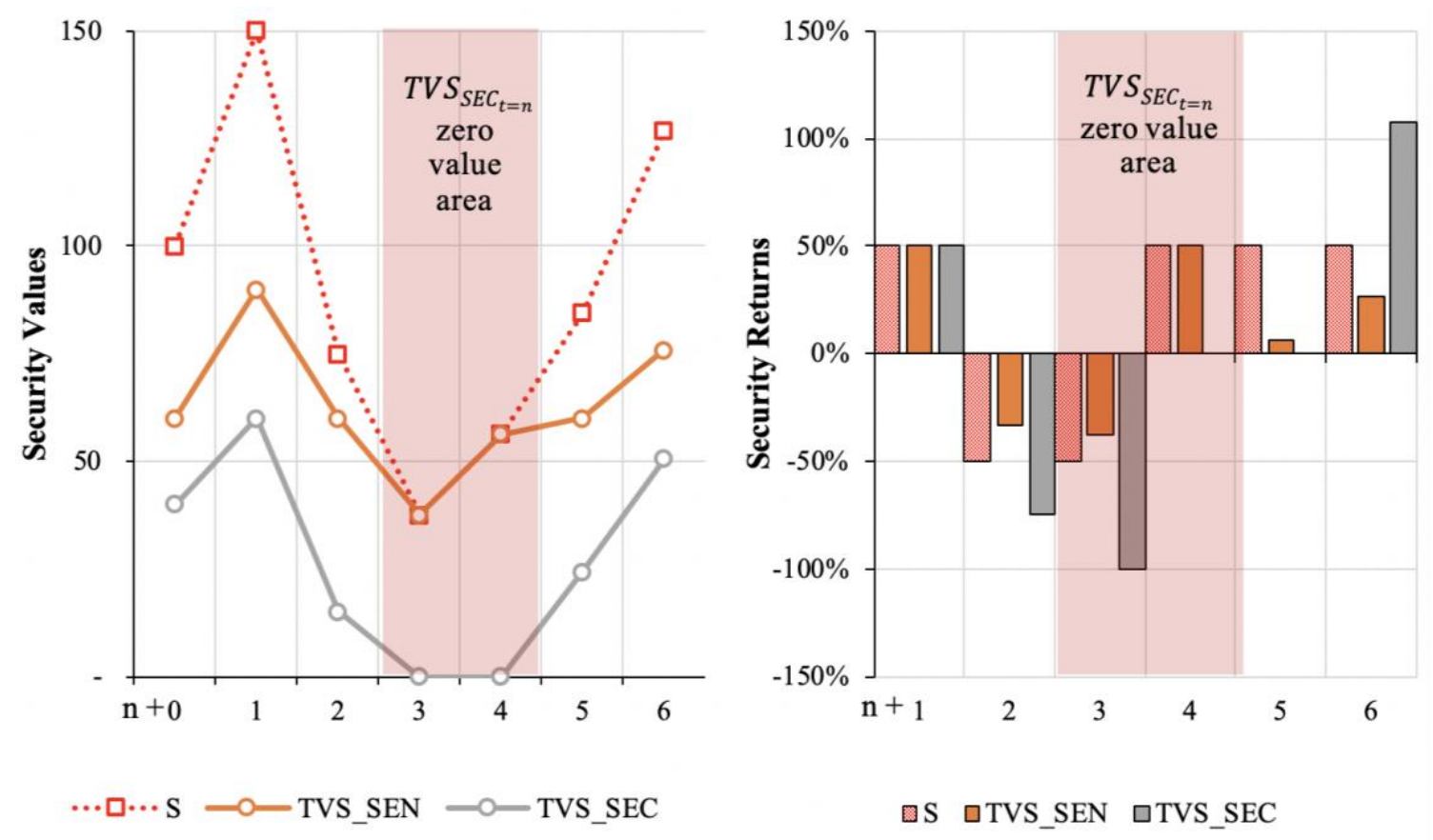

Figure 5: Sample Values (US\$) and Returns (\%) of $S_{t=n}, T V S_{S E N_{t=n}}$, and $T V S_{S E C_{t=n}}$.

The illustrations above clearly show that a single underlying with an observable or measurable price (and / or value, as used interchangeably in the current context) can be used to create two or more TVSs that will generate various returns even using a simplified pricing formula, which might omit some other possible aspects.

Such value model of TVS suggests the following price patterns based on the value of underlying: if $S_{t} \geq X_{i} \Rightarrow T V S_{i_{t}}=\min \left(S_{t}-T V S_{i-1_{t}}, \max \left(w_{i} S_{t}, X_{i}\right)\right)$, and if $S_{t}<X_{i} \Rightarrow$ $T V S_{i_{t}}=S_{t}-T V S_{i-1_{t}}$, which also imply that if $S_{t}<T V S_{i-1_{t}} \Rightarrow T V S_{i_{t}}=0$.

However, this model omits a price premium that must be paid for receiving a superior claim right on value tranche of a particular security, which on its own is of value to investors. Under this view, the value of has three primary components: intrinsic value, time value and seniority, leading to the following conclusion ( 3 )

$$
\sum_{i=1}^{t} T V S_{i_{t}} \geq S_{t}
$$

Based on the basic principles of time value of money, and ( 3 ), earlier presented model ( 2 ) can be further extended to ( 4.1 ) in the case of TVS with maturity, 


$$
T V S_{i_{t}} \geq \min \left(S_{t}-T V S_{i-1_{t}}, \max \left(w_{i} \frac{S_{t}}{(1+r)^{n}}, \frac{X_{i}}{(1+r)^{n}}\right)\right)
$$

Or can be extended to ( 4.2 ) in the case of perpetual TVS, which can primarily be used for equities to accommodate time value of TVS.

$$
T V S_{i_{t}} \geq \min \left(S_{t}-T V S_{i-1_{t}}, \max \left(w_{i} \frac{S_{t}}{r}, \frac{X_{i}}{r}\right)\right)
$$

These values ( 4.1 ), ( 4.2 ) become the lower limits of the Tranched Value Security on a particular underlying, with the term $S_{t}-T V S_{i-1_{t}}$ not being discounted as it already includes the time value effect.

\section{TVS Applications}

This section lays out tests conducted to verify performance of Tranched Value Securities based on the presented earlier model ( 2 ) with equity and debt instruments. First simulated results are assessed, with following case studies evaluation.

\section{A. Simulated Results}

\section{A.1. Simulated Results: Equity Security}

This section assesses performance of TVS securities issued on the basis of simulated underlying equity security (common stock). For the purpose of modeling the possible price behavior of the equity security (E), it can be assumed that the underlying has a market price of $E_{t}$ at time $t . E_{t}=U S \$ 100.00$ at $t=0$, and has a mean periodic (expected) rate of return $E\left(r_{t}\right)=\mu=0.10$ with standard deviation $\sigma=0.50$. $E_{t}$ follows a lognormal distribution. Based on these inputs, $E_{t+i}$ was modelled using Monte Carlo simulation utilizing model ( 5 ) for 1,000 periods

$$
S_{t}=S_{t-1} \times e^{r}
$$

where $r$ is (6)

$$
r=E\left(r_{t}\right)+\sigma \times z \text { for all } z \rightarrow X \sim N(\mu, \sigma)
$$




$$
\begin{gathered}
\Phi(z) \rightarrow \text { probabilityof } z \\
F^{-1}(z) \rightarrow z
\end{gathered}
$$

Furthermore, it is assumed that five Tranched Value Securities are issued from $E_{t}$ with characteristics presented on Figure 6.A.

The results presented on Figure 6.A-6.G are obtained for the minimum values of five tranches of TVS and one underlying equity security. As evident, all securities experience various price fluctuations, with ETVS-A being the most stable, while ETVS-E and ETVS-D being the most volatile, at the same time experiencing defaults the most often in $37 \%$, and $22 \%$ cases respectively out of 1,000 simulated periods. Default rates are compensated by the highest maximum returns of the three most junior value tranches (ETVS-C, ETVS-D, ETVS-E). This is the result of junior value tranches losing all value (having a market price of zero), when the value of ETVS-A becomes equal to the value of underlying equity security, due to its value seniority. ETVS Senior and ETVS Subordinated almost always have a fixed price floor (Figure 6.C) below which their value barely falls, unless the underlying equity security experiences severe price declines.

Price value distributions (Figure 6.D) and return distributions (Figure 6.F) illustrate that due to the tranching nature of the securities, and embeded protection in them against the value claim of the lower-level TVS, distribution profiles of TVSs have been transformed and do not follow the initially simulated lognormal distribution, while being highly skewed to the right, with high excess kurtosis on a return-basis, being changed to leptokurtic forms, with only the safest tranche - ETVS Senior, experiencing excess kurtosis of less than that of the underlying equity security.

Correlations between the securities prices (Figure 6.E) reveals that while between some securities there is significant co-movement, between some others (ETVS-D and ETVS-A) it is less than what would be expected from securities which represent portions of the same underlying. However, return correlations (Figure 6.G) depict that between some security pairs there is almost no co-movement at all (correlation of $\approx 0.1$ between ETVS-D and all other securities, correlations of 0.13-0.23 between ETVS-C and all others), while the returns of the most senior tranches are the most consistent with the returns of 
underlying equity security. Based on the statistical assessment ETVS-D generated the highest mean return, with the value of $244 \%$, while the mean return of the underlying equity security was $24 \%$ (10.0x less than the return of ETVS-D). The lowest mean return was generated by ETVS-E due to the significant number of defaults in $37 \%$ of simulated periods, with the value of $-10 \%$. At the same time, the range of returns is the highest for ETVS-D, and ETVS-C, while for ETVS-A it is lower than even for the underlying, as this value tranche essentially contains less risk than the underlying equity security, which is evident from the twice reduced standard deviation.

The results of the assessment conducted on the underlying equity security and five securitized value tranches of the underlying are depicted on Figure 6.E, and Figure 6.G, summarizing a significant performance transformation of the original underlying due to tranching of its value. As a conclusion of assessment of simulated underlying equity, Tranched Value Securities significantly transformed the performance and returns of the underlying, with the highest returns being provided by ETVS Mezzanine, and ETVS-E exhibiting the riskiest performance, which is supported by the highest number of defaults. While the highest volatility was experienced by ETVS-D and ETVS-C. The return distributions for all TVSs exhibited extreme positive skewness and extreme positive kurtosis. At the same time ETVS-D and ETVS-C are the least correlated value tranches with any other issued security and underling, while ETVS-A, exhibits strong positive correlation with underlying equity security. Which together suggest significant diversification benefits in crisis and positive market situations, while satisfying various risk appetites of potential investors. 
Assumed Issuance Information

\begin{tabular}{|l|c|c|c|}
\hline \multicolumn{1}{|c|}{ Security } & Code & $\begin{array}{c}\text { Value Share } \\
\mathbf{( \% )}\end{array}$ & $\begin{array}{c}\text { Minimum } \\
\text { Value* (US\$) }\end{array}$ \\
\hline Common Equity & E & 1.00 & 100.00 \\
\hline ETVS Senior & ETVS-A & 0.30 & 30.00 \\
\hline ETVS Subordinated & ETVS-B & 0.25 & 25.00 \\
\hline ETVS Junior & ETVS-C & 0.20 & 20.00 \\
\hline ETVS Mezzanine & ETVS-D & 0.15 & 15.00 \\
\hline ETVS Equity & ETVS-E & 0.10 & 10.00 \\
\hline
\end{tabular}

\section{TVS Price Share of Total Price of Underlying (\%)}

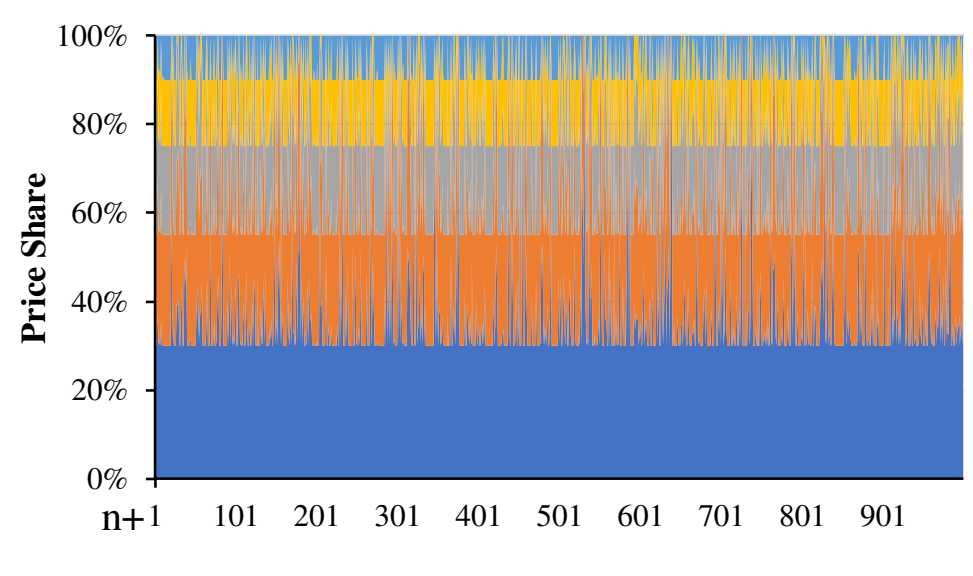

Combined Price Data for Five TVSs and Underlying (US\$)

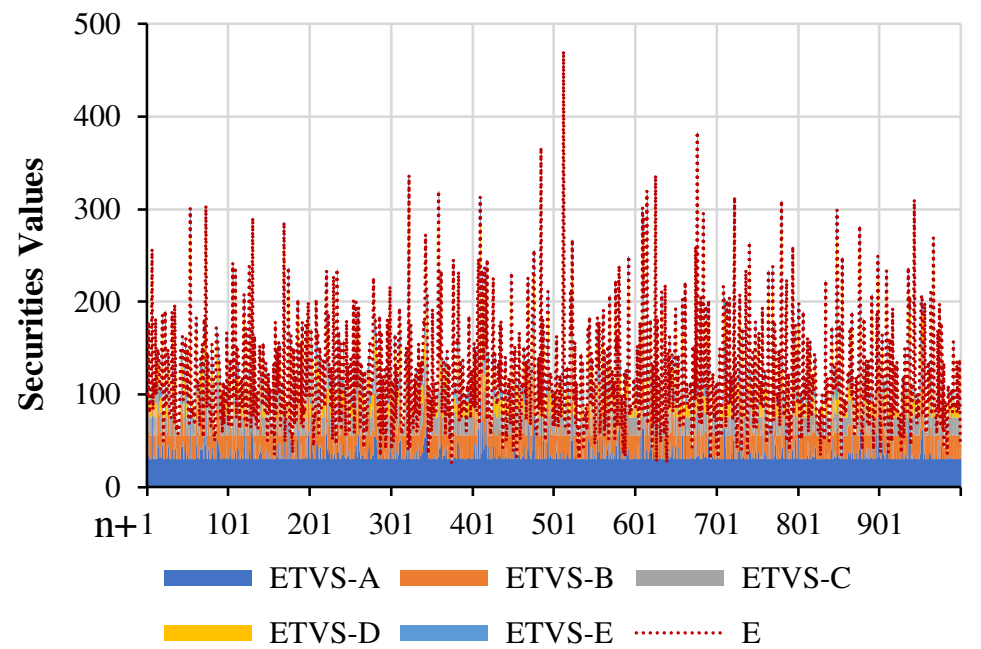

Securities Performance (Limited to $-\mathbf{1 0 0} \%$ to $+\mathbf{5 0 0 \%}$ )

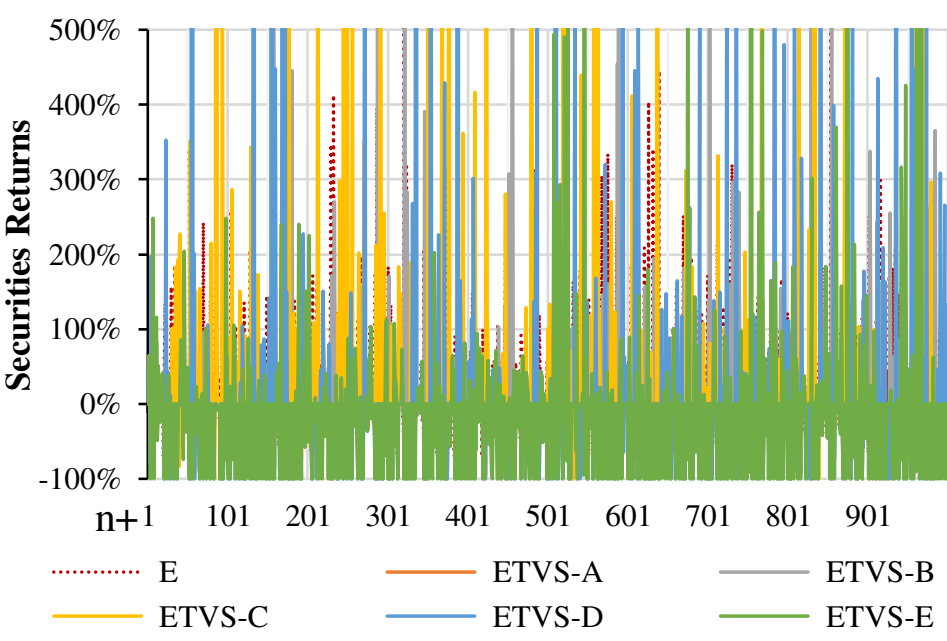

Figure 6.A. Issuance, Price and Return Summary. 
Securities Return Full Snapshot

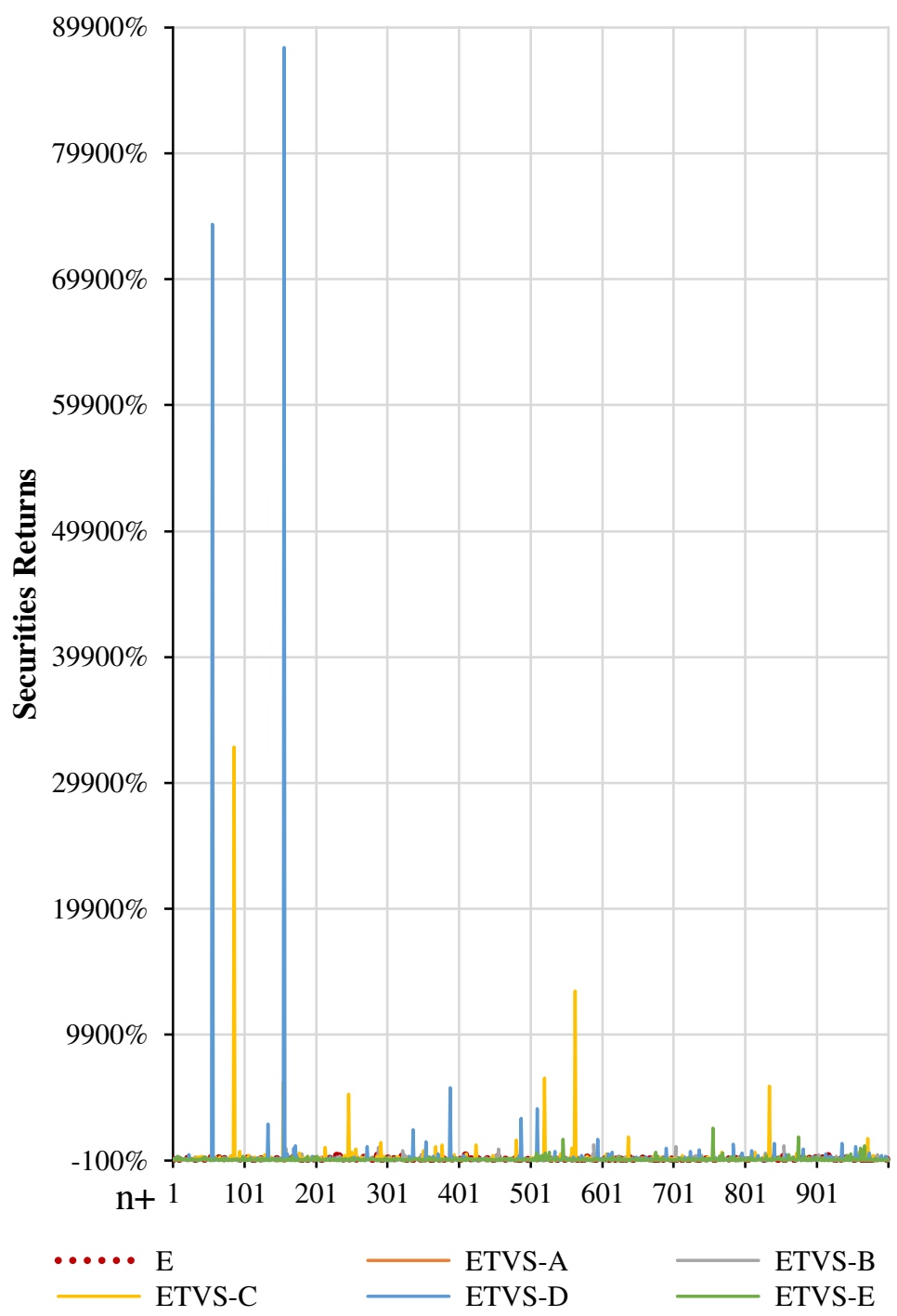

TVS Default Rates (When Price Equals to Zero)

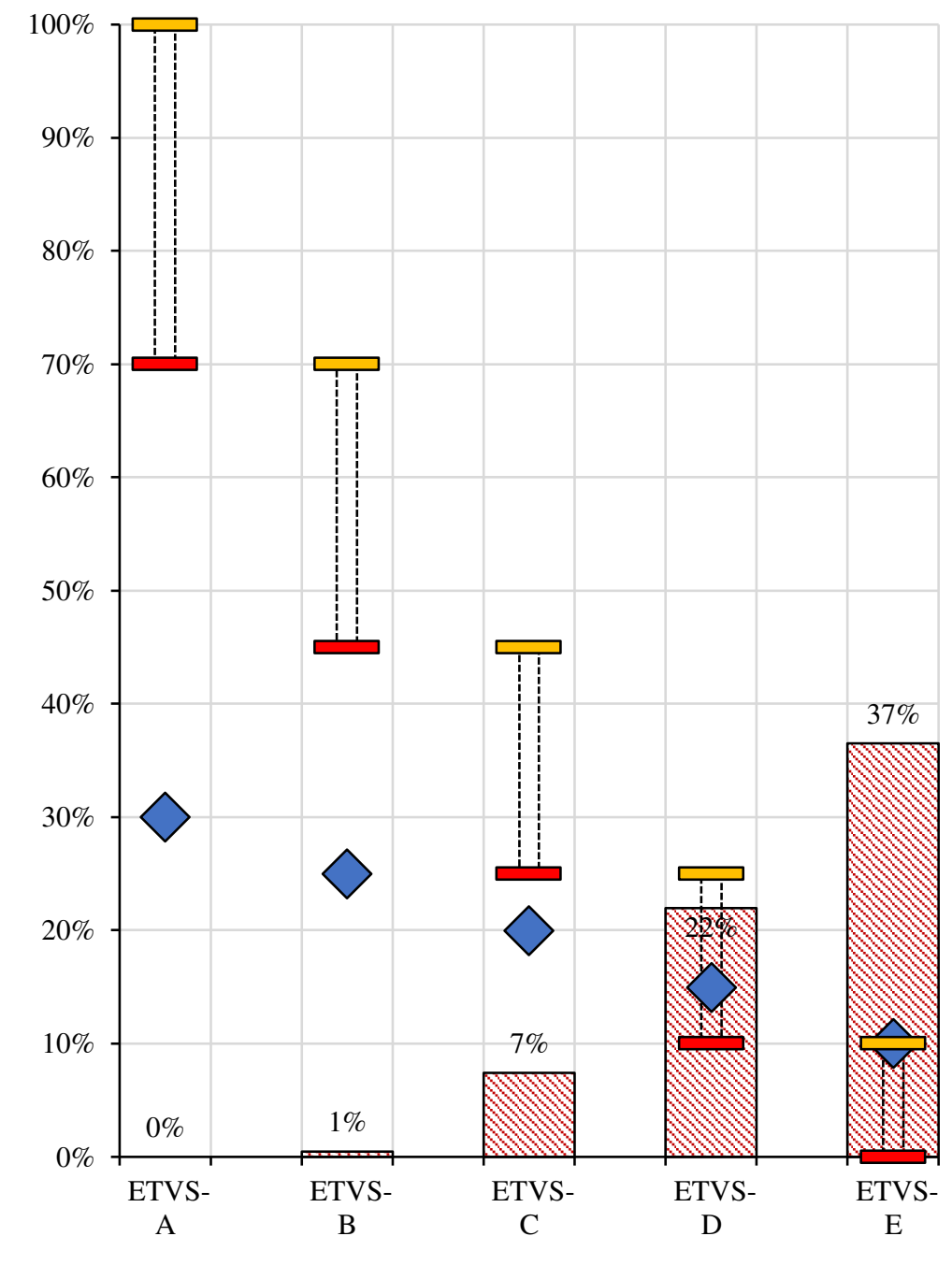

$\otimes$ Default Rates $\diamond$ Value Share - Attachment Point - Detachment Point

Figure 6.B. Return and Default Rates (\%). 
E

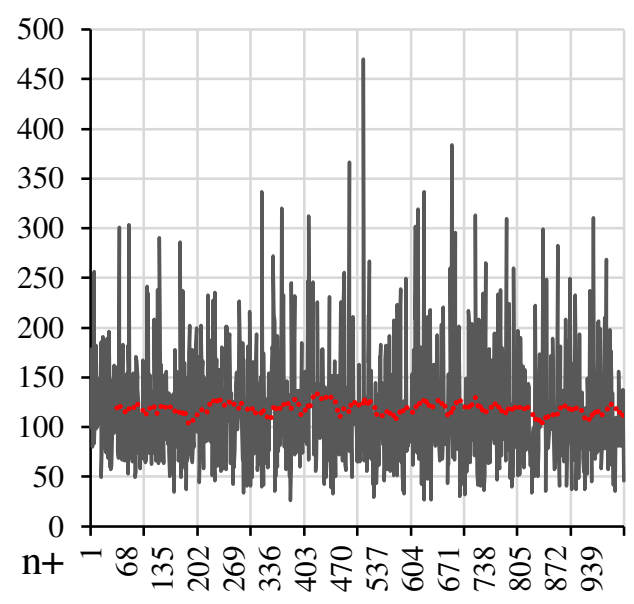

ETVS-C

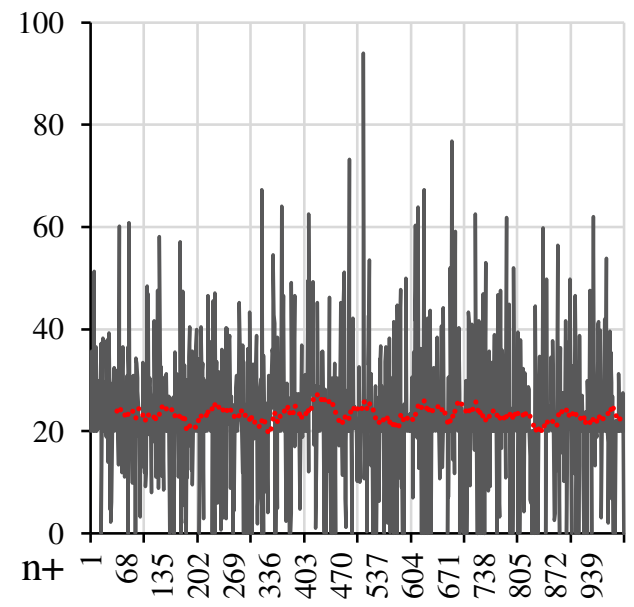

ETVS-A

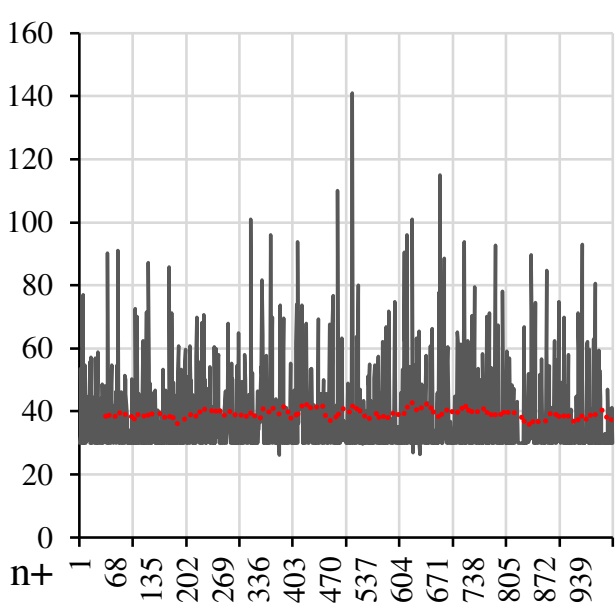

ETVS-D

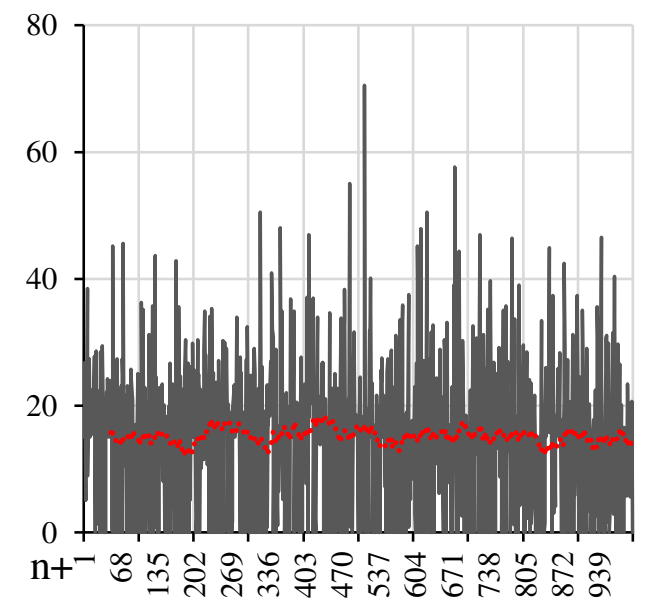

ETVS-B

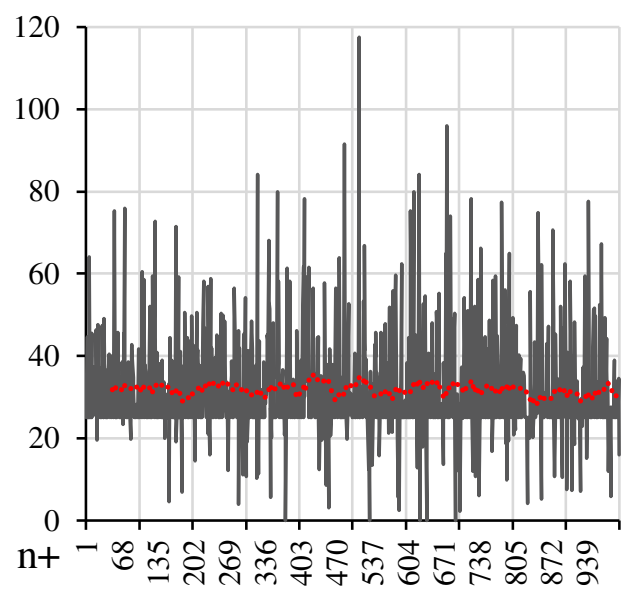

ETVS-E

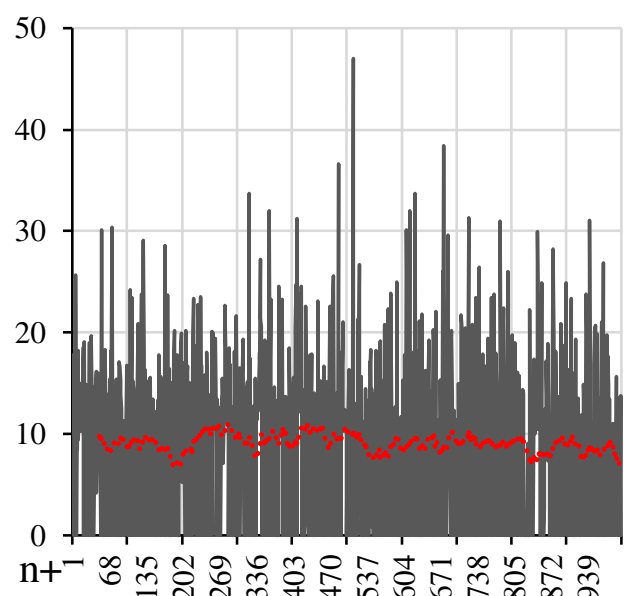

Figure 6.C. Price Charts (US\$) with SMA(50). 
E

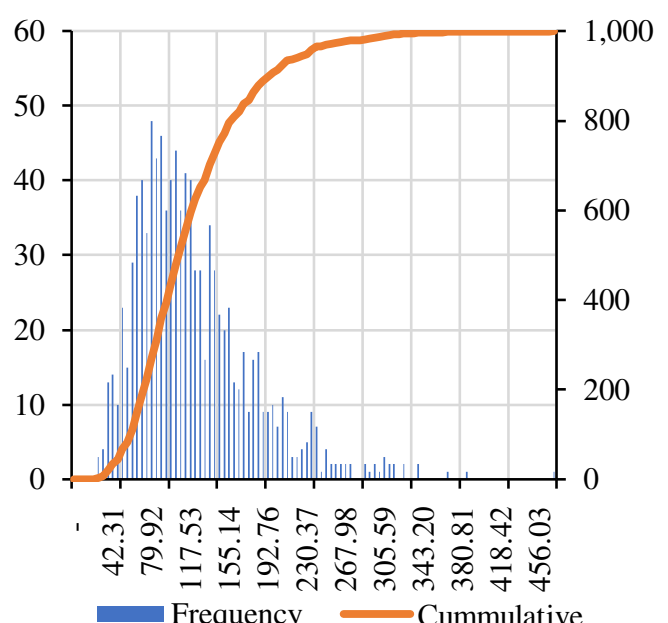

ETVS-C

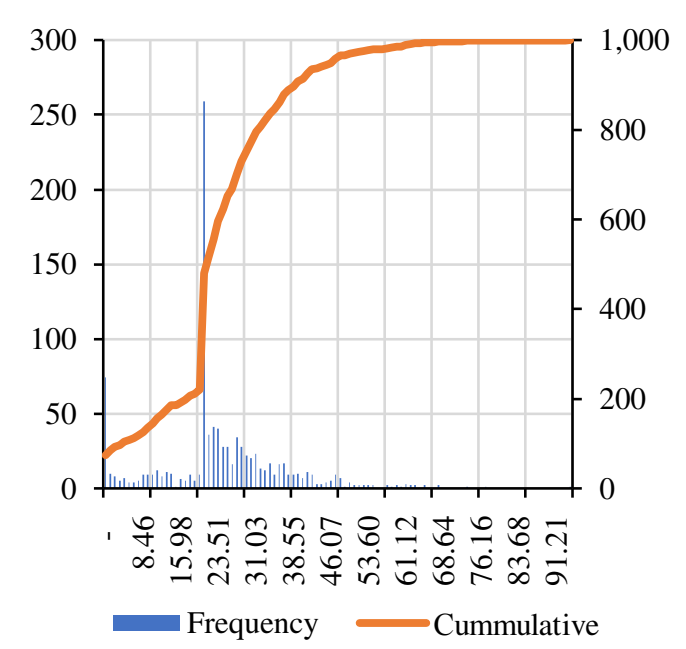

ETVS-A

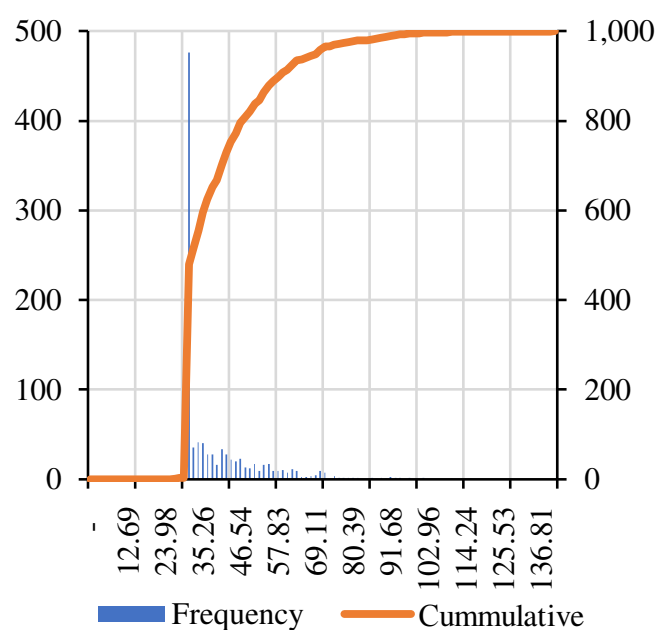

ETVS-D

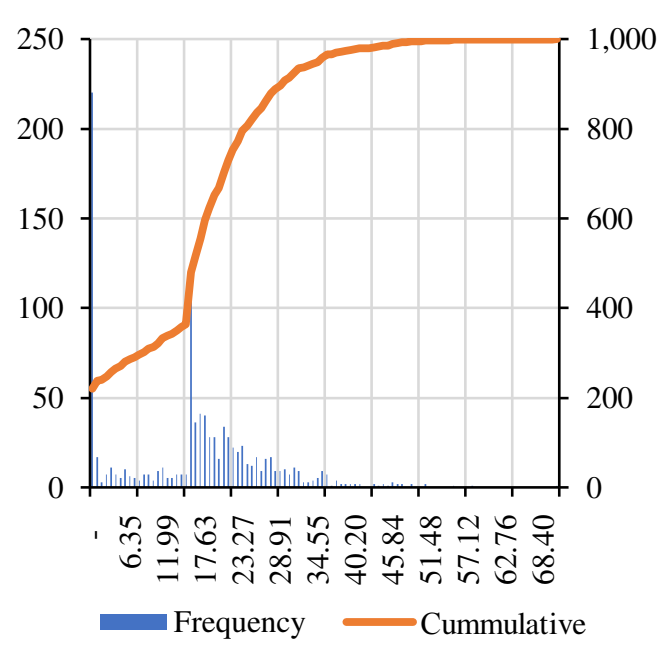

ETVS-B

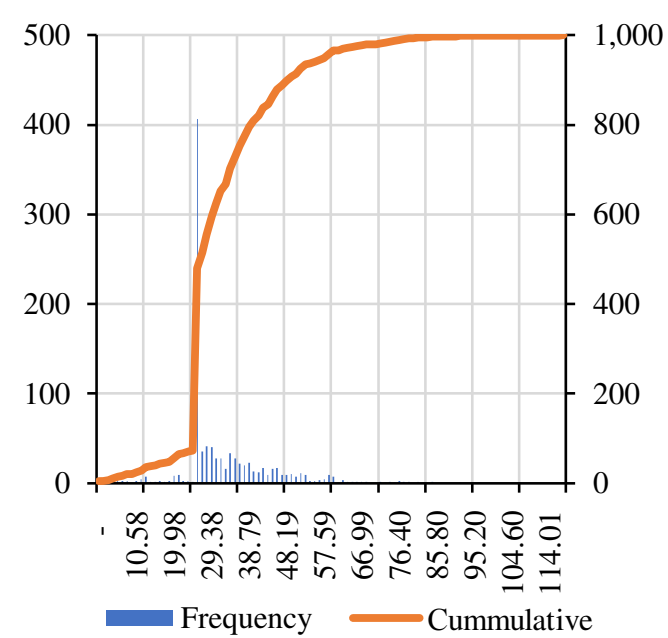

ETVS-E

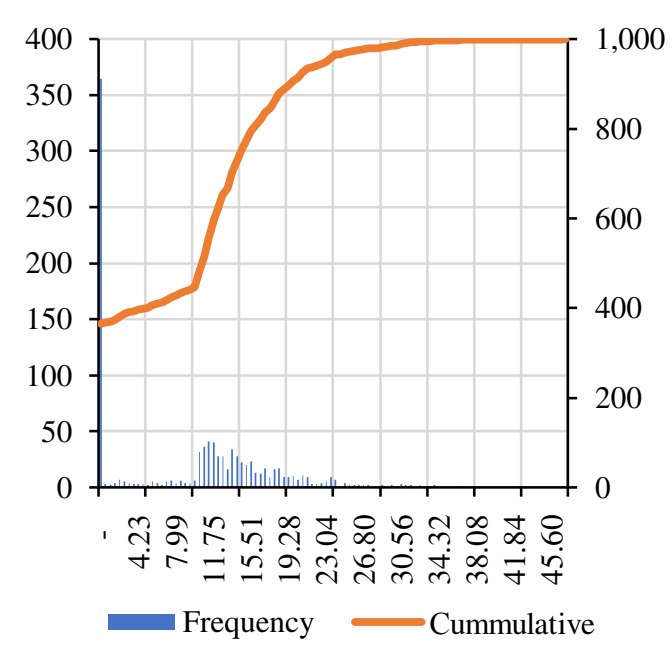

Figure 6.D. Price Distribution Histograms (US\$). 
Table of Statistical Summary for Price

\begin{tabular}{|l|r|r|r|r|r|r|}
\hline & \multicolumn{1}{|c|}{ E } & \multicolumn{1}{|c|}{ ETVS-A } & \multicolumn{1}{c|}{ ETVS-B } & \multicolumn{1}{c|}{ ETVS-C } & \multicolumn{1}{c|}{ ETVS-D } & \multicolumn{1}{c|}{ ETVS-E } \\
\hline Count & 1,000 & 1,000 & 1,000 & 1,000 & 1,000 & 1,000 \\
\hline Mean & 118.24 & 39.12 & 31.76 & 23.19 & 15.15 & 9.02 \\
\hline Median & 106.09 & 31.83 & 26.52 & 21.22 & 15.91 & 10.61 \\
\hline Mode & $\mathrm{N} / \mathrm{A}$ & 30.00 & 25.00 & 20.00 & 0.00 & 0.00 \\
\hline Minimum & 26.15 & 26.15 & 0.00 & 0.00 & 0.00 & 0.00 \\
\hline Maximum & 470.13 & 141.04 & 117.53 & 94.03 & 70.52 & 47.01 \\
\hline Range & 443.99 & 114.89 & 117.53 & 94.03 & 70.52 & 47.01 \\
\hline Sample Variance & $3,278.29$ & 199.26 & 164.03 & 163.11 & 131.48 & 69.29 \\
\hline $\begin{array}{l}\text { Standard } \\
\text { Deviation }\end{array}$ & 57.26 & 14.12 & 12.81 & 12.77 & 11.47 & 8.32 \\
\hline $\begin{array}{l}\text { Mean/ Standard } \\
\text { Deviation }\end{array}$ & 2.07 & 2.77 & 2.48 & 1.82 & 1.32 & 1.08 \\
\hline Standard Error & 1.81 & 0.45 & 0.41 & 0.40 & 0.36 & 0.26 \\
\hline Kurtosis & 2.95 & 6.53 & 4.88 & 1.93 & 0.30 & $(0.22)$ \\
\hline Excess Kurtosis & $(0.05)$ & 3.53 & 1.88 & $(1.07)$ & $(2.70)$ & $(3.22)$ \\
\hline Skewness & 1.37 & 2.24 & 1.60 & 0.60 & 0.42 & 0.50 \\
\hline
\end{tabular}

Price Correlations

\begin{tabular}{ccccccc} 
& E & ETVS-A & ETVS-B & ETVS-C & ETVS-D & ETVS-E \\
\hline E & 1.00 & 0.96 & 0.97 & 0.97 & 0.96 & 0.95 \\
\hline ETVS-A & 0.96 & 1.00 & 0.96 & 0.88 & 0.86 & 0.88 \\
\hline ETVS-B & 0.97 & 0.96 & 1.00 & 0.93 & 0.88 & 0.88 \\
\hline ETVS-C & 0.97 & 0.88 & 0.93 & 1.00 & 0.94 & 0.89 \\
\hline ETVS-D & 0.96 & 0.86 & 0.88 & 0.94 & 1.00 & 0.96 \\
\hline ETVS-E & 0.95 & 0.88 & 0.88 & 0.89 & 0.96 & 1.00 \\
\hline
\end{tabular}

Chart of Statistical Summary for Price

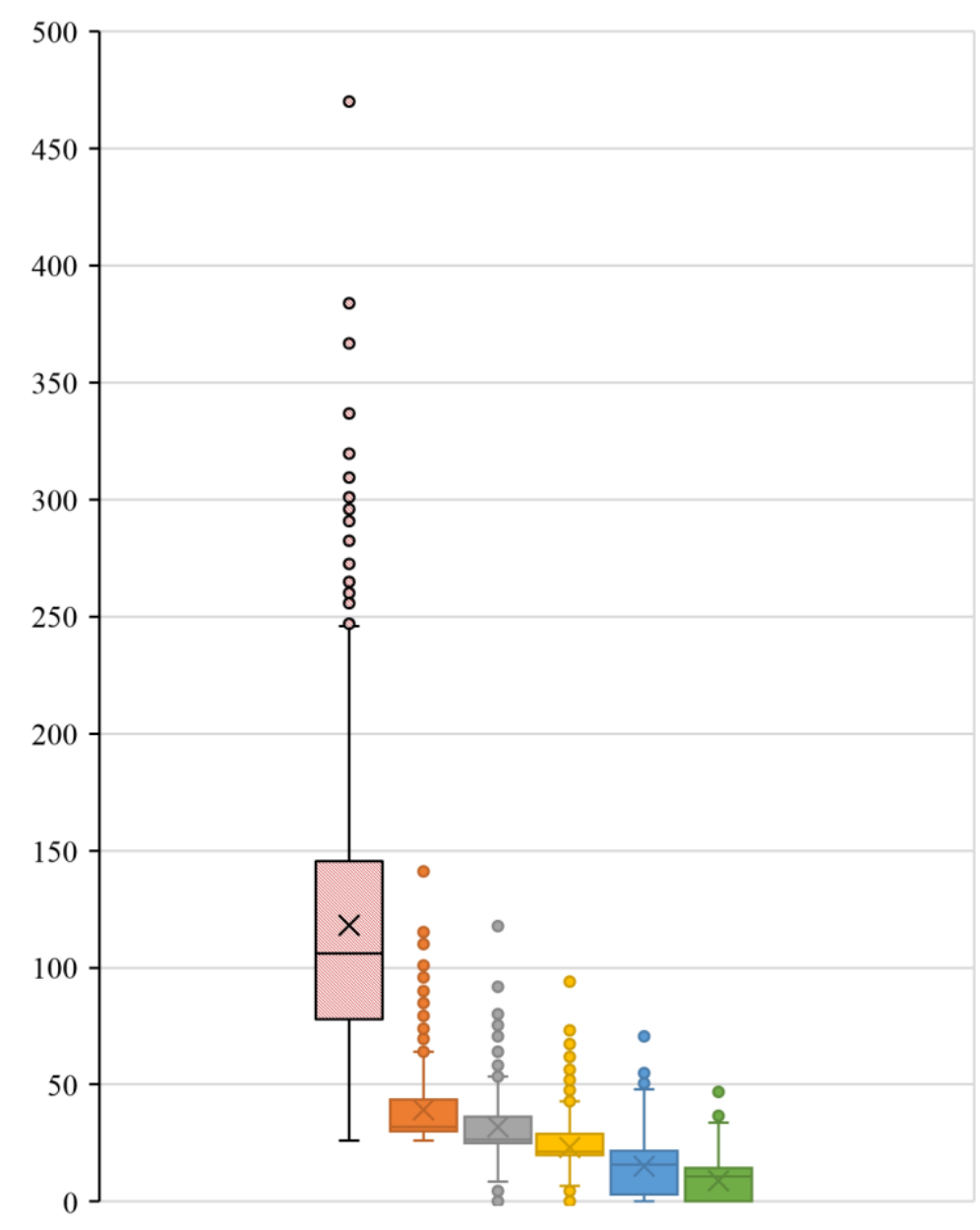

$\square \mathrm{E}$

$\square$ ETVS-A $\square$ ETVS-B

$\square$ ETVS-C $\square$ ETVS-D $\square$ ETVS-E

Figure 6.E. Price Statistical Summary (US\$). 


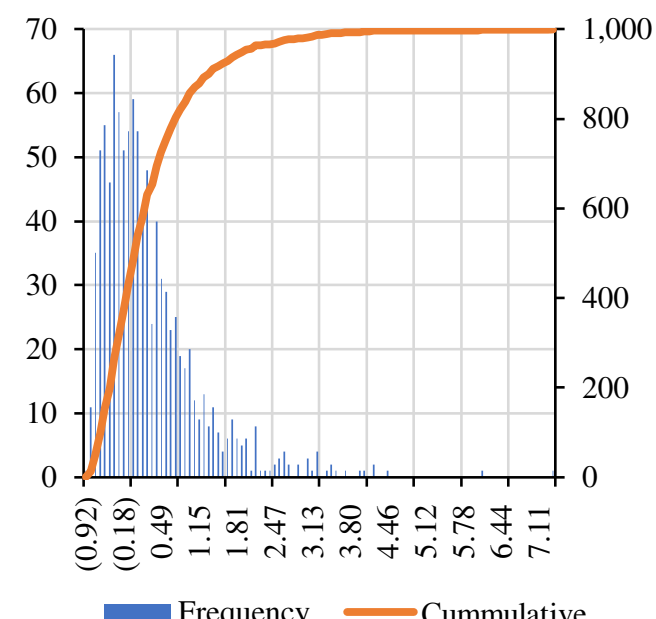

ETVS-C

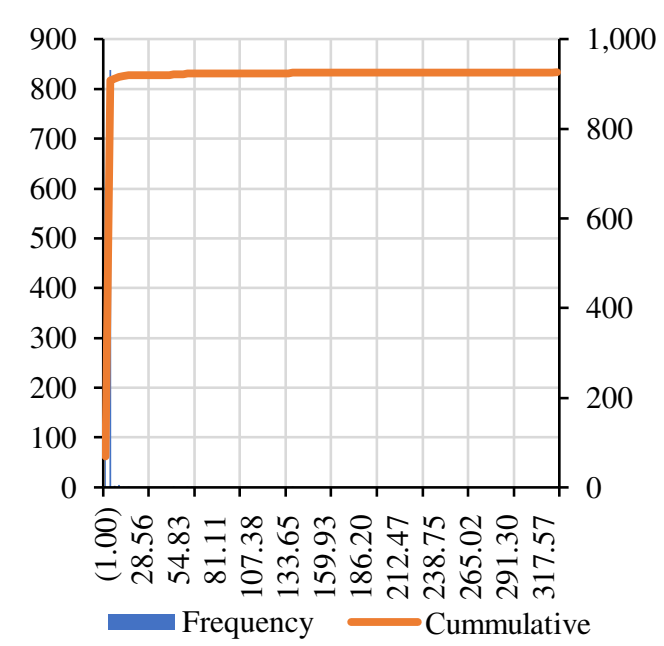

ETVS-A

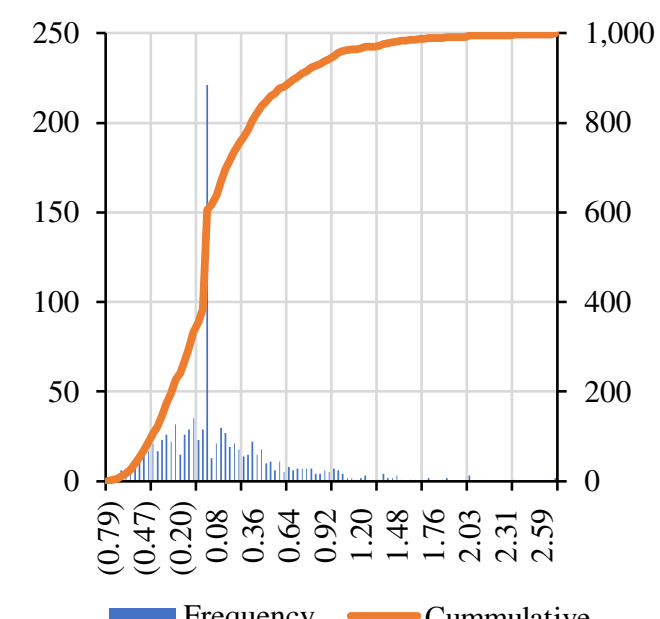

Frequency Cummulative

ETVS-D

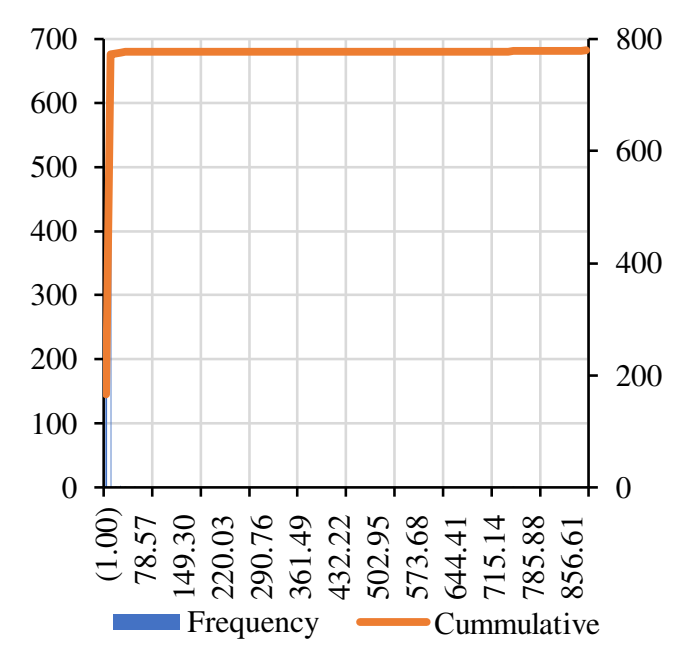

ETVS-B

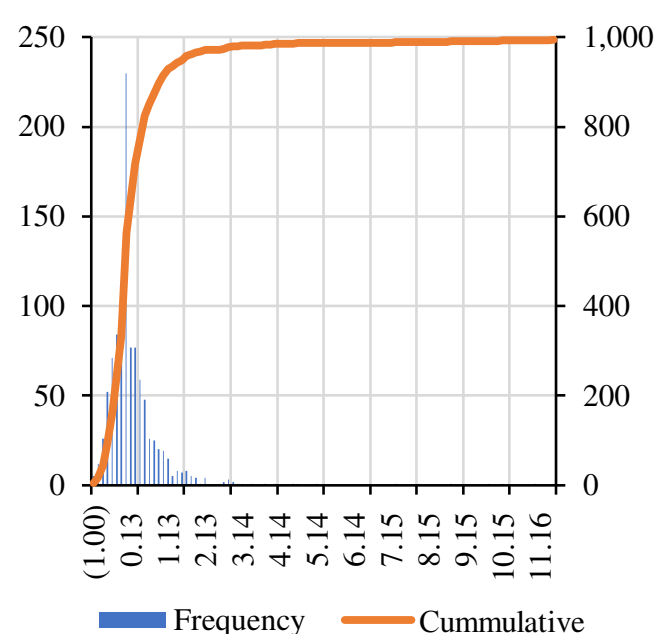

ETVS-E

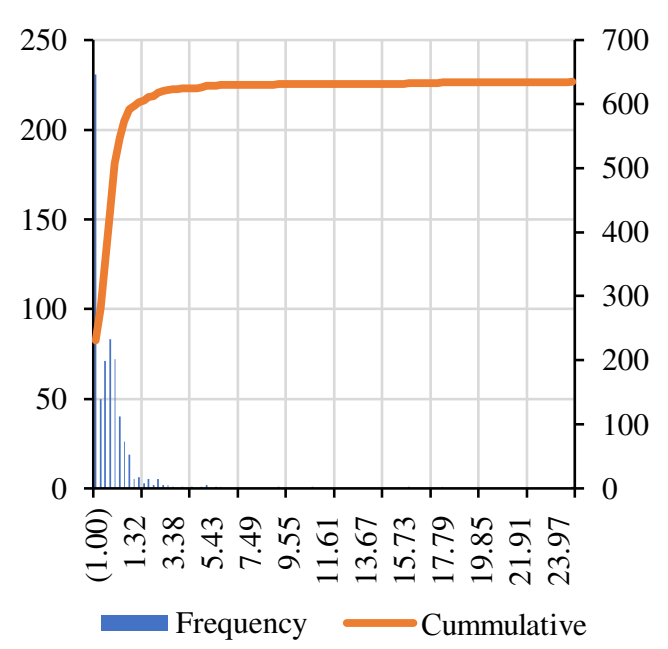

Figure 6.F. Return Distribution Histograms (\%). 
Table of Statistical Summary for Return

\begin{tabular}{|l|r|r|r|r|r|r|}
\hline & \multicolumn{1}{|c|}{ E } & \multicolumn{1}{|c|}{ ETVS-A } & \multicolumn{1}{c|}{ ETVS-B } & \multicolumn{1}{c|}{ ETVS-C } & \multicolumn{1}{c|}{ ETVS-D } & \multicolumn{1}{c|}{ ETVS-E } \\
\hline Count & 999 & 999 & 999 & 999 & 999 & 999 \\
\hline Mean & 0.24 & 0.09 & 0.19 & 0.99 & 2.44 & $(0.10)$ \\
\hline Median & 0.01 & 0.00 & 0.00 & 0.00 & $(0.16)$ & $(0.35)$ \\
\hline Mode & $\mathrm{N} / \mathrm{A}$ & 0.00 & 0.00 & $(1.00)$ & $(1.00)$ & $(1.00)$ \\
\hline Minimum & $(0.92)$ & $(0.79)$ & $(1.00)$ & $(1.00)$ & $(1.00)$ & $(1.00)$ \\
\hline Maximum & 7.36 & 2.70 & 11.53 & 327.42 & 883.13 & 24.74 \\
\hline Range & 8.28 & 3.48 & 12.53 & 328.42 & 884.13 & 25.74 \\
\hline Sample Variance & 0.78 & 0.22 & 1.05 & 152.01 & $1,715.85$ & 3.10 \\
\hline $\begin{array}{l}\text { Standard } \\
\text { Deviation }\end{array}$ & 0.88 & 0.47 & 1.02 & 12.33 & 41.42 & 1.76 \\
\hline $\begin{array}{l}\text { Mean/ Standard } \\
\text { Deviation }\end{array}$ & 0.27 & 0.19 & 0.19 & 0.08 & 0.06 & $(0.06)$ \\
\hline Standard Error & 0.03 & 0.01 & 0.03 & 0.39 & 1.31 & 0.06 \\
\hline Kurtosis & 8.56 & 4.60 & 53.47 & 548.59 & 393.36 & 91.84 \\
\hline Excess Kurtosis & 5.56 & 1.60 & 50.47 & 545.59 & 390.36 & 88.84 \\
\hline Skewness & 2.23 & 1.66 & 6.18 & 21.93 & 19.72 & 8.16 \\
\hline
\end{tabular}

\section{Return Correlations}

E ETVS-A ETVS-B ETVS-C ETVS-D

\begin{tabular}{lcccccc} 
E & 1.00 & 0.82 & 0.78 & 0.23 & 0.08 & 0.53 \\
\hline ETVS-A & 0.82 & 1.00 & 0.57 & 0.13 & 0.04 & 0.46 \\
\hline ETVS-B & 0.78 & 0.57 & 1.00 & 0.13 & 0.04 & 0.47 \\
\hline ETVS-C & 0.23 & 0.13 & 0.13 & 1.00 & 0.05 & 0.48 \\
\hline ETVS-D & 0.08 & 0.04 & 0.04 & 0.05 & 1.00 & 0.51 \\
\hline ETVS-E & 0.53 & 0.46 & 0.47 & 0.48 & 0.51 & 1.00
\end{tabular}

Chart of Statistical Summary for Return

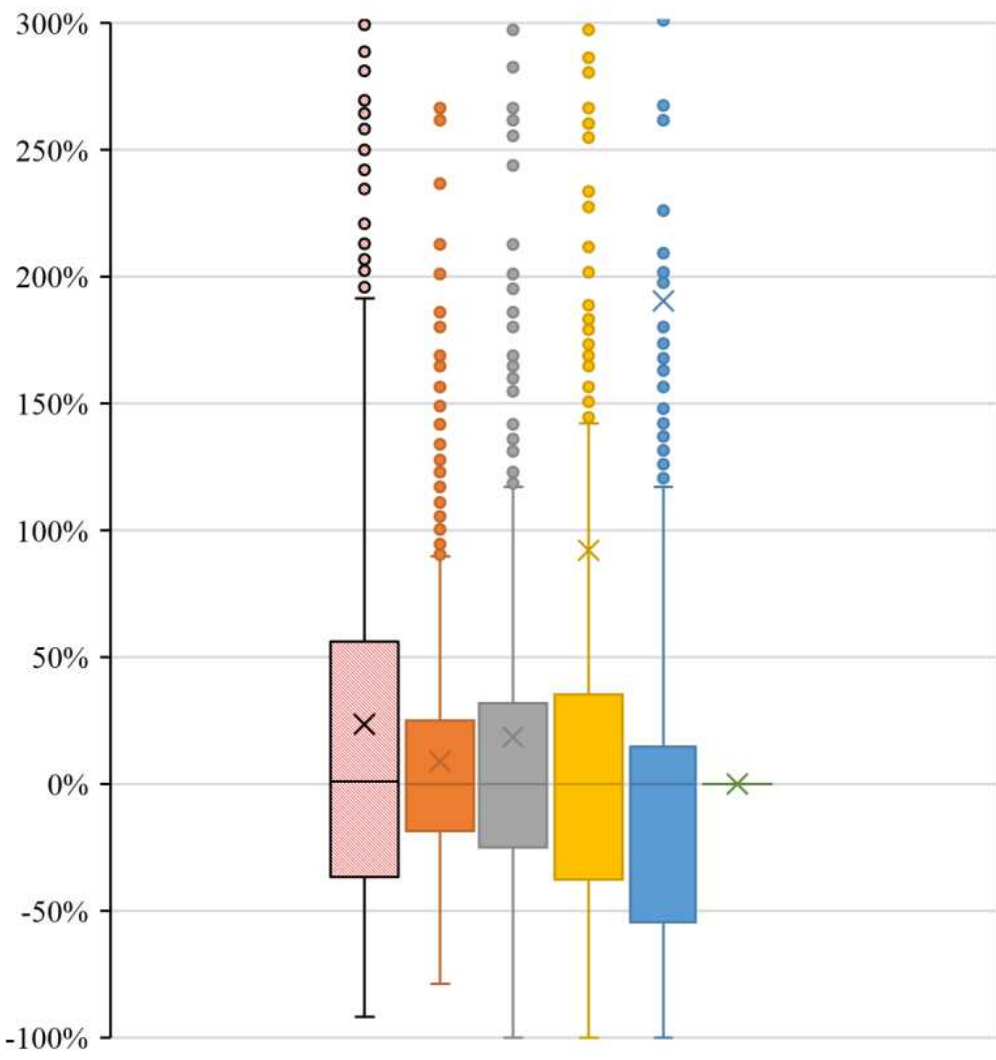

$\square \mathrm{E}$

$\square$ ETVS-A $\square$ ETVS-B

$\square$ ETVS-C $\square$ ETVS-D $\square$ ETVS-E

Figure 6.G. Return Statistical Summary (\%). 


\section{A.2. Simulated Results: Fixed Income Security}

This section assesses the performance of TVS securities issued on the basis of simulated underlying fixed-income (debt) security. For the purpose of modeling the possible price behavior of the debt security (D), it can be assumed that it has the following characteristics: Face Value $(F V)=$ US $\$ 100.00$, Maturity $(N)=1,000$ days $=2.74$ years, Coupons $(\mathrm{C})=0.05$ annually, Yield-to-Maturity $(\mathrm{YTM})=0.05$ at $t=0$, the resulting Present Value $(\mathrm{PV})=\mathrm{US} \$ 100.00$ at $t=0$. Furthermore, it is assumed that YTM has a standard deviation $\sigma=0.10$, and $E(Y T M)=\mu=0.05$. For the purpose of simplicity, it is assumed that YTM follows a lognormal distribution. Based on these inputs, YTM was modelled using Monte Carlo simulation utilizing model ( 5 ) for 1,000 periods.

Furthermore, it is assumed that five Tranched Value Securities are issued from $D_{t}$ with characteristics presented on Figure 7.A. The results presented on Figure 7.A-7.G are obtained for the minimum values of five tranches of TVS and one underlying debt security.

As evident, securities experience various price fluctuations (Figure 7.A), but DTVS-A, DTVS-B, and DTVS-C have a clear price floor (Figure 7.B) below which they never decline (only DTVS-C declined insignificantly several times) as the yields increase, while the underlying, and two junior value tranches continually experience value fluctuations bellow the initial PV at issuance. As a result, DTVS-D and DTVS-E experienced market price of zero multiple times amounting to $1 \%$ and $27 \%$ respectively (Figure 7.B). The default rates are compensated by the highest maximum yields with the values of $8 \%$ and 17\% for DTVS-D and DTVS-E respectively (Figure 7.B, Figure 7.G).

Price value distributions (Figure 7.D) and return distributions (Figure 7.F) illustrate that due to the tranching nature of the securities, and embeded protection in them against the value claim of the lower-level TVS, distribution profiles of TVSs have been transformed, while the three most senior TVSs being skewed to the left, and other TVS having a positive skewness. All securities (except for underlying) exhibit high excess kurtosis on a YTM-basis, and have been changed to leptokurtic forms (from initially platykurtic distribution of YTM of the underlying). 
Correlations between the securities prices (Figure 7.E) reveals that three the most senior value tranches of debt underlying have perfect positive correlation of 0.99-1.00 with each other, while two the most junior value tranches have positive but less strong correlation with all other securities. YTM correlations (Figure 7.G) depict exactly the same picture for DTVS-A, DTVS-B, DTVS-C pairs, and DTVS-D, DTVS-E pairs, while all TVSs have imperfect positive correlation with the underlying debt security.

Based on the statistical assessment ETVS-E generated the highest maximum YTM, with the value of $17 \%$, while the maximum return of the underlying debt security was $7 \%$ (2.4x less than the YTM of ETVS-E). At the same time, all securities generated nearly the same mean YTM of 1\%, except for the underlying with the value of $5 \%$.

The results of the assessment conducted on the underlying debt security and five securitized value tranches of the underlying are depicted on Figure 7.E, and Figure 7.G, summarizing a significant performance transformation of the original underlying due to tranching of its value. As a conclusion of assessment of simulated underlying fixed income security, Tranched Value Securities significantly transformed the performance and returns of the underlying debt security, with the highest returns being provided by DTVS Equity, which at the same time exhibited the most risks, which is supported by the highest number of defaults and the highest standard deviation of YTM. YTM distributions for DTVS Senior, DTVS Subordinated and DTVS Junior exhibited negative skewness, while DTVS Mezzanine and DTVS Equity exhibited positive skewness, which was greater than that of the underlying debt security. At the same time, all YTM distributions have been transformed to leptokurtic forms, while the underlying fixed income security exhibited platykurtic distribution of YTM. Furthermore, DTVS-D and DTVS-E are the least correlated value tranches with any other issued security and underling, while DTVS-A, DTVS-B and DTVS-C exhibit nearly perfect positive correlation with each other, and strong positive correlation with underlying debt security. Which together suggest significant diversification benefits in crisis and positive market situations, while satisfying various risk appetites of potential investors. 
Assumed Issuance Information

\begin{tabular}{|l|c|c|c|}
\hline \multicolumn{1}{|c|}{ Security } & Code & $\begin{array}{c}\text { Value } \\
\text { Share (\%) }\end{array}$ & $\begin{array}{c}\text { Minimum } \\
\text { Value* (US\$) }\end{array}$ \\
\hline Fixed Income & D & 1.00 & 100.00 \\
\hline DTVS Senior & DTVS-A & 0.30 & 30.00 \\
\hline DTVS Subordinated & DTVS-B & 0.25 & 25.00 \\
\hline DTVS Junior & DTVS-C & 0.20 & 20.00 \\
\hline DTVS Mezzanine & DTVS-D & 0.15 & 15.00 \\
\hline DTVS Equity & DTVS-E & 0.10 & 10.00 \\
\hline
\end{tabular}

\section{TVS Price Share of Total Price of Underlying (\%)}

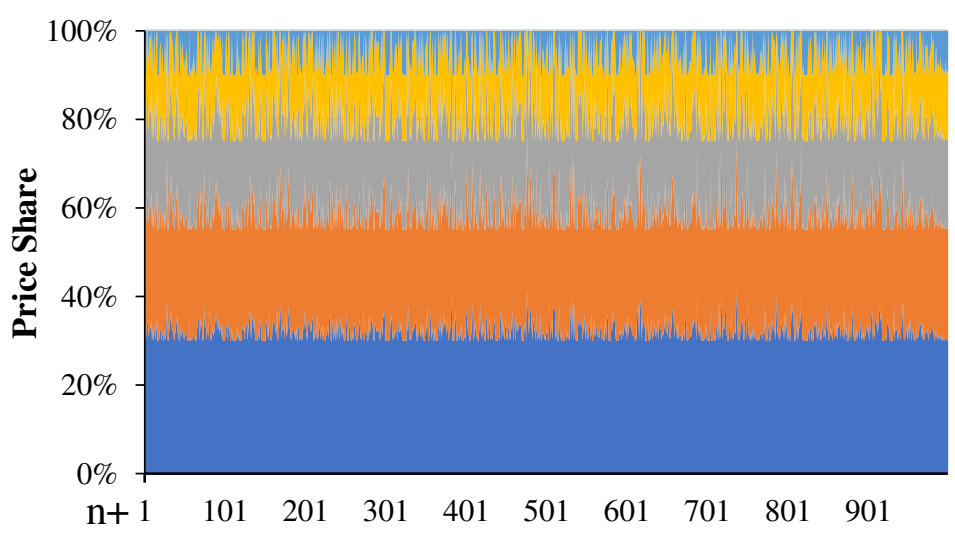

DTVS-A $\approx$ DTVS-B $\approx$ DTVS-C $\backsim$ DTVS-D $\approx$ DTVS-E

\section{Combined Price Data for Five TVSs and Underlying (US\$)}

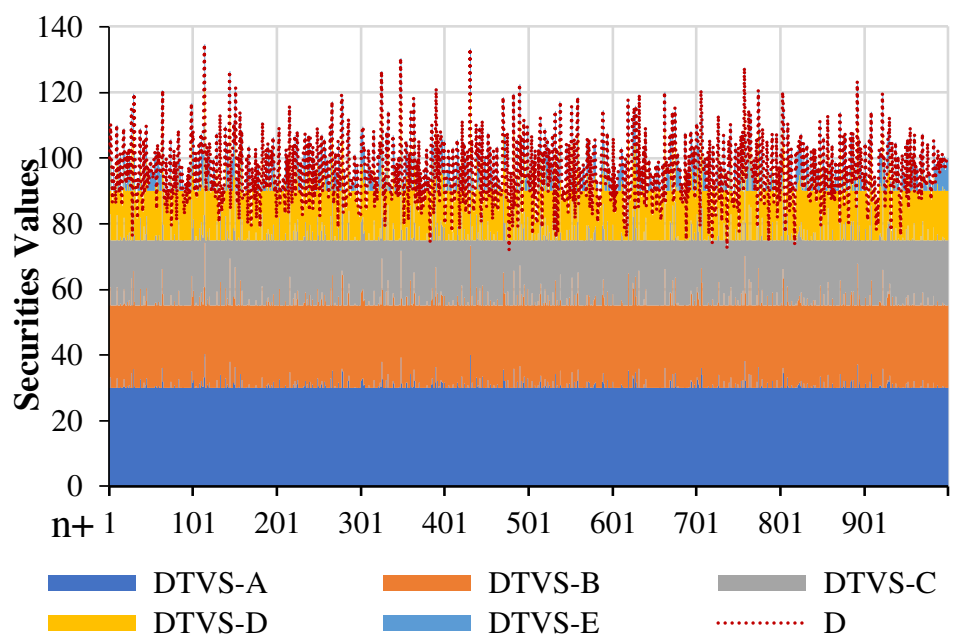

Securities YTM (Limited to $0 \%$ to $+8 \%$ )

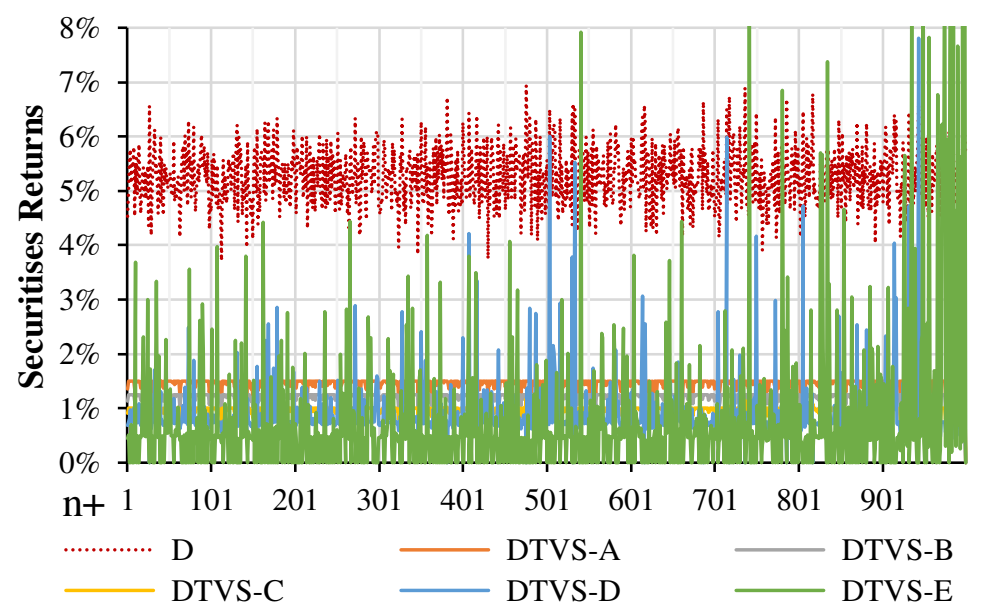

Figure 7.A. Issuance, Price and Return Summary. 
Securities YTM Full Snapshot

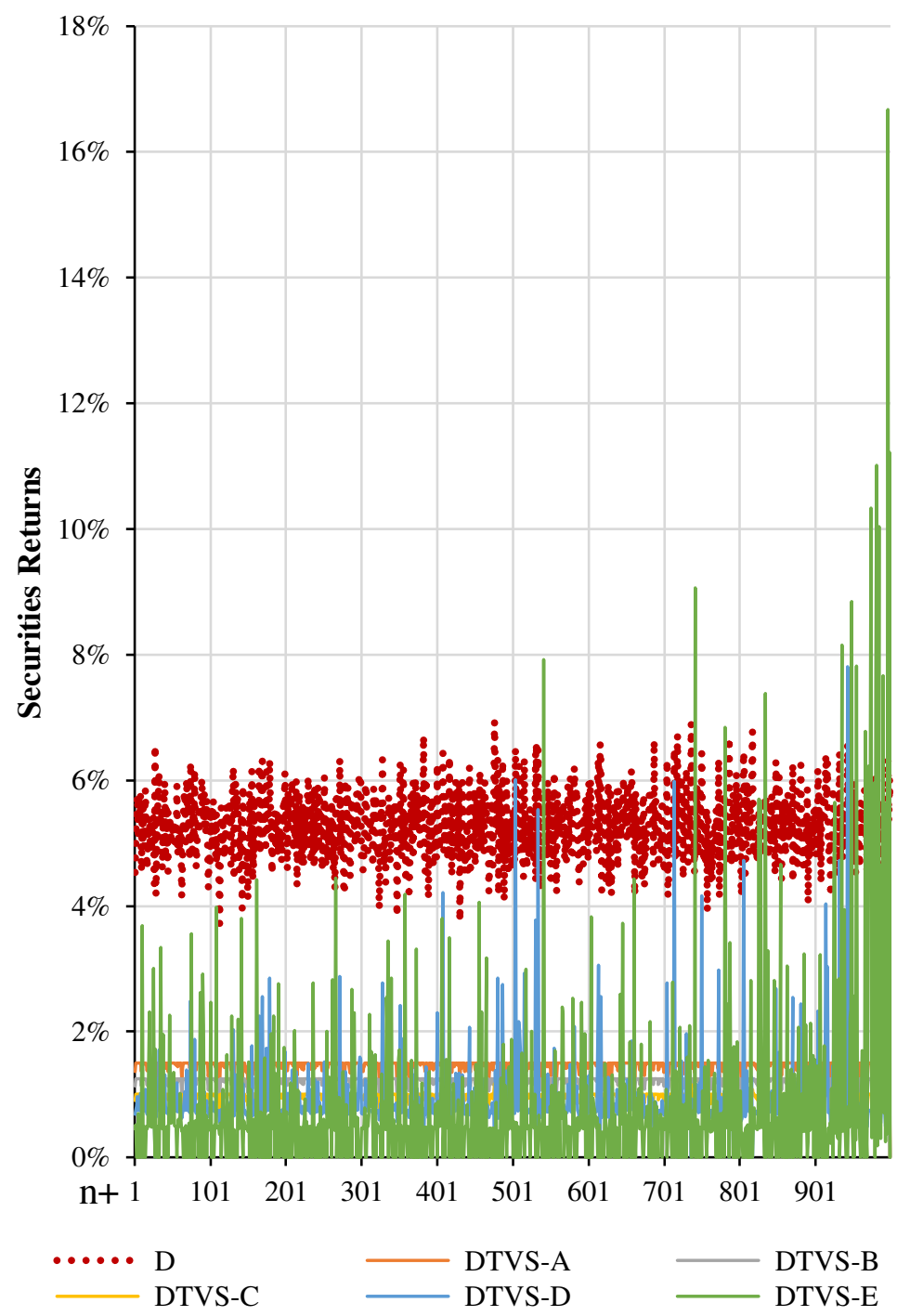

TVS Default Rates (When Price Equals to Zero)

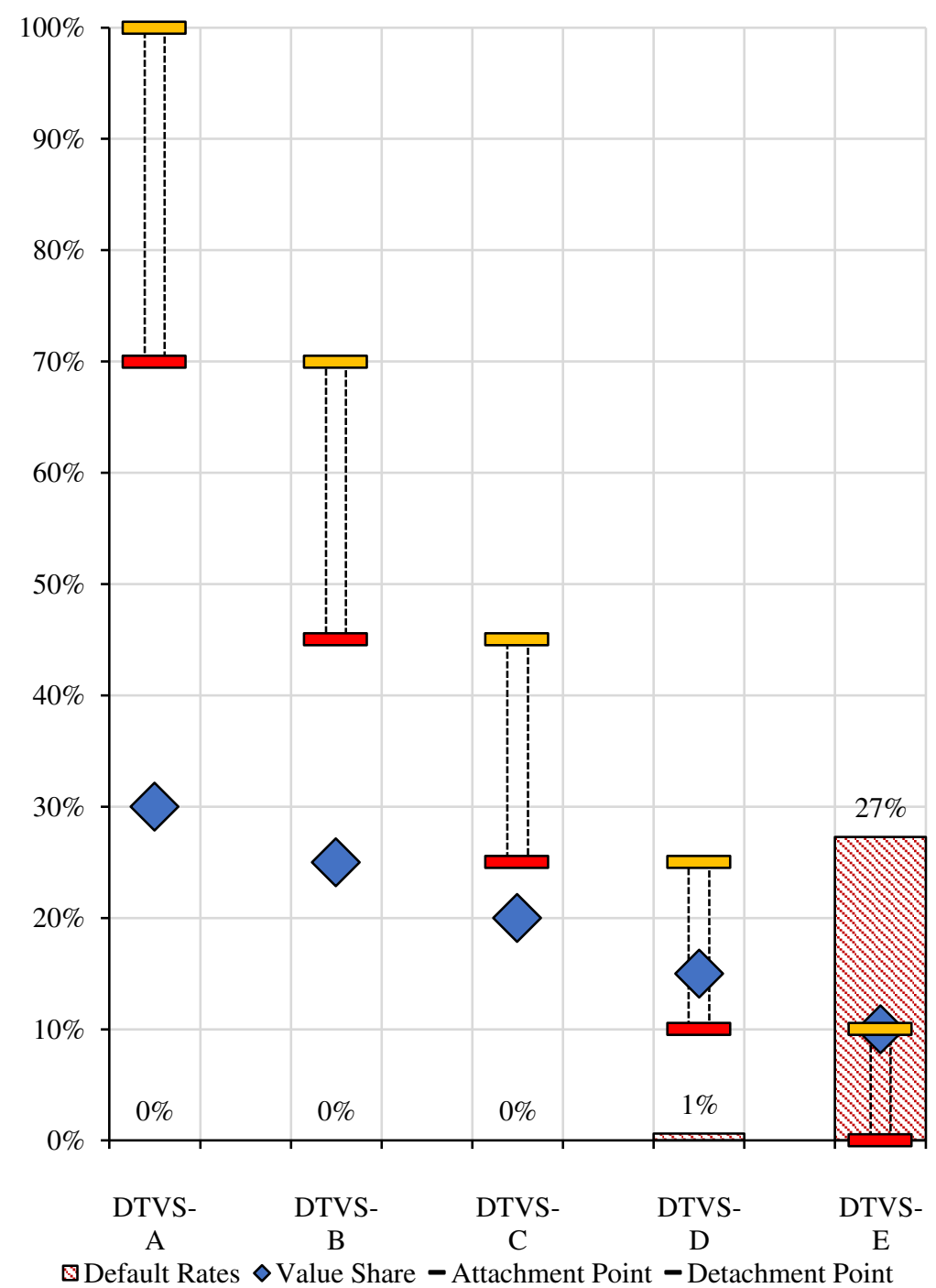

Figure 7.B. Return and Default Rates (\%). 

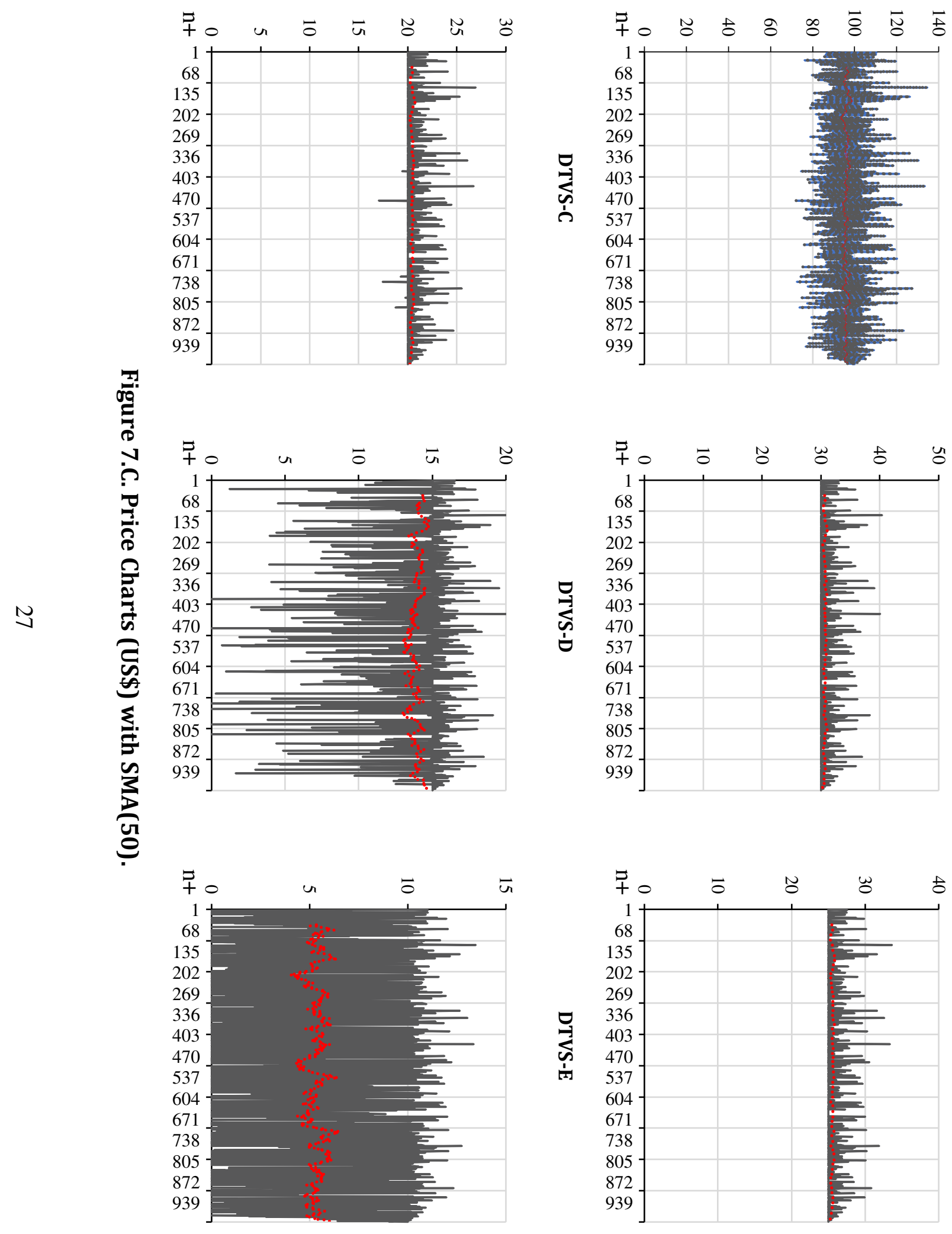

ํㅓㅁ

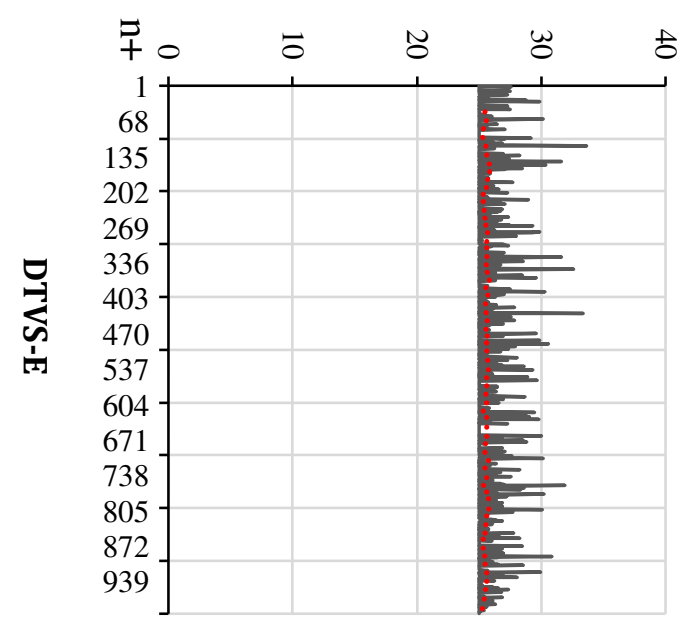

导 
D

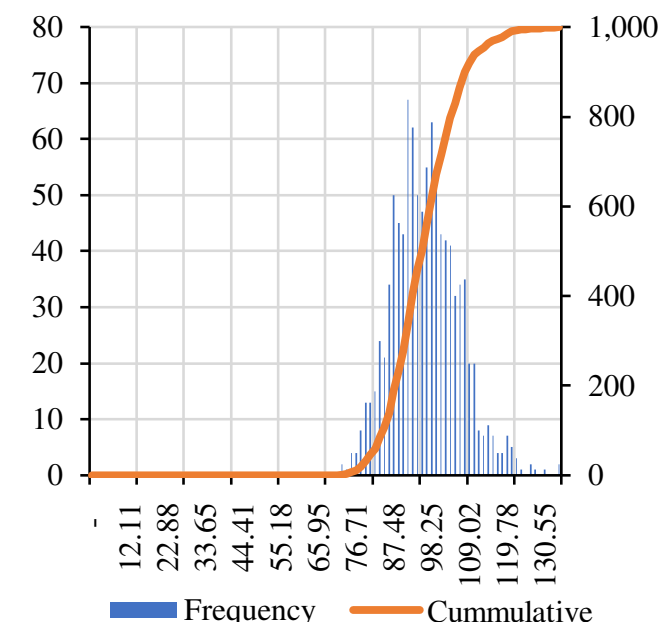

DTVS-C

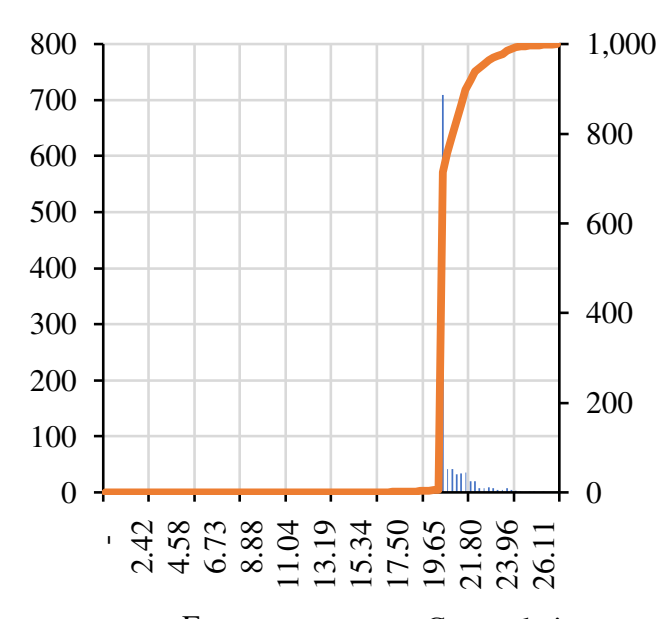

DTVS-A

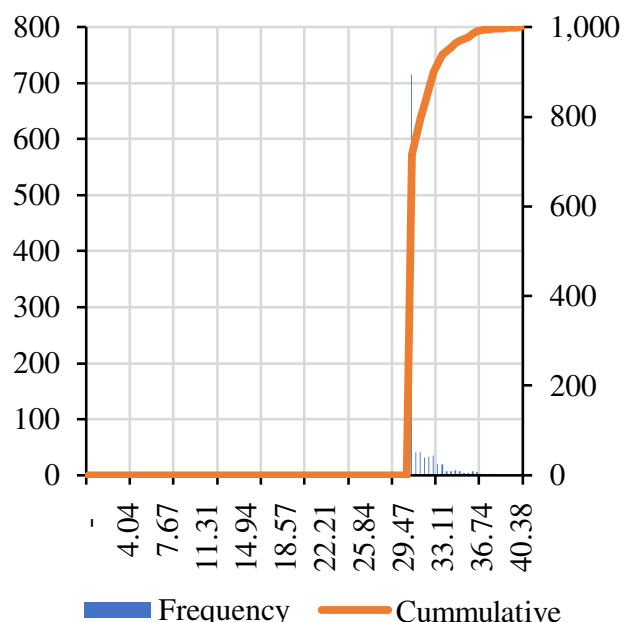

DTVS-D

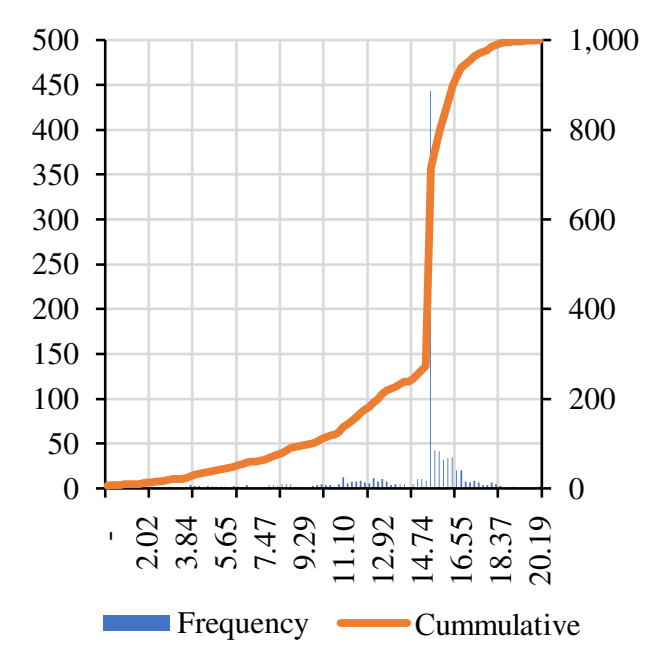

DTVS-B

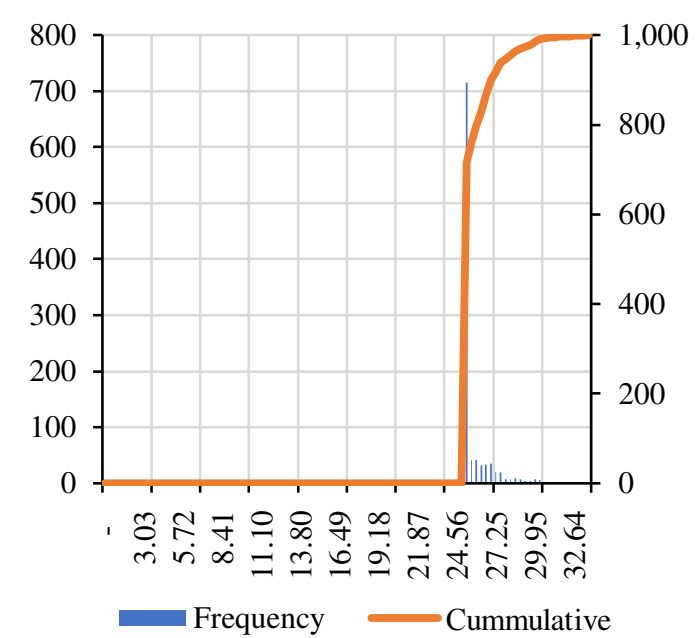

DTVS-E

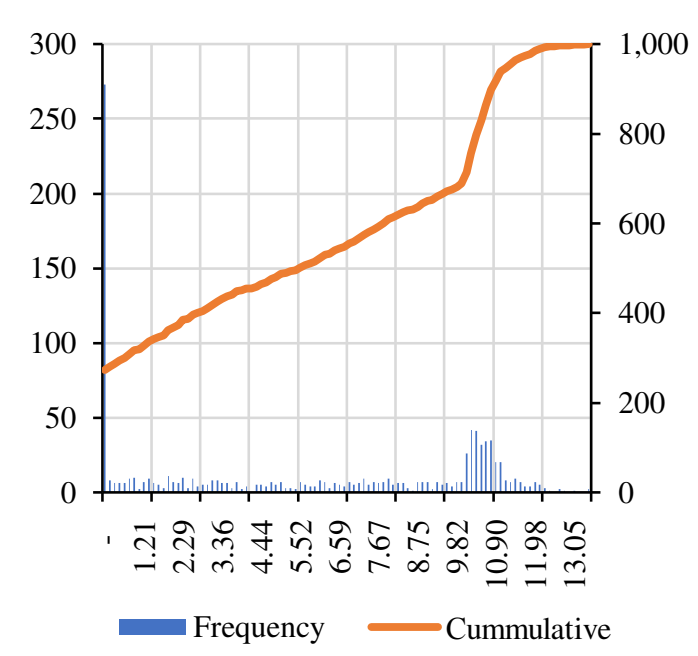

Figure 7.D. Price Distribution Histograms (US\$). 
Table of Statistical Summary for Price

\begin{tabular}{|l|r|r|r|r|r|r|}
\hline & \multicolumn{1}{|c|}{ D } & \multicolumn{1}{c|}{ DTVS-A } & \multicolumn{1}{c|}{ DTVS-B } & \multicolumn{1}{c|}{ DTVS-C } & \multicolumn{1}{c|}{ DTVS-D } & \multicolumn{1}{c|}{ DTVS-E } \\
\hline Count & $1,000.00$ & $1,000.00$ & $1,000.00$ & $1,000.00$ & $1,000.00$ & $1,000.00$ \\
\hline Mean & 95.96 & 30.66 & 25.55 & 20.43 & 13.96 & 5.36 \\
\hline Median & 95.49 & 30.00 & 25.00 & 20.00 & 15.00 & 5.49 \\
\hline Mode & 100.00 & 30.00 & 25.00 & 20.00 & 15.00 & - \\
\hline Minimum & 72.05 & 30.00 & 25.00 & 17.05 & - & - \\
\hline Maximum & 134.59 & 40.38 & 33.65 & 26.92 & 20.19 & 13.46 \\
\hline Range & 62.54 & 10.38 & 8.65 & 9.87 & 20.19 & 13.46 \\
\hline Sample Variance & 91.28 & 2.00 & 1.39 & 0.91 & 10.45 & 20.56 \\
\hline $\begin{array}{l}\text { Standard } \\
\text { Deviation }\end{array}$ & 9.55 & 1.41 & 1.18 & 0.96 & 3.23 & 4.53 \\
\hline $\begin{array}{l}\text { Mean/ Standard } \\
\text { Deviation }\end{array}$ & 10.04 & 21.68 & 21.68 & 21.37 & 4.32 & 1.18 \\
\hline Standard Error & 0.30 & 0.04 & 0.04 & 0.03 & 0.10 & 0.14 \\
\hline Kurtosis & 0.49 & 10.49 & 10.49 & 10.13 & 4.84 & $(1.68)$ \\
\hline Excess Kurtosis & $(2.51)$ & 7.49 & 7.49 & 7.13 & 1.84 & $(4.68)$ \\
\hline Skewness & 0.45 & 2.97 & 2.97 & 2.79 & $(2.17)$ & 0.03 \\
\hline
\end{tabular}

\section{Price Correlations}

DTVS-A DTVS-B DTVS-C DTVS-D DTVS-E

\begin{tabular}{|c|c|c|c|c|c|c|}
\hline D & 1.00 & 0.80 & 0.80 & 0.81 & 0.80 & 0.91 \\
\hline DTVS-A & 0.80 & 1.00 & 1.00 & 0.99 & 0.42 & 0.60 \\
\hline DTVS-B & 0.80 & 1.00 & 1.00 & 0.99 & 0.42 & 0.60 \\
\hline DTVS-C & 0.81 & 0.99 & 0.99 & 1.00 & 0.45 & 0.60 \\
\hline DTVS-D & 0.80 & 0.42 & 0.42 & 0.45 & 1.00 & 0.63 \\
\hline DTVS-E & 0.91 & 0.60 & 0.60 & 0.60 & 0.63 & 1.00 \\
\hline
\end{tabular}

Chart of Statistical Summary for Price

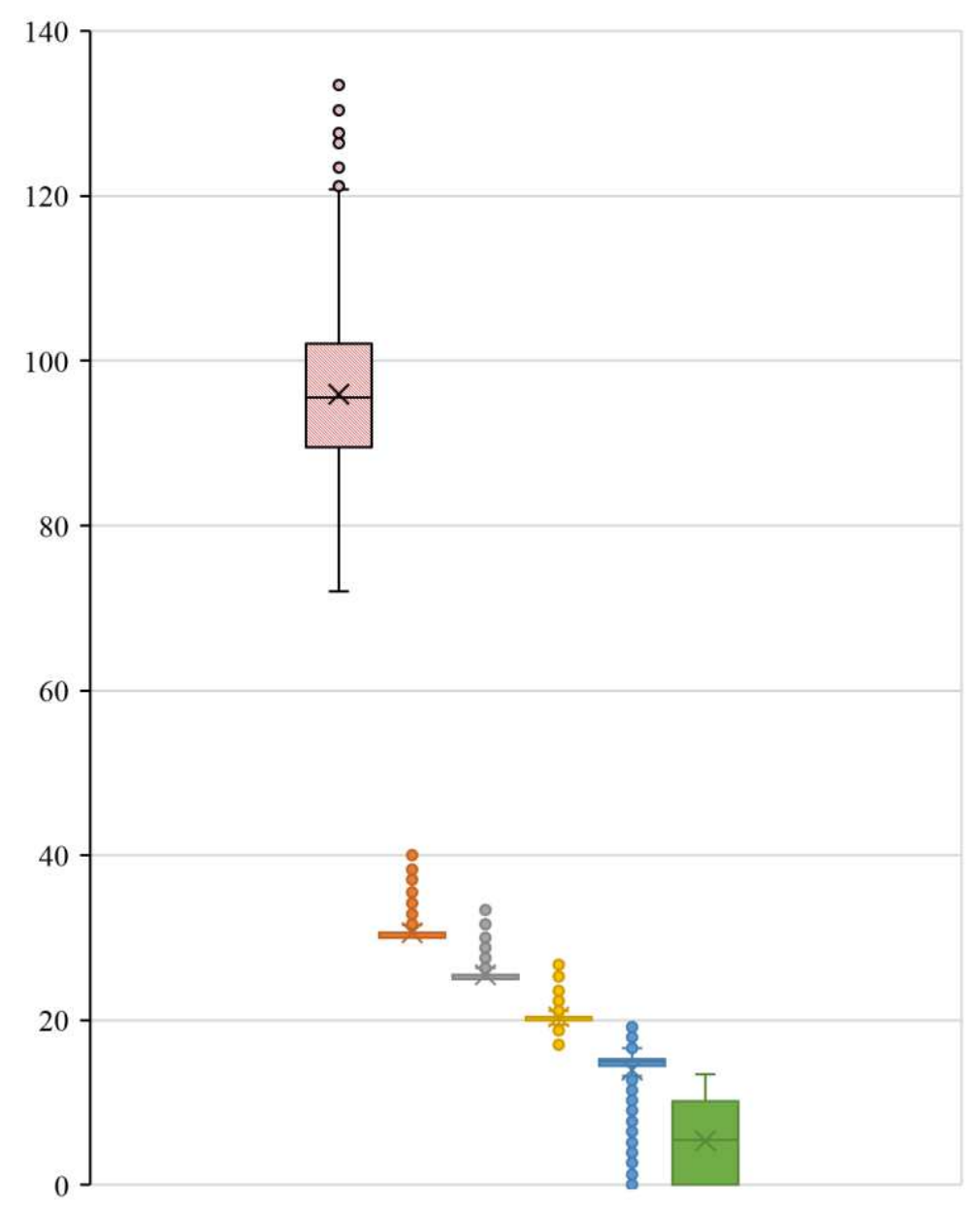

$\square \mathrm{D}$

$\square$ DTVS-A $\square$ DTVS-B

$\square$ DTVS-C $\square$ DTVS-D $\square$ DTVS-E

Figure 7.E. Price Statistical Summary (US\$). 
D

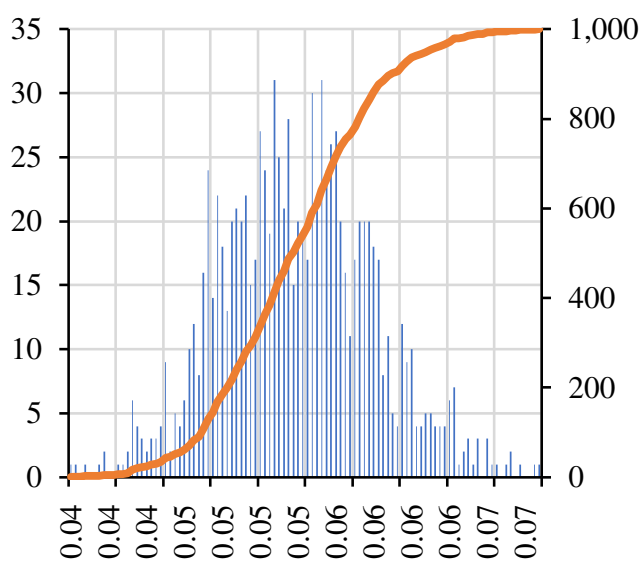

Frequency Cummulative DTVS-C

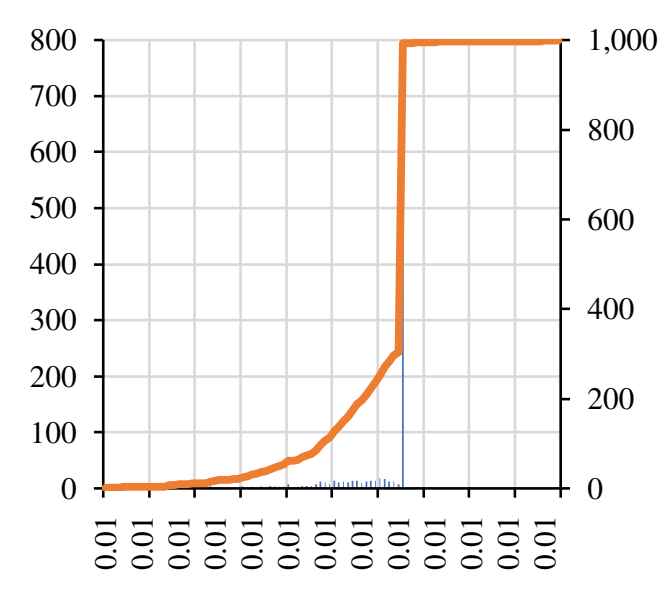

DTVS-A

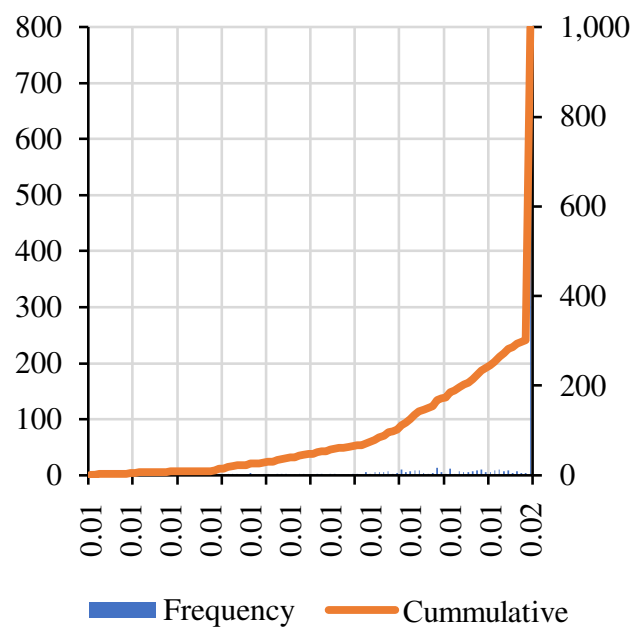

DTVS-D

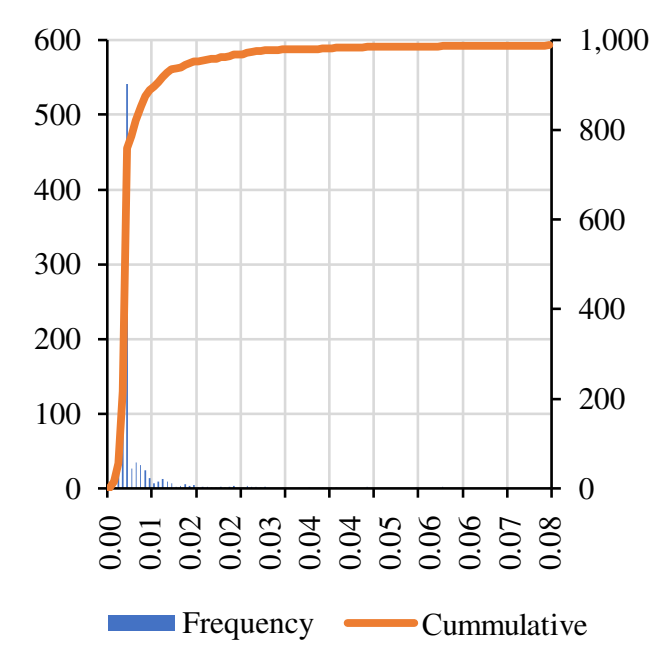

DTVS-B

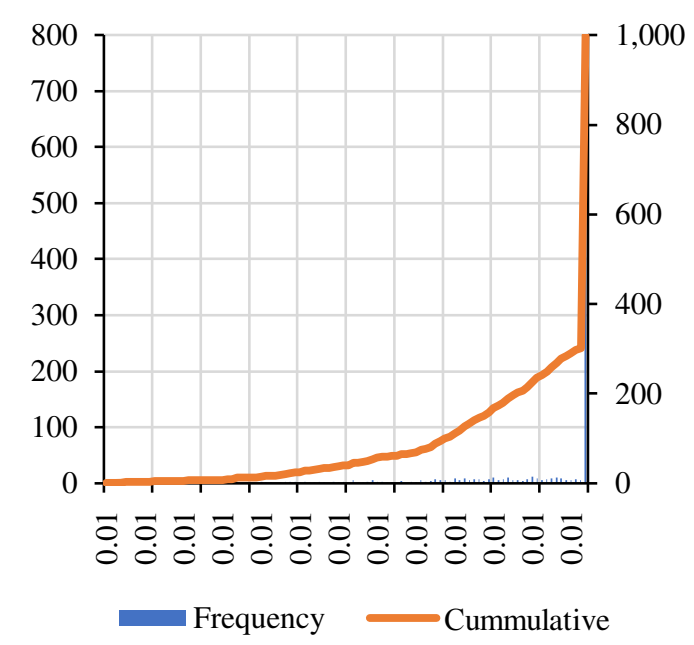

DTVS-E

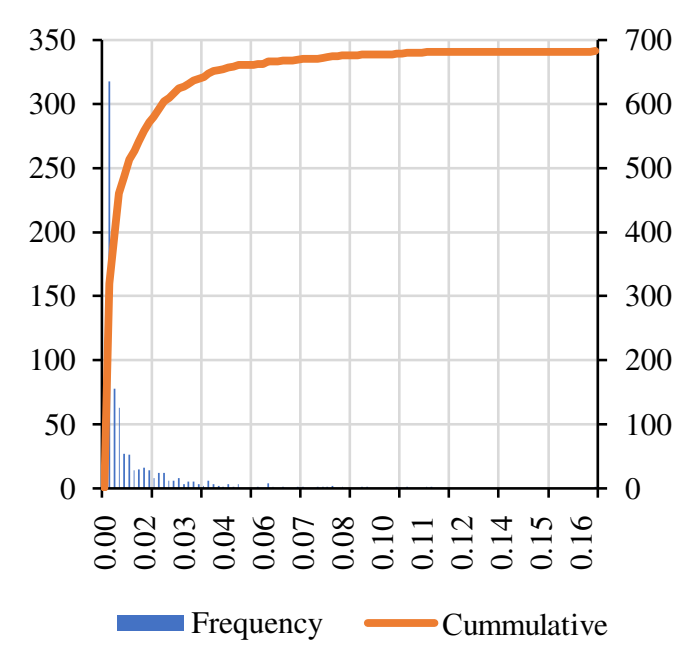

Figure 7.F. YTM Distribution Histograms (\%). 
Table of Statistical Summary for YTM

\begin{tabular}{|l|r|r|r|r|r|r|}
\hline & \multicolumn{1}{|c|}{ D } & \multicolumn{1}{c|}{ DTVS-A } & \multicolumn{1}{c|}{ DTVS-B } & \multicolumn{1}{c|}{ DTVS-C } & \multicolumn{1}{c|}{ DTVS-D } & \multicolumn{1}{c|}{ DTVS-E } \\
\hline Count & $1,000.00$ & $1,000.00$ & $1,000.00$ & $1,000.00$ & $1,000.00$ & $1,000.00$ \\
\hline Mean & 0.05 & 0.01 & 0.01 & 0.01 & 0.01 & 0.01 \\
\hline Median & 0.05 & 0.02 & 0.01 & 0.01 & 0.01 & 0.01 \\
\hline Mode & N/A & 0.02 & 0.01 & 0.01 & 0.01 & N/A \\
\hline Minimum & 0.04 & 0.01 & 0.01 & 0.01 & 0.00 & 0.00 \\
\hline Maximum & 0.07 & 0.02 & 0.01 & 0.01 & 0.08 & 0.17 \\
\hline Range & 0.03 & 0.00 & 0.00 & 0.01 & 0.07 & 0.16 \\
\hline Sample Variance & 0.00 & 0.00 & 0.00 & 0.00 & 0.00 & 0.00 \\
\hline $\begin{array}{l}\text { Standard } \\
\text { Deviation }\end{array}$ & 0.01 & 0.00 & 0.00 & 0.00 & 0.01 & 0.02 \\
\hline $\begin{array}{l}\text { Mean/ Standard } \\
\text { Deviation }\end{array}$ & 10.08 & 22.17 & 21.30 & 19.59 & 1.59 & 0.75 \\
\hline Standard Error & 0.00 & 0.00 & 0.00 & 0.00 & 0.00 & 0.00 \\
\hline Kurtosis & $(0.01)$ & 6.75 & 7.39 & 8.70 & 48.42 & 23.96 \\
\hline Excess Kurtosis & $(3.01)$ & 3.75 & 4.39 & 5.70 & 45.42 & 20.96 \\
\hline Skewness & 0.14 & $(2.54)$ & $(2.62)$ & $(2.57)$ & 6.06 & 4.18 \\
\hline
\end{tabular}

YTM Correlations

\begin{tabular}{|lcccccc} 
& D & DTVS-A & DTVS-B & DTVS-C & DTVS-D & DTVS-E \\
\hline D & 1.00 & 0.72 & 0.71 & 0.71 & 0.59 & 0.62 \\
\hline DTVS-A & 0.72 & 1.00 & 1.00 & 0.98 & 0.22 & 0.30 \\
\hline DTVS-B & 0.71 & 1.00 & 1.00 & 0.98 & 0.22 & 0.30 \\
\hline DTVS-C & 0.71 & 0.98 & 0.98 & 1.00 & 0.21 & 0.30 \\
\hline DTVS-D & 0.59 & 0.22 & 0.22 & 0.21 & 1.00 & 0.29 \\
\hline DTVS-E & 0.62 & 0.30 & 0.30 & 0.30 & 0.29 & 1.00 \\
\hline
\end{tabular}

Chart of Statistical Summary for YTM

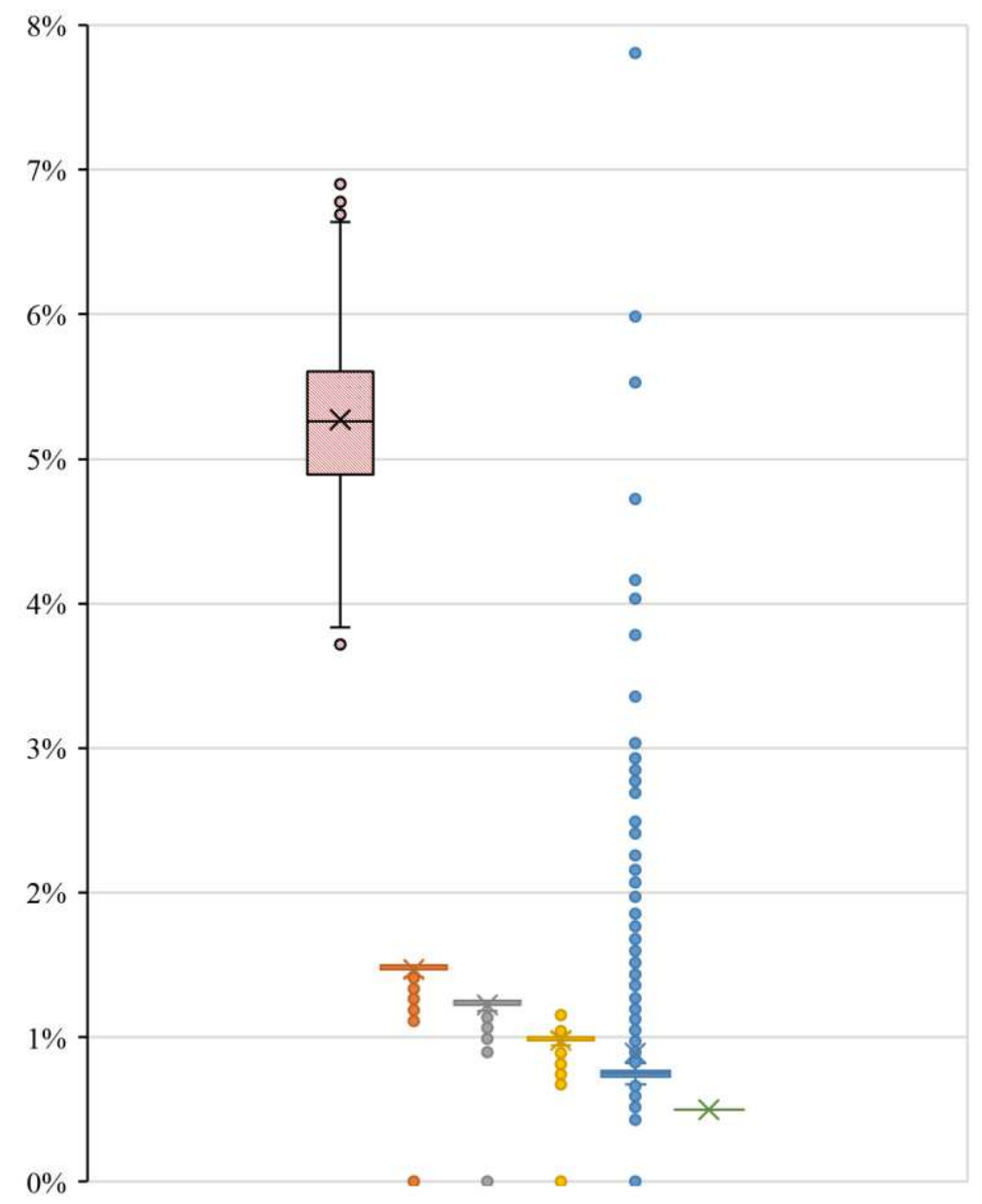

$\square$ D $\square$ DTVS-A $\square$ DTVS-B

$\square$ DTVS-C $\square$ DTVS-D $\square$ DTVS-E

Figure 7.G. YTM Statistical Summary (\%). 


\section{B. Case Studies}

\section{B.1. Case Study: Equity Security}

This section assesses the performance of TVS securities as if they were issued with General Electric Ordinary Common Stock (NYSE: GE) as underlying. For the purpose of analysis GE monthly performance for the period of $01 / 01 / 2007-01 / 12 / 2017$ is used.

It is assumed that five Tranched Value Securities were issued with GE as underlying on $01 / 01 / 2007$ when the opening price for GE was US\$37.41, with characteristics presented on Figure 8.A.

The results of the assessment are presented on Figure 8.A-8.H and were obtained for the minimum values of five value tranches and GE stock. Based on the assessment, it is evident that GETVS-A was the only value tranche that never reached a value of zero, thus from time to time having a value equal to the value of underlying, during the times of severe price declines in GE stock, when the other value tranches exhibited a value of zero. That is evident from the TVSs attachment and detachment points, that indicate that for GETVS-E in order to decline in value, a decline in value of GE stock of any value greater than zero is enough, while in order for it to have value completely wiped out, a decline of $10 \%$ is required. At the same time for GE TVS Senior, a decline of at least $70 \%$ is required in the value of GE, in order to start reducing its minimum value, and a decline of $100 \%$ of GE stock is required, to wipe out all value of GETVS-A, which at the same time would wipe out value in all other tranches. This results in the highest number of defaults in GETVS-E, amounting to $89 \%$ (this value tranche reached a value of zero at $01 / 05 / 2008$ and hasn't recovered until the end of the assessed period), with GETVS-D having the second highest number of value defaults amounting to $71 \%$. Moreover, as a result of value tranching, distribution profiles of TVSs significantly differ from price distribution profile of GE stock, displaying a clear price floor for some securities. At the same time, price distributions of the three most junior TVSs exhibit positive skewness, while the other two tranches have a negative skewness, while GETVS-A, and GETVS-E are the only securities with positive excess kurtosis, whilst all other securities (GE stock including) have negative excess 
kurtosis. Other price statistics, such as price range, standard deviation, and correlations also indicate a varying performance of all six securities.

Return profiles of all securities display a highly volatile performance, some of the return values reaching values above $100 \%$ and $-100 \%$, which indicate significantly magnified performance of the underlying GE stock. Furthermore, return distributions of all value tranches indicate significantly changed shapes, while the original distribution of GE was somewhat normal. All securities except for GE and GETVS-A have a significant number of returns outliers, in some cases (GETVS-C) having significantly extreme values amounting to nearly 40.0x of monthly return. GETVS-C also exhibited the highest monthly mean return amounting to $41 \%$, while all other securities generated mean returns in the range of $-11 \%$ (GETVS-E) to 2\% (GETVS-B). As a result of this, standard deviation of returns of GETVS-C was also the highest, amounting to 4.08 which is higher than the GE's standard deviation of 0.08 nearly 51.0x times. Return distributions of all value tranches, except for GETVS-E exhibited either slightly positive, either extreme positive excess kurtosis, while GE stock had a negative excess kurtosis. At the same time, all securities, except for the underlying stock and GETVS-A, had positive skewness. Return correlations between the underlying was the lowest with GETVS-C and GETVS-A, while correlations between GETVS-C, GETVS-D and GETVS-E with GETVS-A, and GETVS-B were nearly zero.

Furthermore, Beta coefficient for GE was $1.10 \mathrm{x}$, which was transformed to $0.99 \mathrm{x}$ in GETVS-A, 1.65x in GETVS-B, -0.78x in GETVS-C, -0.15x in GETVS-D, and 4.81x in GETVS$\mathrm{E}$, while the weighted average for all TVSs is reduced to $1.01 \mathrm{x}$, which all together with the above suggest significant transformation of underlying security performance, generating significant diversification benefits in various market states. 
Assumed Issuance Information

\begin{tabular}{|l|c|c|c|}
\hline \multicolumn{1}{|c|}{ Security } & Code & $\begin{array}{c}\text { Value } \\
\text { Share (\%) }\end{array}$ & $\begin{array}{c}\text { Minimum } \\
\text { Value* (US\$) }\end{array}$ \\
\hline NYSE: GE & GE & 1.00 & 37.41 \\
\hline GE TVS Senior & GETVS-A & 0.30 & 11.22 \\
\hline GE TVS Subordinated & GETVS-B & 0.25 & 9.35 \\
\hline GE TVS Junior & GETVS-C & 0.20 & 7.48 \\
\hline GE TVS Mezzanine & GETVS-D & 0.15 & 5.61 \\
\hline GE TVS Equity & GETVS-E & 0.10 & 3.74 \\
\hline
\end{tabular}

open price as of 01/01/2007

TVS Price Share of Total Price of Underlying (\%)

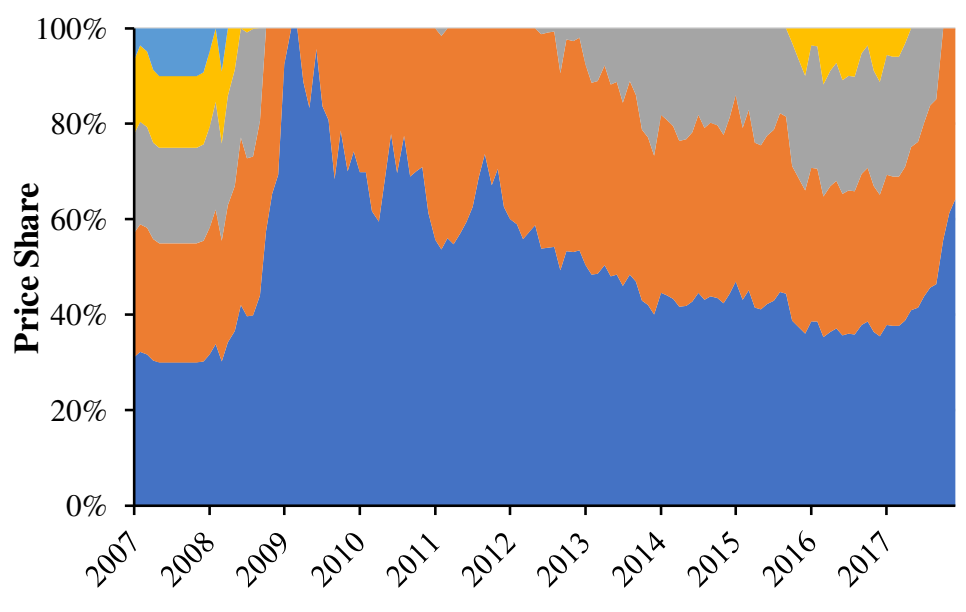

-GETVS-A $\backsim$ GETVS-B $\backsim$ GETVS-C $\backsim$ GETVS-D $\backsim$ GETVS-E

\section{Combined Price Data for Five TVSs and Underlying (US\$)}
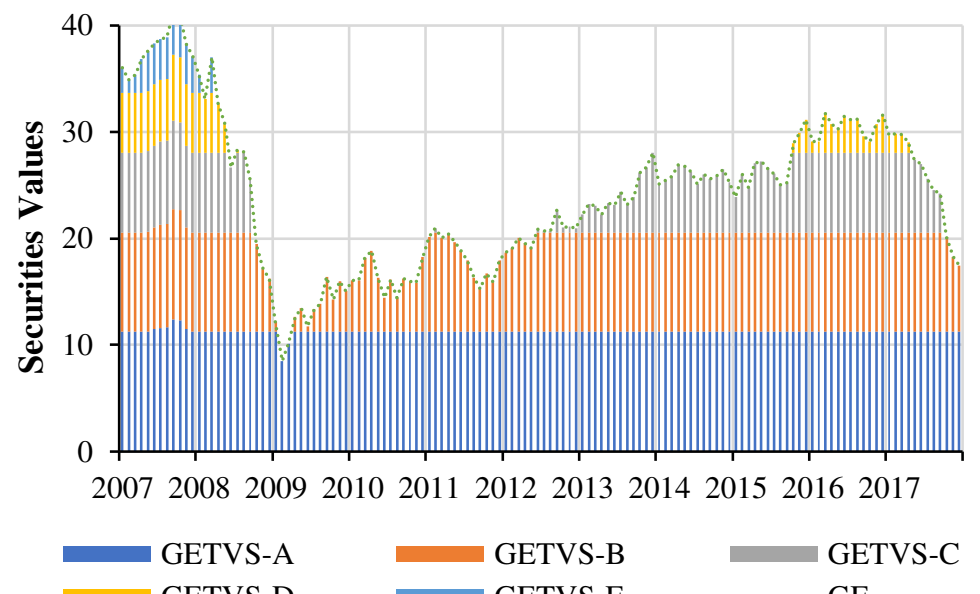

GETVS-D GETVS-E $\quad$ G …….... GE

\section{Securities Performance (Limited to $-\mathbf{1 0 0 \%}$ to $+\mathbf{1 0 0 \%}$ )}

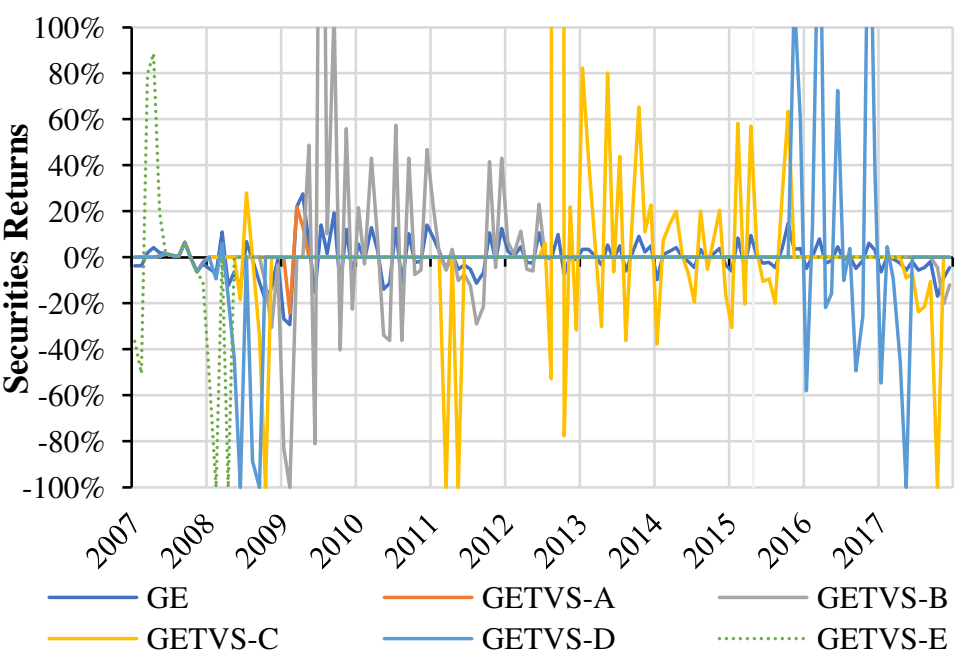

Figure 8.A. Issuance, Price and Return Summary. 
Securities Return Full Snapshot

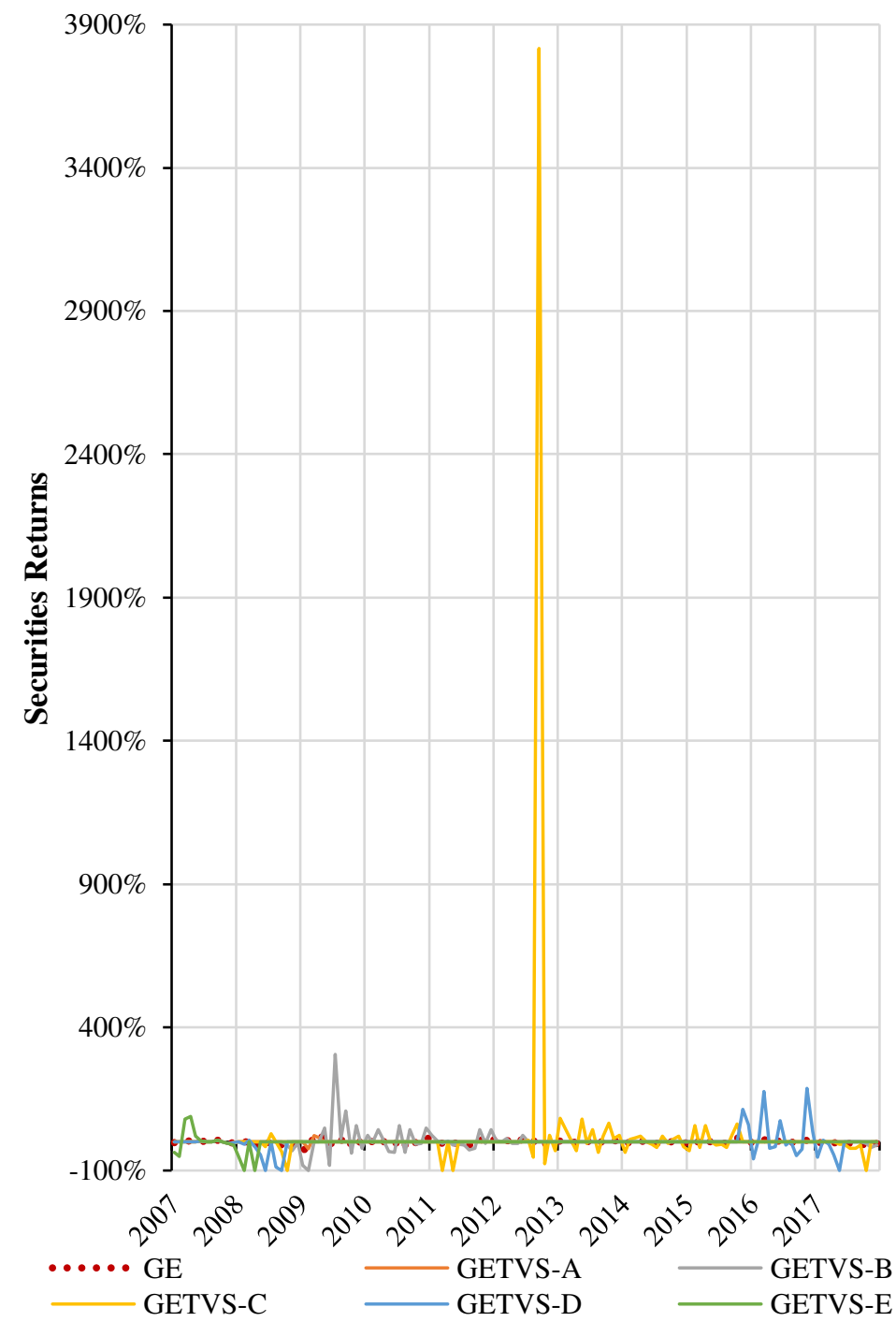

TVS Default Rates (When Price Equals to Zero)

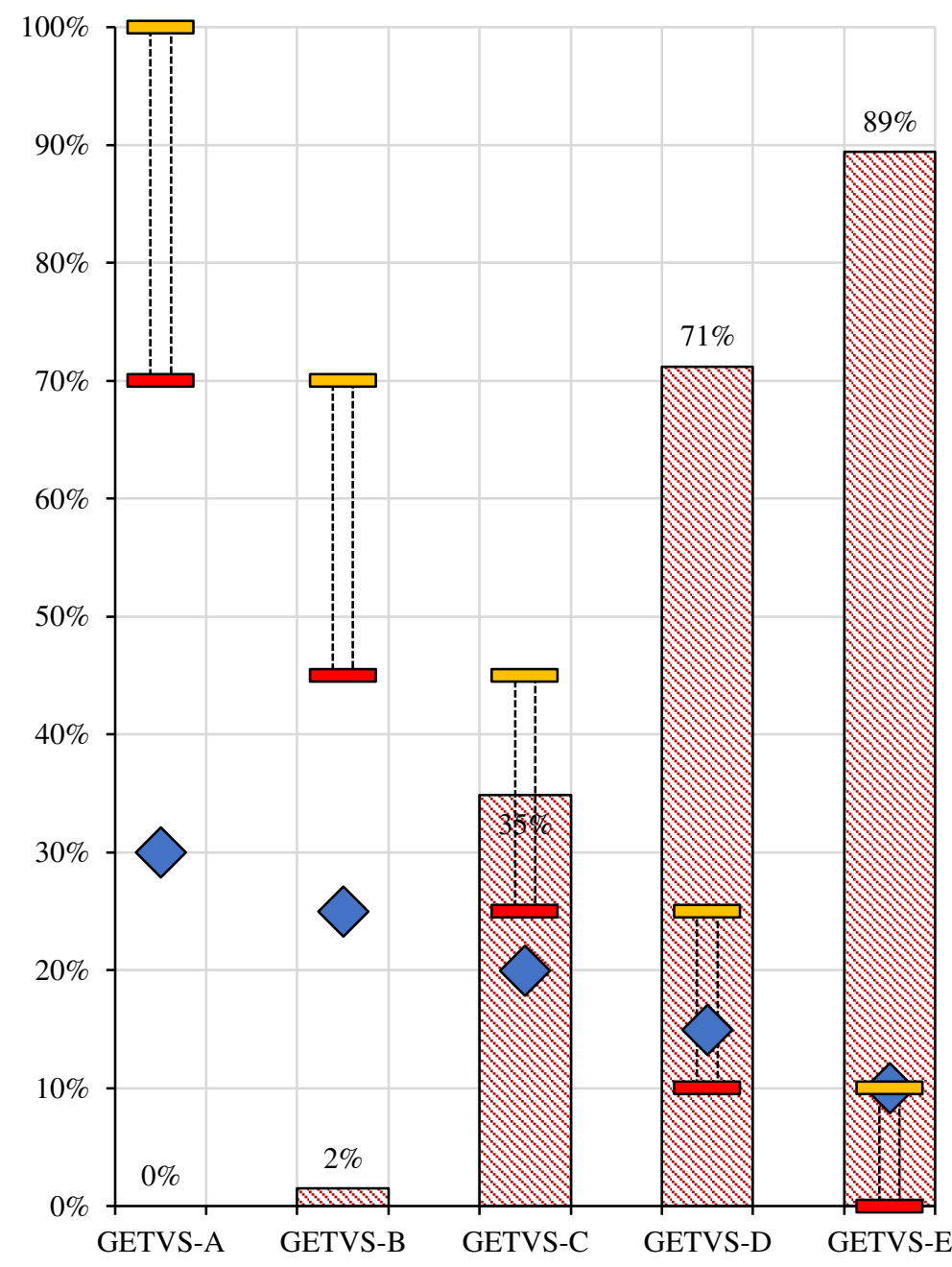

$\diamond$ Default Rates $\diamond$ Value Share - Attachment Point - Detachment Point

Figure 8.B. Return and Default Rates (\%). 

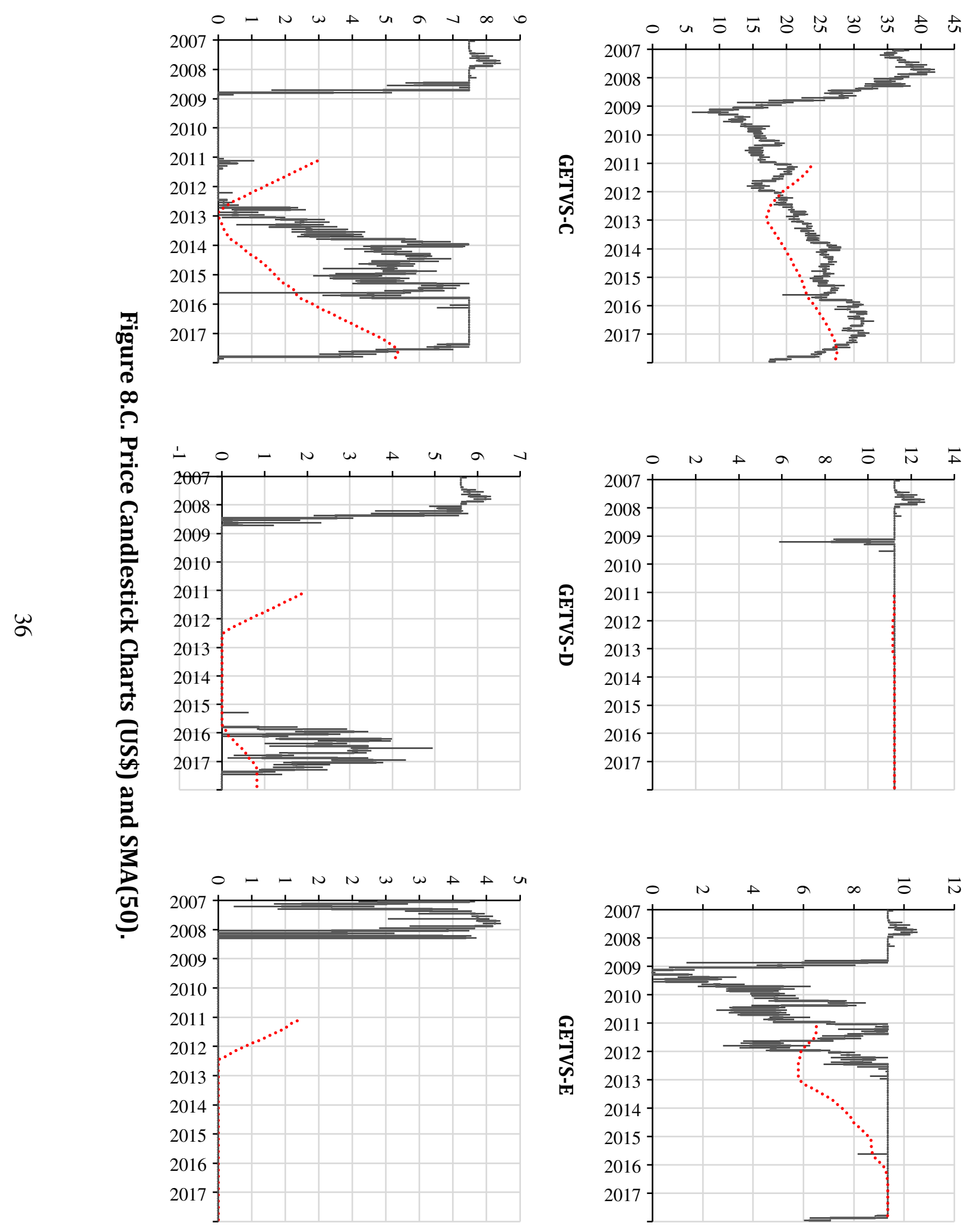

คำ

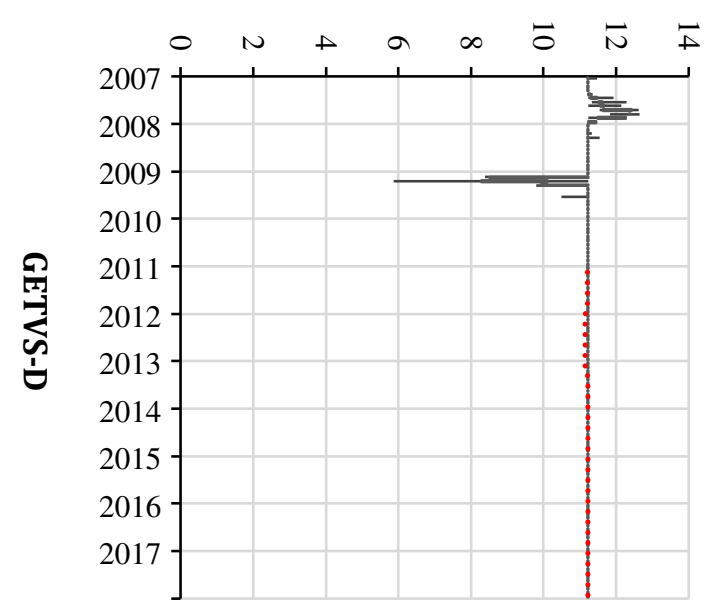

棛

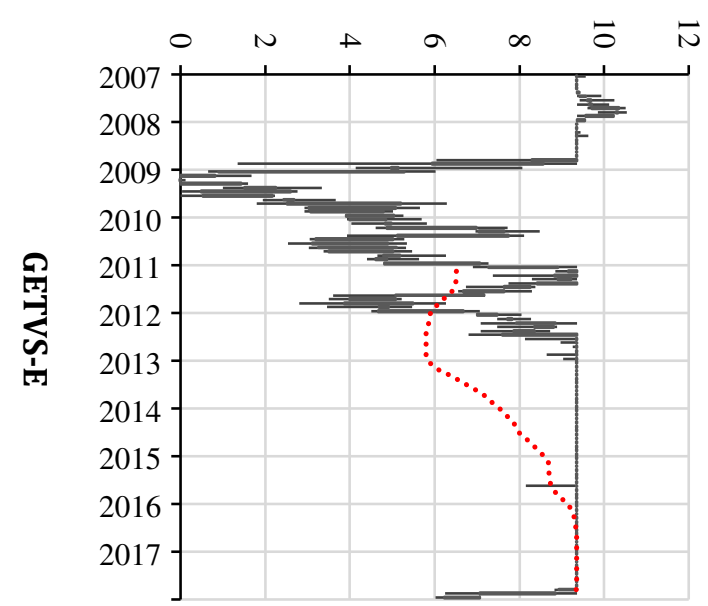

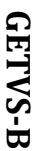


GE

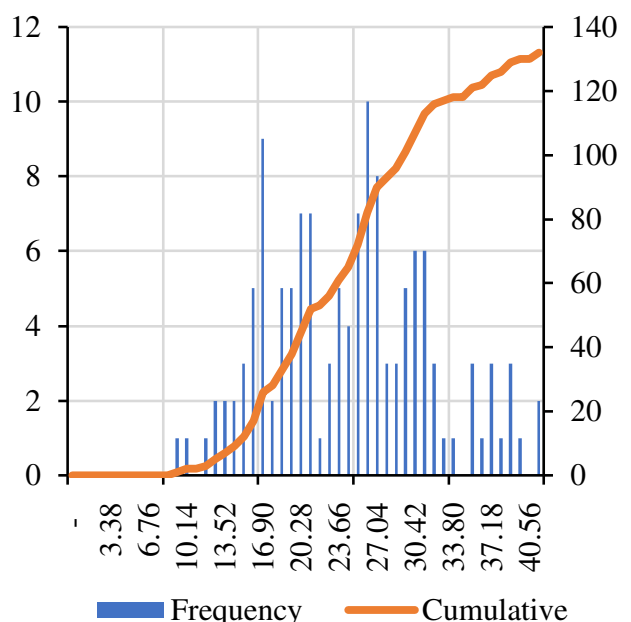

GETVS-C

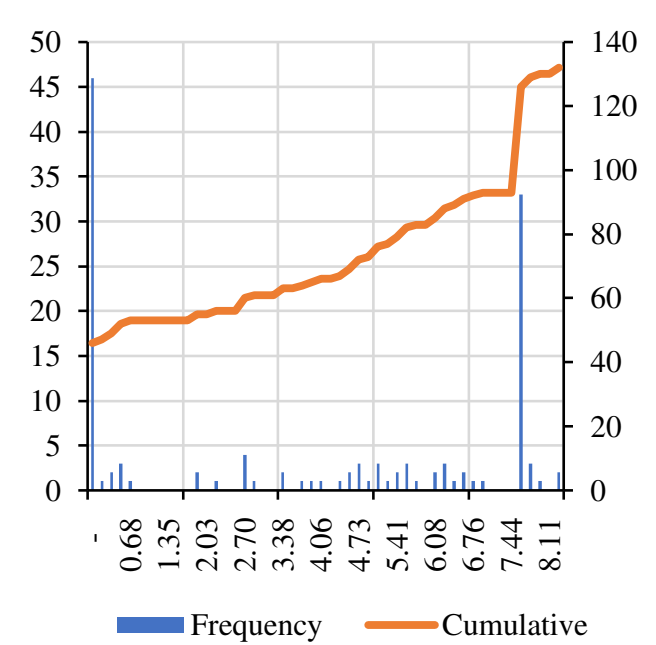

GETVS-A

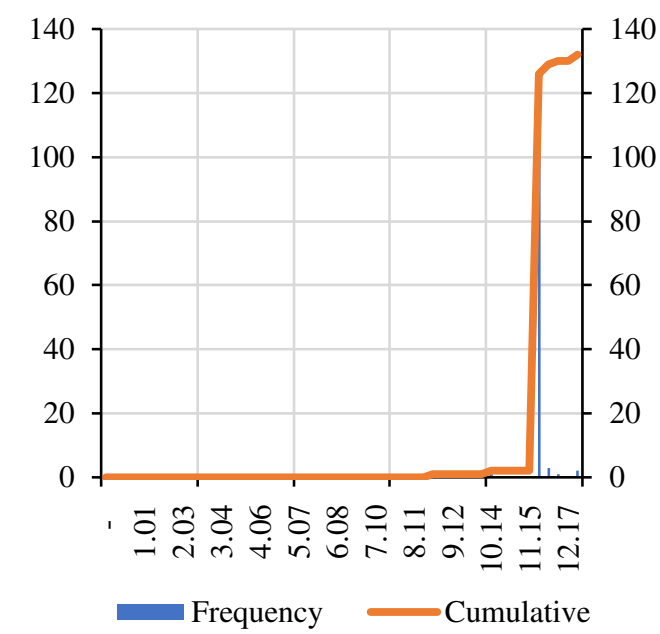

GETVS-D

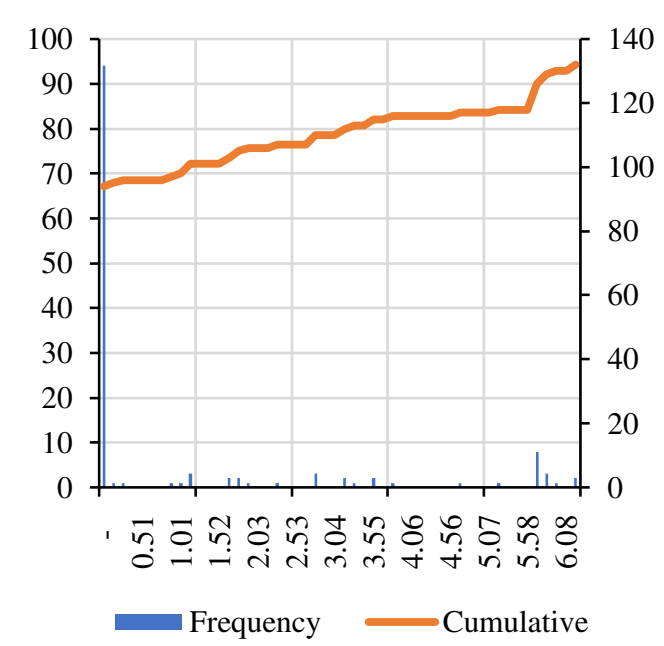

GETVS-B

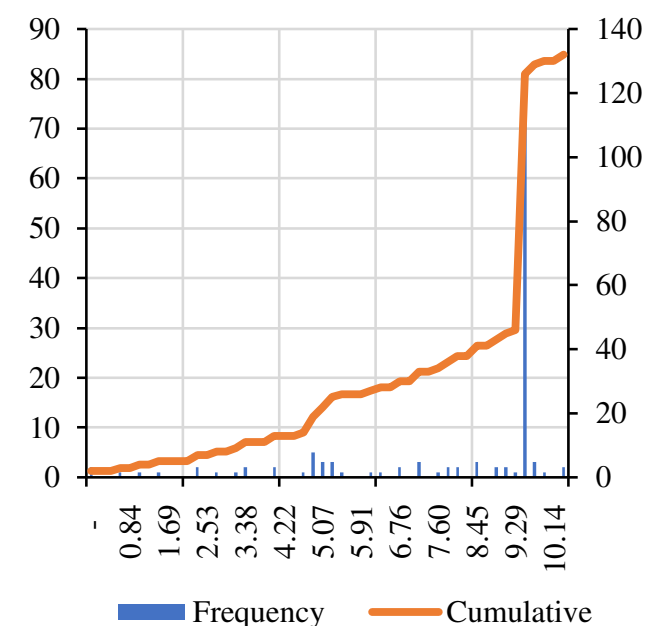

GETVS-E

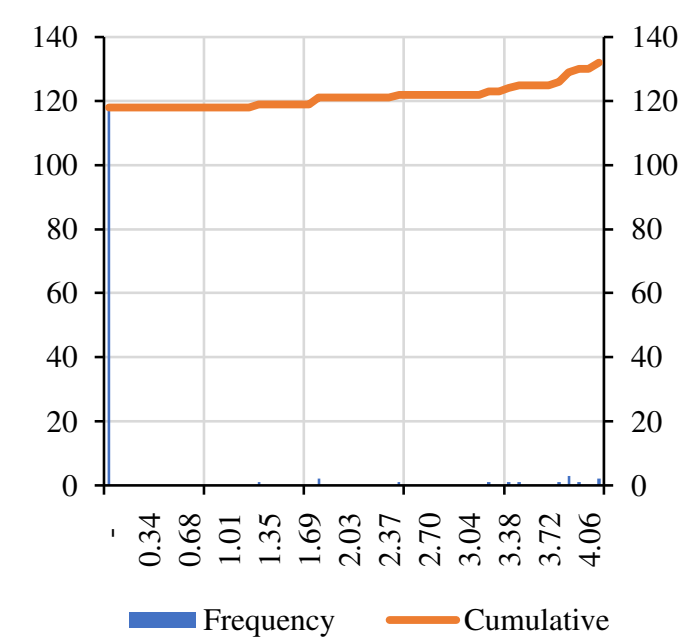

Figure 8.D. Price Distribution Histograms (US\$). 
Table of Statistical Summary for Price

\begin{tabular}{|l|r|r|r|r|r|r|}
\hline & \multicolumn{1}{|c|}{ GE } & \multicolumn{1}{|c|}{ GETVS-A } & \multicolumn{1}{c|}{ GETVS-B } & \multicolumn{1}{|c|}{ GETVS-C } & \multicolumn{1}{c|}{ GETVS-D } & \multicolumn{1}{c|}{ GETVS-E } \\
\hline Count & 132.00 & 132.00 & 132.00 & 132.00 & 132.00 & 132.00 \\
\hline Mean & 24.21 & 11.22 & 7.99 & 3.65 & 1.02 & 0.34 \\
\hline Median & 24.68 & 11.22 & 9.35 & 4.10 & 0.00 & 0.00 \\
\hline Mode & 35.36 & 11.22 & 9.35 & 0.00 & 0.00 & 0.00 \\
\hline Minimum & 8.51 & 8.51 & 0.00 & 0.00 & 0.00 & 0.00 \\
\hline Maximum & 41.40 & 12.42 & 10.35 & 8.28 & 6.21 & 4.14 \\
\hline Range & 32.89 & 3.91 & 10.35 & 8.28 & 6.21 & 4.14 \\
\hline Sample Variance & 51.91 & 0.09 & 5.99 & 10.72 & 3.72 & 1.06 \\
\hline $\begin{array}{l}\text { Standard } \\
\text { Deviation }\end{array}$ & 7.20 & 0.30 & 2.45 & 3.27 & 1.93 & 1.03 \\
\hline $\begin{array}{l}\text { Mean/ Standard } \\
\text { Deviation }\end{array}$ & 3.36 & 37.40 & 3.26 & 1.11 & 0.53 & 0.33 \\
\hline Standard Error & 0.63 & 0.03 & 0.21 & 0.28 & 0.17 & 0.09 \\
\hline Kurtosis & $(0.48)$ & 55.49 & 1.91 & $(1.76)$ & 1.46 & 7.12 \\
\hline Excess Kurtosis & $(3.48)$ & 52.49 & $(1.09)$ & $(4.76)$ & $(1.54)$ & 4.12 \\
\hline Skewness & 0.26 & $(5.16)$ & $(1.70)$ & 0.01 & 1.73 & 2.94 \\
\hline
\end{tabular}

Price Correlations

GE GETVS- GETVS- GETVS- GETVS- GETVS-

\begin{tabular}{|c|c|c|c|c|c|c|}
\hline GE & 1.00 & 0.42 & 0.77 & 0.92 & 0.80 & 0.64 \\
\hline $\begin{array}{l}\text { GETVS- } \\
\text { A }\end{array}$ & 0.42 & 1.00 & 0.40 & 0.24 & 0.30 & 0.37 \\
\hline $\begin{array}{l}\text { GETVS- } \\
\text { B }\end{array}$ & 0.77 & 0.40 & 1.00 & 0.65 & 0.33 & 0.22 \\
\hline $\begin{array}{l}\text { GETVS- } \\
\text { C }\end{array}$ & 0.92 & 0.24 & 0.65 & 1.00 & 0.64 & 0.41 \\
\hline $\begin{array}{l}\text { GETVS- } \\
\text { D }\end{array}$ & 0.80 & 0.30 & 0.33 & 0.64 & 1.00 & 0.81 \\
\hline $\begin{array}{l}\text { GETVS- } \\
\text { E }\end{array}$ & 0.64 & 0.37 & 0.22 & 0.41 & 0.81 & 1.00 \\
\hline
\end{tabular}

Chart of Statistical Summary for Price

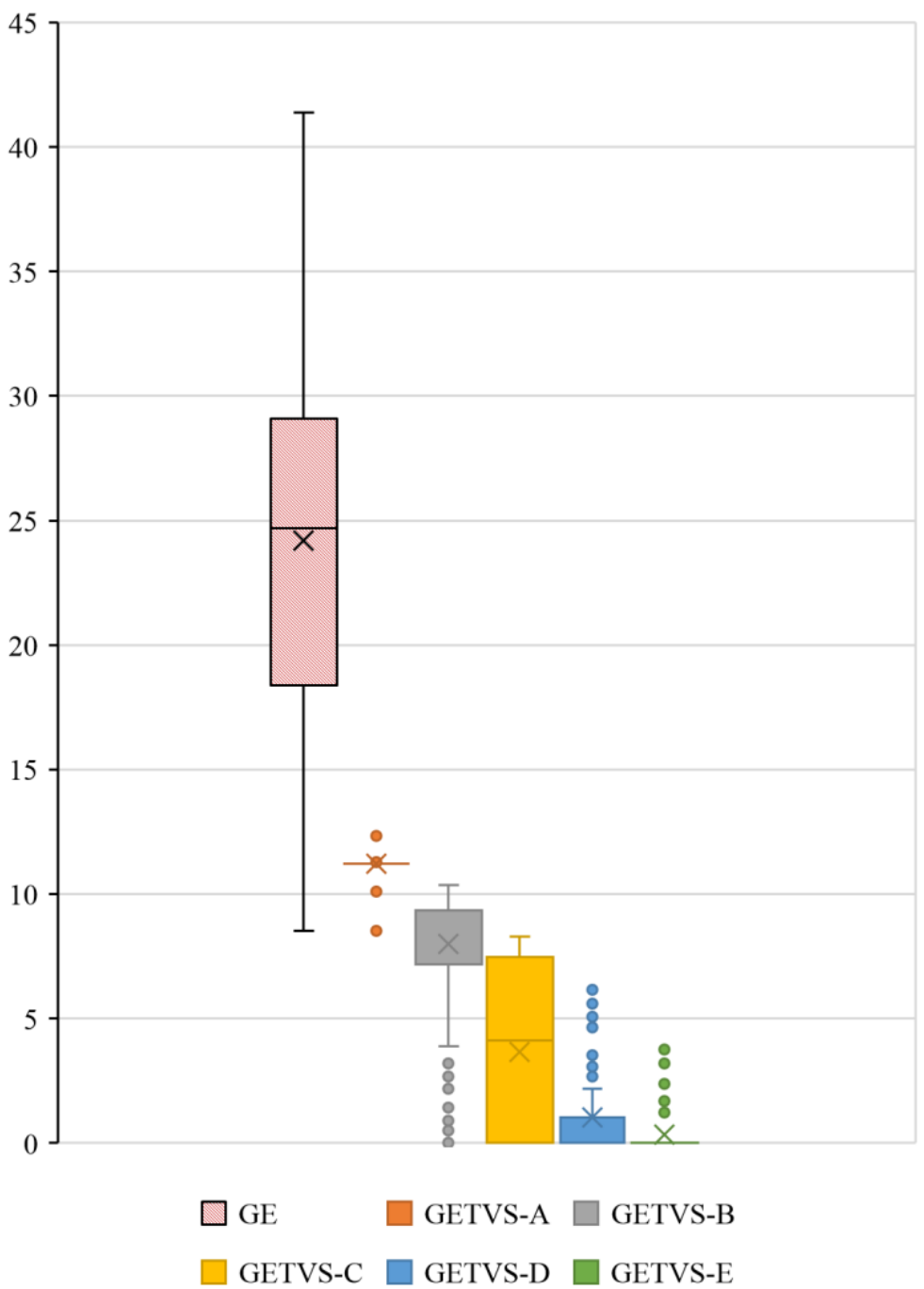

Figure 8.E. Price Statistical Summary (US\$). 
GE

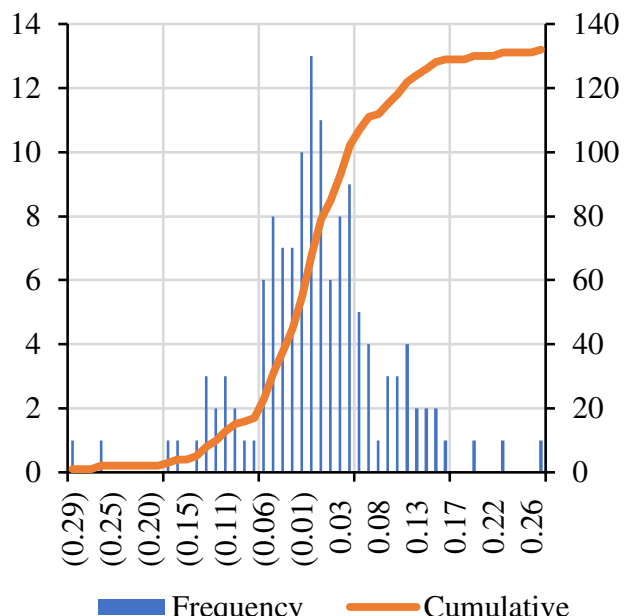

GETVS-C

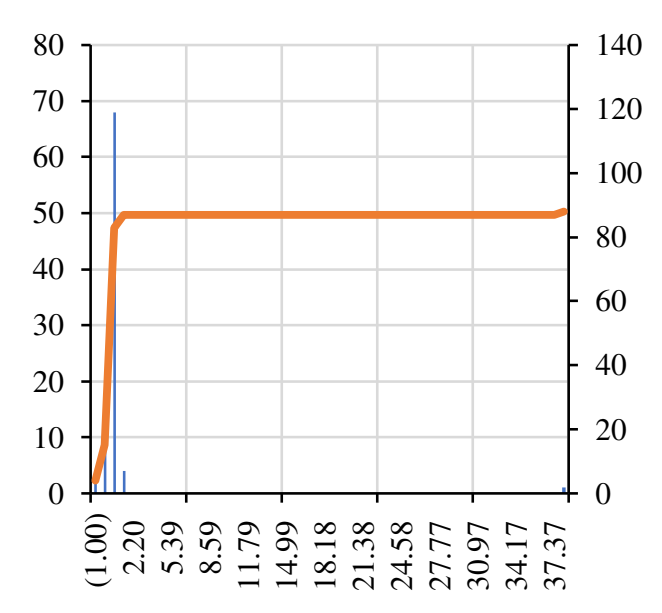

GETVS-A

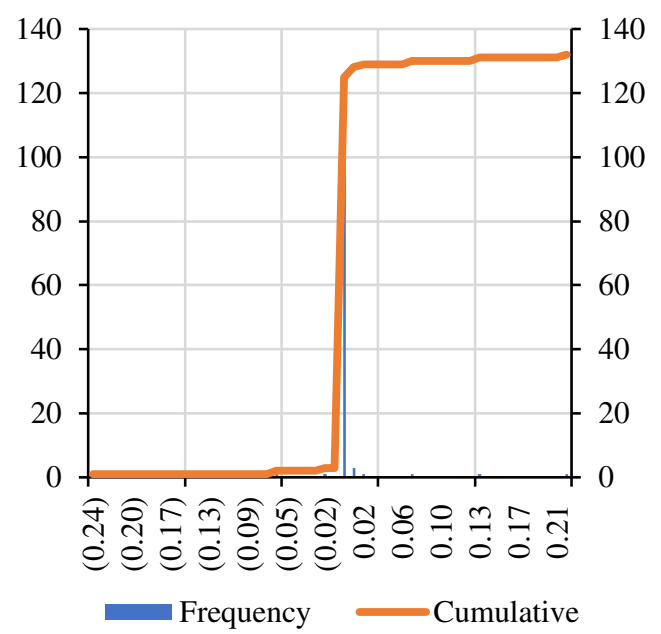

GETVS-D

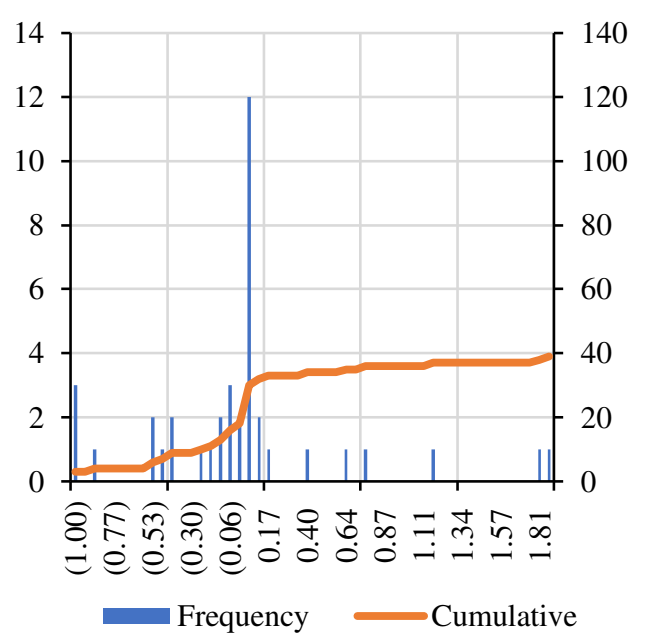

GETVS-B

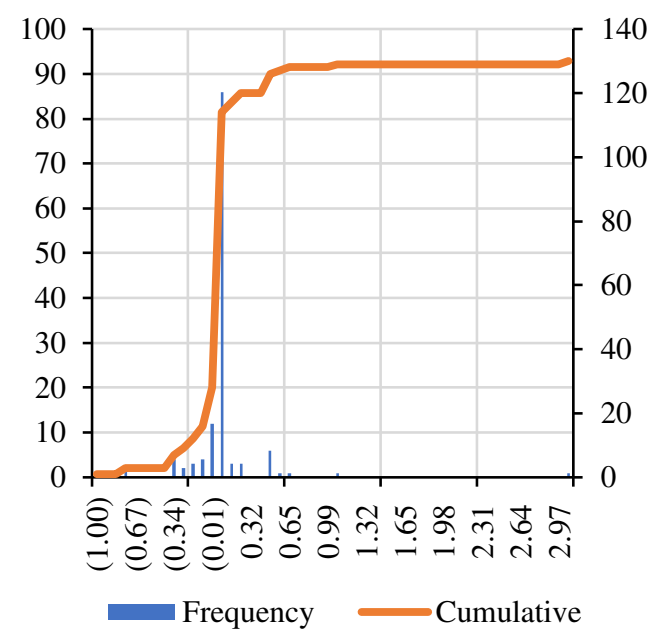

GETVS-E

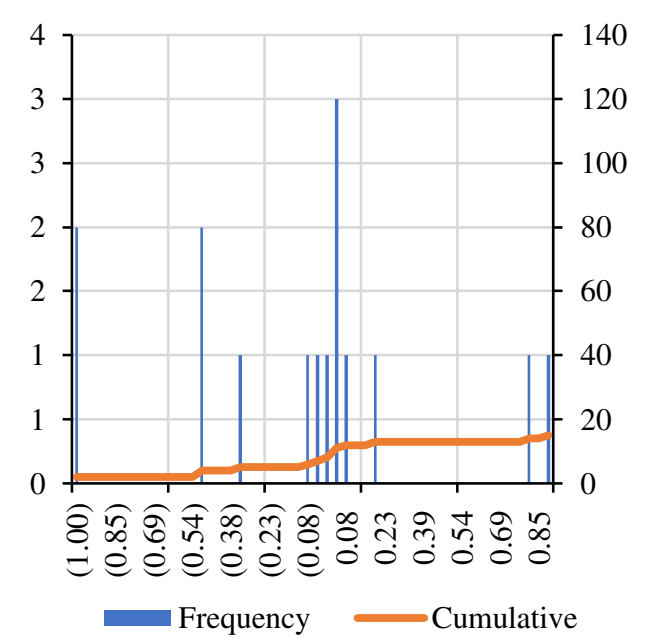

Figure 8.F. Return Distribution Histograms (\%). 
Table of Statistical Summary for Return

\begin{tabular}{|l|r|r|r|r|r|r|}
\hline & \multicolumn{1}{|c|}{ GE } & \multicolumn{1}{c|}{ GETVS-A } & \multicolumn{1}{c|}{ GETVS-B } & \multicolumn{1}{c|}{ GETVS-C } & \multicolumn{1}{c|}{ GETVS-D } & \multicolumn{1}{c|}{ GETVS-E } \\
\hline Count & 132.00 & 132.00 & 130.00 & 88.00 & 39.00 & 15.00 \\
\hline Mean & $(0.00)$ & 0.00 & 0.02 & 0.41 & $(0.02)$ & $(0.11)$ \\
\hline Median & $(0.01)$ & 0.00 & 0.00 & 0.00 & 0.00 & $(0.00)$ \\
\hline Mode & $\mathrm{N} / \mathrm{A}$ & 0.00 & 0.00 & 0.00 & 0.00 & $(1.00)$ \\
\hline Minimum & $(0.29)$ & $(0.24)$ & $(1.00)$ & $(1.00)$ & $(1.00)$ & $(1.00)$ \\
\hline Maximum & 0.28 & 0.22 & 3.05 & 38.17 & 1.87 & 0.89 \\
\hline Range & 0.57 & 0.46 & 4.05 & 39.17 & 2.87 & 1.89 \\
\hline Sample Variance & 0.01 & 0.00 & 0.12 & 16.68 & 0.37 & 0.28 \\
\hline $\begin{array}{l}\text { Standard } \\
\text { Deviation }\end{array}$ & 0.08 & 0.03 & 0.35 & 4.08 & 0.61 & 0.53 \\
\hline $\begin{array}{l}\text { Mean/ Standard } \\
\text { Deviation }\end{array}$ & $(0.02)$ & 0.03 & 0.06 & 0.10 & $(0.03)$ & $0.20)$ \\
\hline Standard Error & 0.01 & 0.00 & 0.03 & 0.44 & 0.10 & 0.14 \\
\hline Kurtosis & 1.92 & 43.91 & 45.32 & 86.81 & 3.07 & 0.33 \\
\hline Excess Kurtosis & $(1.08)$ & 40.91 & 42.32 & 83.81 & 0.07 & $(2.67)$ \\
\hline Skewness & $(0.11)$ & $(0.38)$ & 5.05 & 9.29 & 1.28 & 0.09 \\
\hline
\end{tabular}

\section{Return Correlations}

\begin{tabular}{lcccccc} 
& GE & $\begin{array}{c}\text { GETVS- } \\
\mathrm{A}\end{array}$ & $\begin{array}{c}\text { GETVS- } \\
\mathrm{B}\end{array}$ & $\begin{array}{c}\text { GETVS- } \\
\mathrm{C}\end{array}$ & $\begin{array}{c}\text { GETVS- } \\
\mathrm{D}\end{array}$ & $\begin{array}{c}\text { GETVS- } \\
\mathrm{E}\end{array}$ \\
\hline GE & 1.00 & 0.47 & 0.61 & 0.25 & 0.68 & 0.81 \\
\hline $\begin{array}{l}\text { GETVS- } \\
\text { A }\end{array}$ & 0.47 & 1.00 & 0.25 & 0.00 & 0.03 & 0.07 \\
\hline $\begin{array}{l}\text { GETVS- } \\
\text { B }\end{array}$ & 0.61 & 0.25 & 1.00 & 0.06 & 0.03 & 0.07 \\
\hline $\begin{array}{l}\text { GETVS- } \\
\text { C }\end{array}$ & 0.25 & 0.00 & 0.06 & 1.00 & 0.41 & 0.07 \\
\hline $\begin{array}{l}\text { GETVS- } \\
\text { D }\end{array}$ & 0.68 & 0.03 & 0.03 & 0.41 & 1.00 & 0.61 \\
\hline $\begin{array}{l}\text { GETVS- } \\
\text { E }\end{array}$ & 0.81 & 0.07 & 0.07 & 0.07 & 0.61 & 1.00 \\
\hline
\end{tabular}

\section{Chart of Statistical Summary for Return}

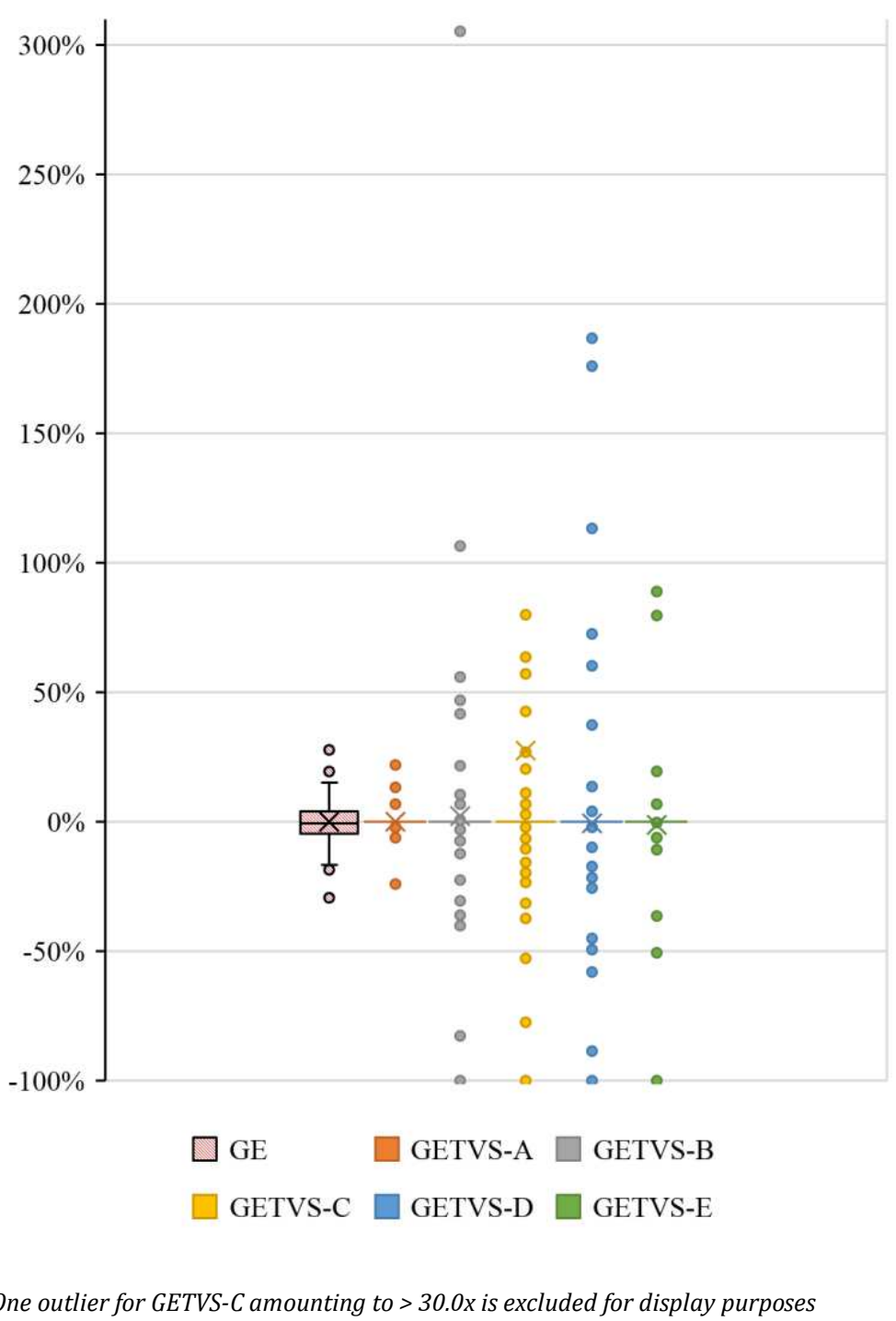

Figure 8.G. Return Statistical Summary (\%). 


\section{GE Regression Summary Output}

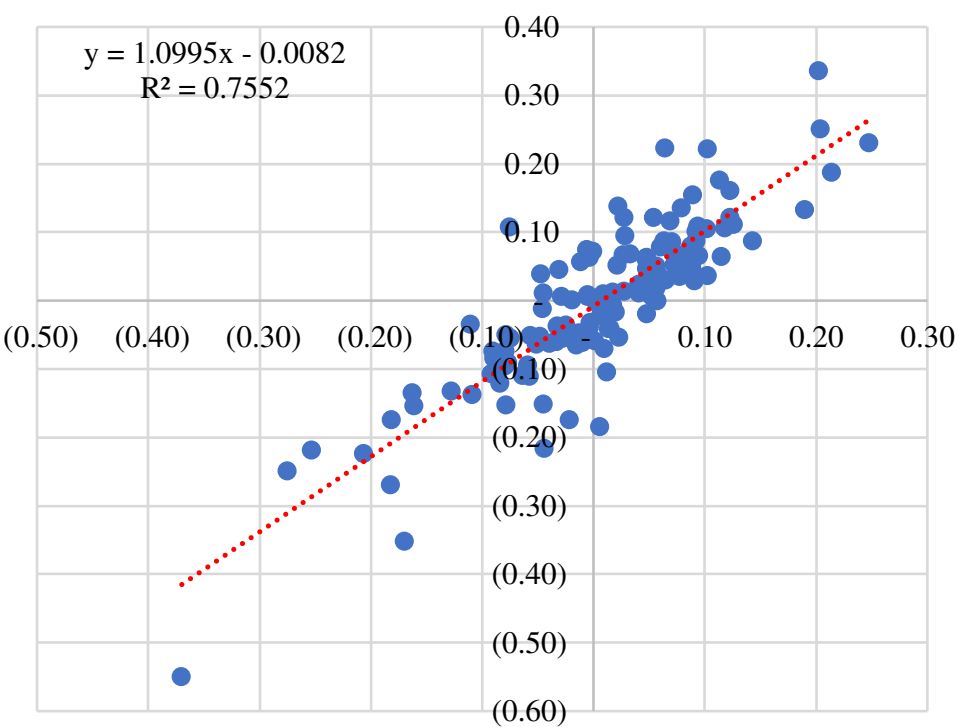

\section{Regression Statistics \\ $\begin{array}{ll}\text { Multiple R } & 0.8690\end{array}$

$$
\text { R Square }
$$ \\ Adjusted R Square $\quad 0.7534$ \\ Standard Error $\quad 0.0594$}

ANOva

ANOVA

Regression

Residual

Total

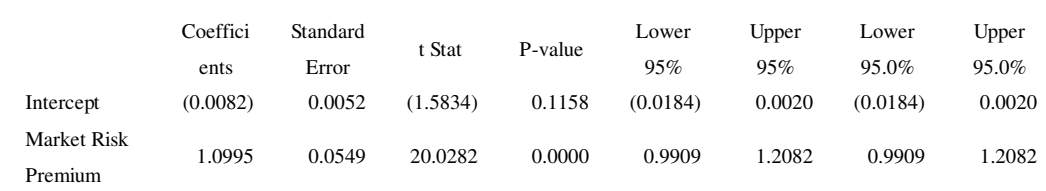

\section{GETVS-A Regression Summary Output}

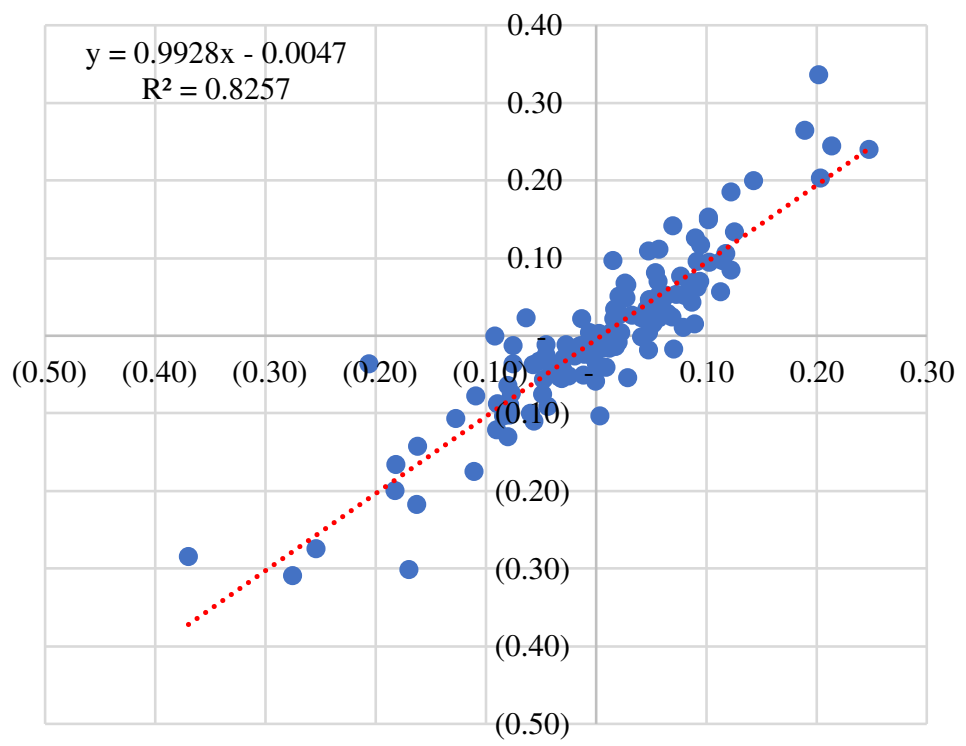

$\begin{array}{lr}\text { Regression Statistics } & \\ \text { Multiple R } & 0.9087 \\ \text { R Square } & 0.8257 \\ \text { Adjusted R Square } & 0.8243 \\ \text { Standard Error } & 0.0433 \\ \text { Observations } & 132\end{array}$

ANOVA

$\begin{array}{llllll} & \text { df } & \text { SS } & \text { MS } & \text { F } & \text { Significance F } \\ & & 1 & 1.1533 & & \end{array}$

Regressio

Residual

Total

$\begin{array}{lcccccccc} & \text { Coeffici } & \text { Standard } & & & \text { Lower } & \text { Upper } & \text { Lower } & \text { Upper } \\ & \text { ents } & \text { Error } & \text { Stat } & \text { P-value } & \text { 95\% } & 95 \% & 95.0 \% & 95.0 \% \\ \text { Intercept } & (0.0047) & 0.0038 & (1.2522) & 0.2127 & (0.0122) & 0.0027 & (0.0122) & 0.0027 \\ \text { Market Risk } & 0.9928 & 0.0400 & 24.8149 & 0.0000 & 0.9137 & 1.0720 & 0.9137 & 1.0720\end{array}$

Figure 8.H.1. Regression Analysis. 


\section{GETVS-B Regression Summary Output}

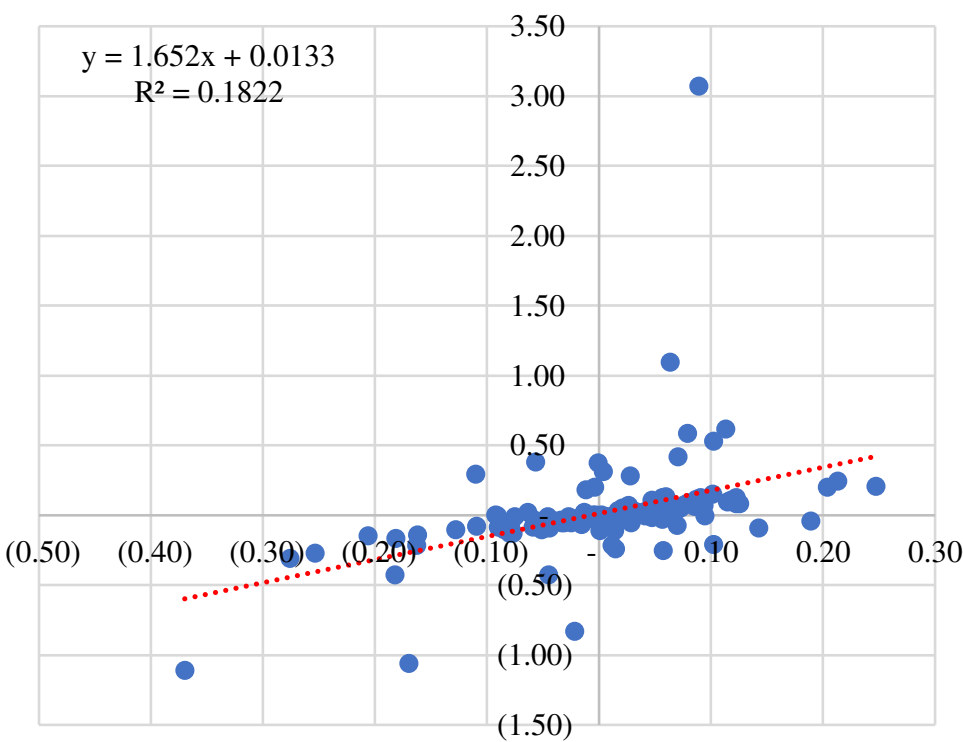

Regression Statistics

$\begin{array}{lr}\text { Multiple R } & 0.4269 \\ \text { R Square } & 0.1822 \\ \text { Adjusted R Square } & 0.1758 \\ \text { Standard Error } & 0.3281 \\ \text { Observations } & 130\end{array}$

Observations

ANOVA

\section{Regression}

Residual

Total

$\begin{array}{lcccccccc} & \text { Coeffici } & \text { Standard } & \mathrm{t} \text { Stat } & \text { P-value } & \text { Lower } & \text { Upper } & \text { Lower } & \text { Upper } \\ & \text { ents } & \text { Error } & & & 95 \% & 95 \% & 95.0 \% & 95.0 \% \\ \text { Intercept } & 0.0133 & 0.0288 & 0.4618 & 0.6450 & (0.0437) & 0.0703 & (0.0437) & 0.0703 \\ \text { Market Risk } & 1.6520 & 0.3093 & 5.3409 & 0.0000 & 1.0400 & 2.2641 & 1.0400 & 2.2641 \\ \text { Premium } & & & & & & & & \end{array}$

\section{GETVS-C Regression Summary Output}

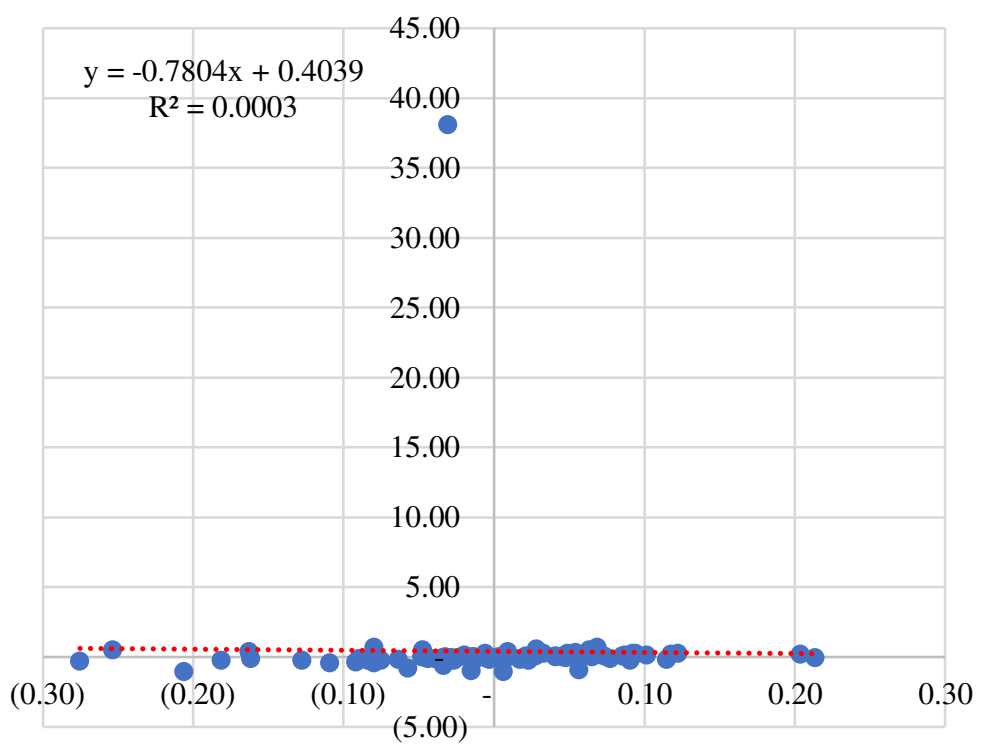

Regression Statistics

\begin{tabular}{ll} 
Multiple R & 0.0165 \\
\hline RSP & 0.003
\end{tabular}

R Square $\quad 0.0003$

Adjusted R Square $\quad(0.0114)$

Standard Error $\quad 4.1017$

Observations $\quad 88$

ANOVA

$\begin{array}{lrrrrr}\text { Regression } & 1 & 0.3928 & 0.3928 & 0.0233 & 0.8789\end{array}$

$\begin{array}{llll}\text { Residual } & 86 & 1,446.8336 & 16.8236\end{array}$

$87 \quad 1,447.2264$

$\begin{array}{lcccccccc} & \text { Coeffici } & \text { Standard } & \text { t Stat } & \text { P-value } & \text { Lower } & \text { Upper } & \text { Lower } & \text { Upper } \\ & \text { ents } & \text { Error } & & 95 \% & 95 \% & 95.0 \% & 95.0 \% \\ \text { Intercept } & 0.4039 & 0.4373 & 0.9235 & 0.3583 & (0.4655) & 1.2733 & (0.4655) & 1.2733 \\ \text { Market Risk } & & & & & & & & \\ \text { (0.7804) } & 5.1074 & (0.1528) & 0.8789 & (10.9335) & 93727 & (10.9335) & 9.3727\end{array}$

Figure 8.H.2. Regression Analysis. 


\section{GETVS-D Regression Summary Output}

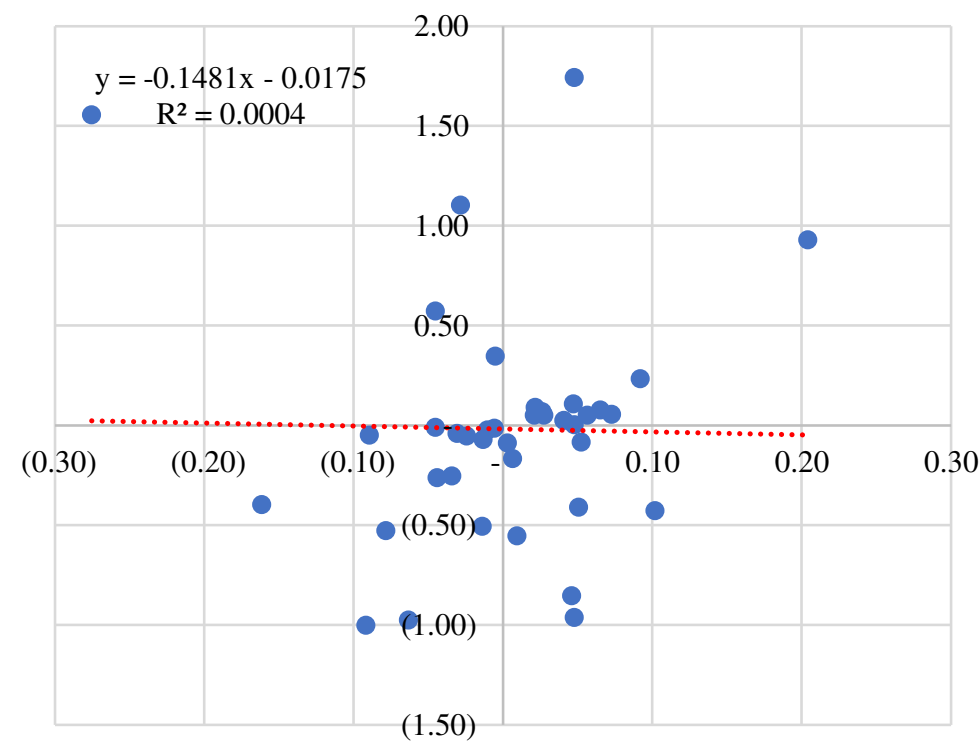

Regression Statistics

$\begin{array}{ll}\text { Multiple R } & 0.0196\end{array}$

Adjusted R Square $\quad(0.0266)$

Standard Error $\quad 0.5979$

Observations

ANOVA

Regression

Residual

Total

$\begin{array}{lcccccccc} & \text { Coeffici } & \text { Standard } & \text { t Stat } & \text { P-value } & \text { Lower } & \text { Upper } & \text { Lower } & \text { Upper } \\ & \text { ents } & \text { Error } & & & 95 \% & 95 \% & 95.0 \% & 95.0 \% \\ \text { Intercept } & (0.0175) & 0.0957 & (0.1832) & 0.8557 & (0.2115) & 0.1765 & (0.2115) & 0.1765 \\ \text { Market Risk } & (0.1481) & 1.2399 & (0.1195) & 0.9055 & (2.6604) & 2.3641 & (2.6604) & 2.3641 \\ \text { Premium } & & & & & & & & \end{array}$

\section{GETVS-E Regression Summary Output}
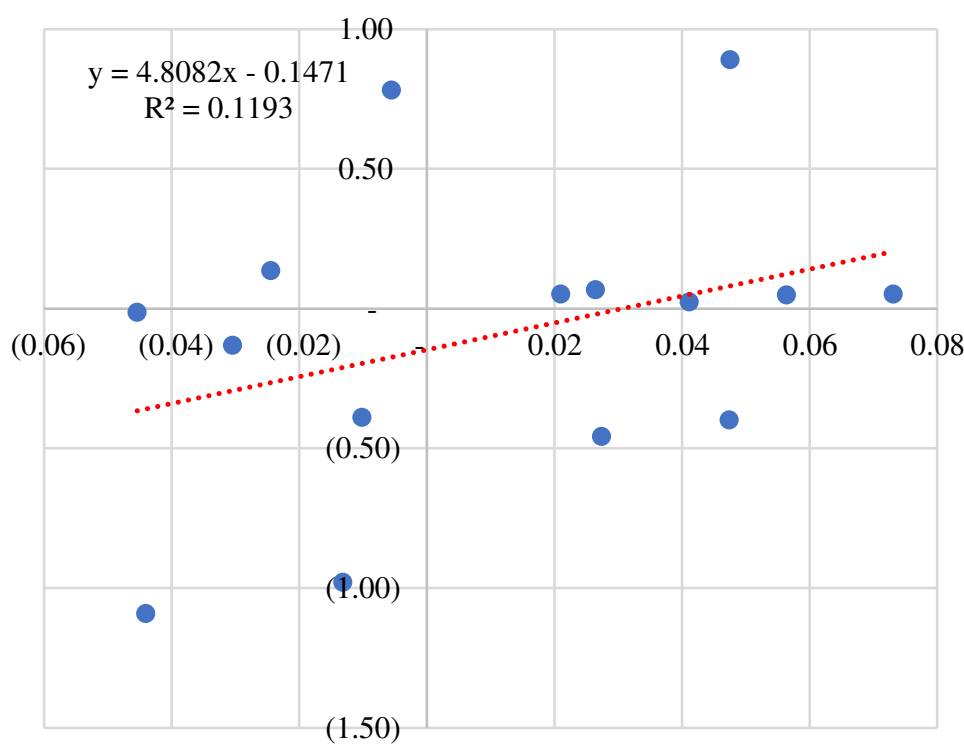

$\begin{array}{lr}\text { Regression Statistics } & \\ \text { Multiple R } & 0.3453 \\ \text { R Square } & 0.1193 \\ \text { Adjusted R Square } & 0.0515 \\ \text { Standard Error } & 0.5199 \\ \text { Observations } & 15\end{array}$

ANOVA

\section{Regression}

Residual

df

$\begin{array}{lllll} & \text { SS } & \text { MS } & \text { F } & \text { Significance F } \\ 1 & 0.4758 & 0.4758 & 1.7603 & 0.2074\end{array}$ 0.4758 $14 \quad 3.9894$

$\begin{array}{lcccccccc} & \text { Coeffici } & \text { Standard } & \text { t Stat } & \text { P-value } & \text { Lower } & \text { Upper } & \text { Lower } & \text { Upper } \\ & \text { ents } & \text { Error } & & & 95 \% & 95 \% & 95.0 \% & 95.0 \% \\ \text { Intercept } & (0.1471) & 0.1402 & (1.0492) & 0.3132 & (0.4500) & 0.1558 & (0.4500) & 0.1558 \\ \text { Market Risk } & & & & & & & & \end{array}$

Figure 8.H.3. Regression Analysis. 


\section{B.2. Case Study: Fixed-Income Security}

This section assesses the performance of TVS securities as if they were issued with APPLE INC. DL-NOTES 2013(13/23) WKN A1HKKX | ISIN US037833AK68 as underlying (further referred as the "bond"), that were issued on 07/05/2013, have a maturity on $03 / 05 / 2023$, and pay a coupon of $2.4 \%$ on semi-annual basis. For the purpose of analysis daily performance for the period of $07 / 05 / 2013-12 / 12 / 2018$ was used. Furthermore, for the purpose of simplicity, accrued interest, and other minor details were omitted as they would not add significant value for the purpose of current assessment.

It is assumed that five Tranched Value Securities were issued with the bond as underlying on $07 / 05 / 2013$ when the opening price was US\$99.19 for each US\$ 100.00 of security's face value, with characteristics presented on Figure 9.A.

The results of the assessment are presented on Figure 9.A-9.G and were obtained for the minimum values of five value tranches and the bond. Based on the assessment, it is evident that AAPLTVS-E was the only value tranche that ever reached a value of zero, while other TVSs experienced insignificant price declines during the times of significant yield increases. That is evident from the TVSs attachment and detachment points, that results in the default rate of AAPLTVS-E amounting to 1\%, while all other value tranches of the bond had a default rate of zero.

Distribution profiles of TVSs significantly differ from price distribution profile of APPLE INC. DL-NOTES 2013(13/23), displaying a clear price floors for three most senior value tranches, below which their price never declined, but which did participate in price increases, during the yield declines. At the same time, price distribution of AAPLTVS-E displays behavior somewhat similar to equity instruments with negative skewness, together with AAPLTVS-D. At the same time only AAPL TVS Equity and the bond had negative excess kurtosis, while all other securities exhibited positive excess kurtosis. Range of price distributions is also the highest for AAPLTVS-E and the bond, while it never exceeds the value of $\$ 2.00$ for all other value tranches. Other price statistics, such as variance and standard deviation display the same situation. AAPLTVS-E is the most 
highly correlated security with the original bond, while other value tranches have nearly twice reduced correlations, but AAPLTVS-A, AAPLTVS-B and AAPLTVS-C have a perfect positive correlation between each other.

Yield-to-maturity (YTM) profiles of the bond display the highest variation, while in AAPLTVS-E this variation gets multiplied several times, displaying even higher instability, while for all other value tranches it is nearly fixed. Furthermore, YTM distributions of all value tranches indicate significantly changed shapes, while the original distribution of APPLE INC. DL-NOTES 2013(13/23) YTM was somewhat normal, all other securities obtained highly skewed distributions either to the positive, or to the negative sides. AAPLTVS-E is the only tranche that has extremely positive skewness, while all other tranches have slightly negative skewness, and the original underlying bond has a slightly positive skewness. Moreover, all securities, except for underlying experience positive excess kurtosis, while AAPLTVS-E exhibits extremely positive excess kurtosis.

None of the securities, except for AAPLTVS-E have YTM outliers, while for AAPLTVS$\mathrm{E}$ there are several ones, with the highest one amounting to $6.5 \mathrm{x}$. This tranche also experienced the highest mean YTM amounting to $11 \%$, while for all other tranches it amounted to $2 \%$, and for the original underling to $3 \%$. Standard deviation of YTMs is also the highest for AAPLTVS Equity amounting to 26\%, while for all other value tranches and the underlying bond it amounts to nearly $0 \%$. Three most senior value tranches' YTMs experience perfect positive correlations, while AAPLTVS-E's YTM almost does not experience any co-movement at all with all other instruments and has a correlation of 0.39 with underlying bond itself only, which all together with the above suggest significant transformation of underlying security performance, generating substantial diversification benefits in various market states, while satisfying diverse risk and return appetites of investors. 
Assumed Issuance Information

\begin{tabular}{|c|c|c|c|}
\hline Security & Code & $\begin{array}{c}\text { Value } \\
\text { Share (\%) }\end{array}$ & $\begin{array}{c}\text { Minimum } \\
\text { Value* (US\$) }\end{array}$ \\
\hline $\begin{array}{l}\text { APPLE INC. DL- } \\
\text { NOTES } 2013(13 / 23)\end{array}$ & US037833AK68 & 1.00 & 99.19 \\
\hline AAPL TVS Senior & AAPLTVS-A & 0.30 & 29.76 \\
\hline $\begin{array}{l}\text { AAPL TVS } \\
\text { Subordinated }\end{array}$ & AAPLTVS -B & 0.25 & 24.80 \\
\hline AAPL TVS Junior & AAPLTVS -C & 0.20 & 19.84 \\
\hline $\begin{array}{l}\text { AAPL TVS } \\
\text { Mezzanine }\end{array}$ & AAPLTVS -D & 0.15 & 14.88 \\
\hline AAPL TVS Equity & AAPLTVS -E & 0.10 & 9.92 \\
\hline
\end{tabular}

TVS Price Share of Total Price of Underlying (\%)

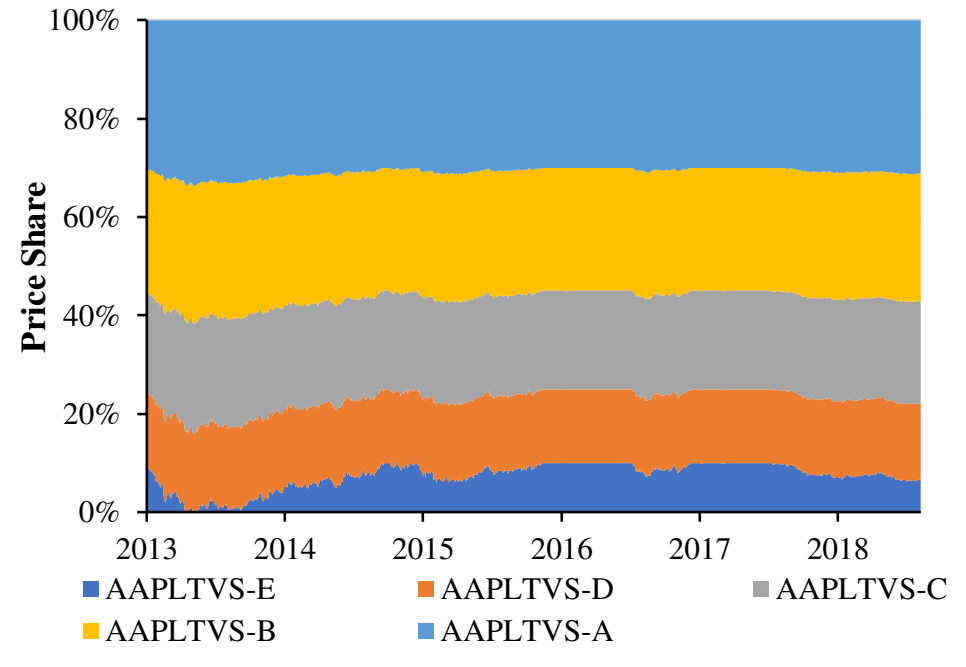

Combined Price Data for Five TVSs and Underlying (US\$)

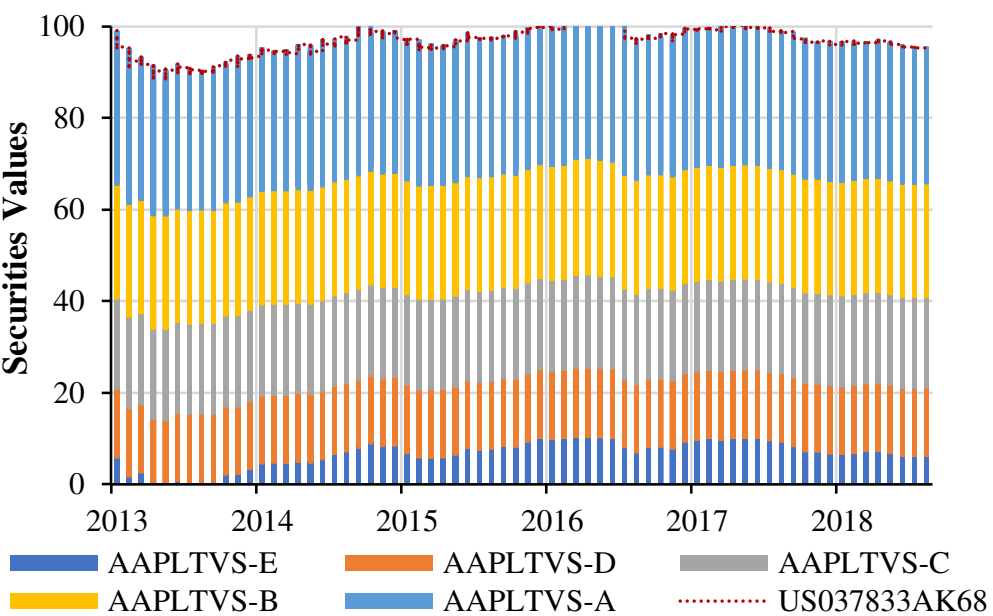

Securities Yields-to-Maturity (Limited to $0 \%$ to $+40 \%$ )

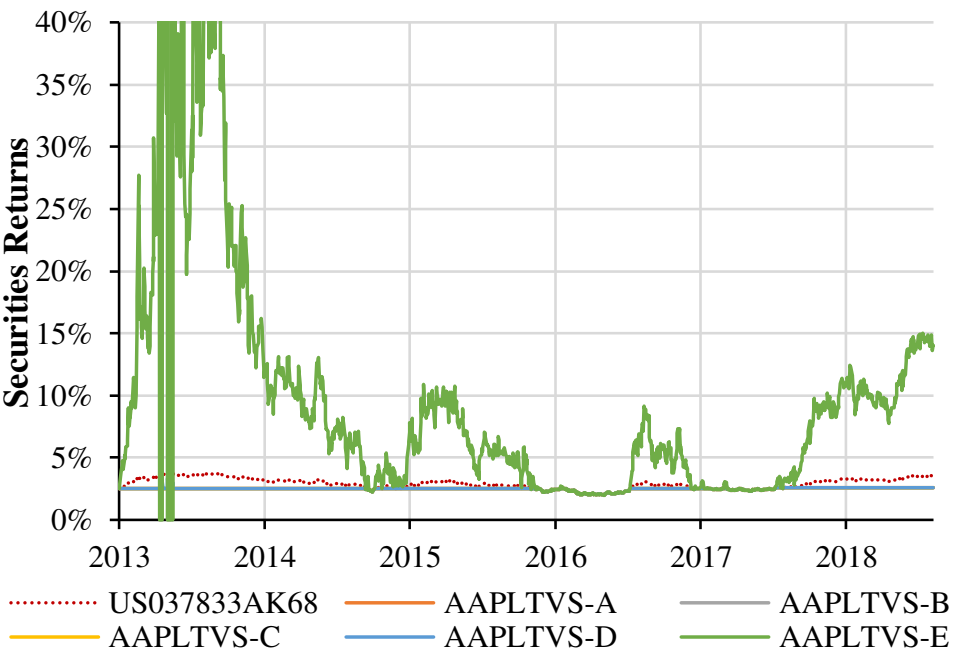

Figure 9.A. Issuance, Price and Return Summary. 
Securities Yields-to-Maturity Full

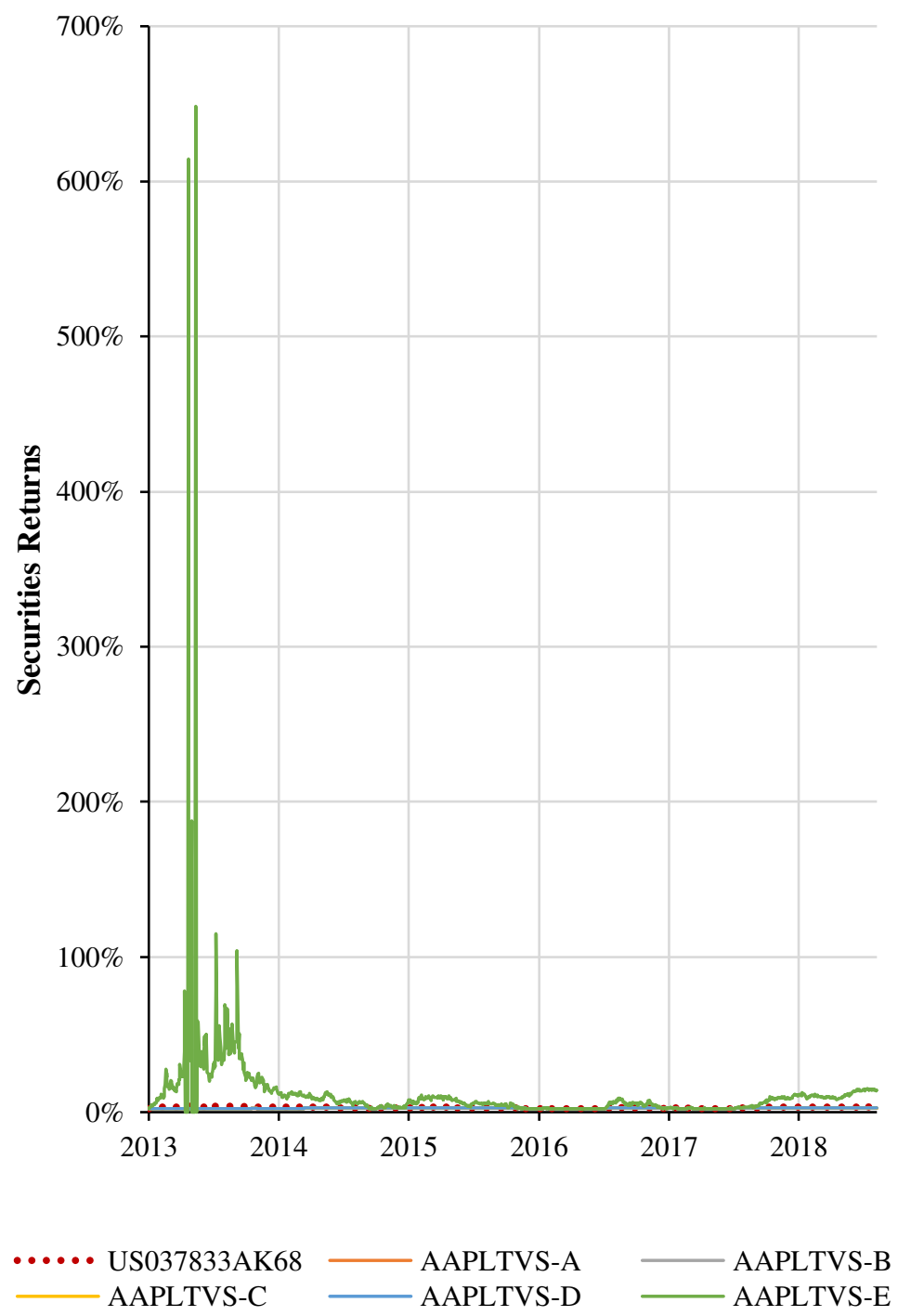

TVS Default Rates (When Price Equals to Zero)

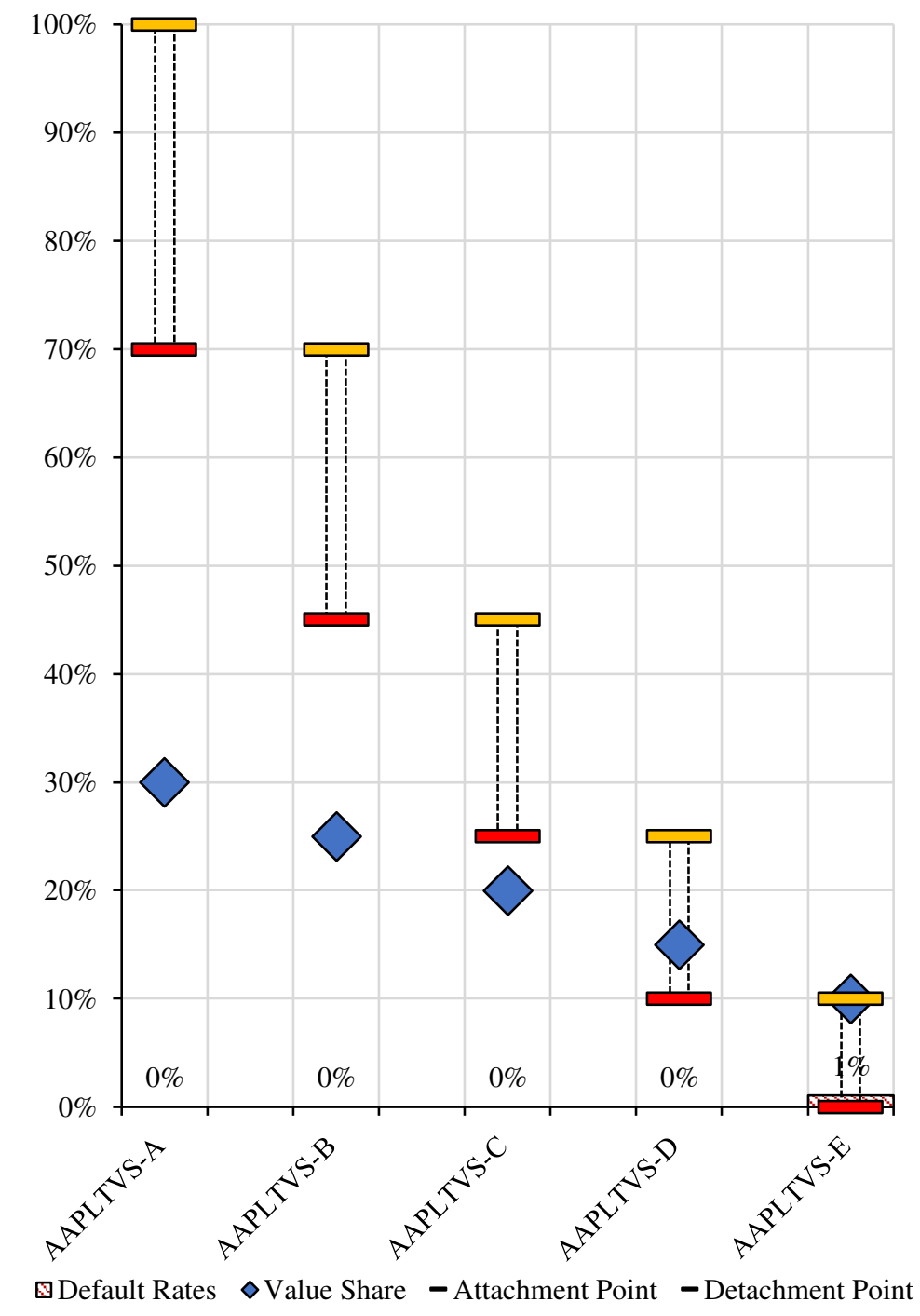

Figure 9.B. Return and Default Rates (\%). 
US037833AK68
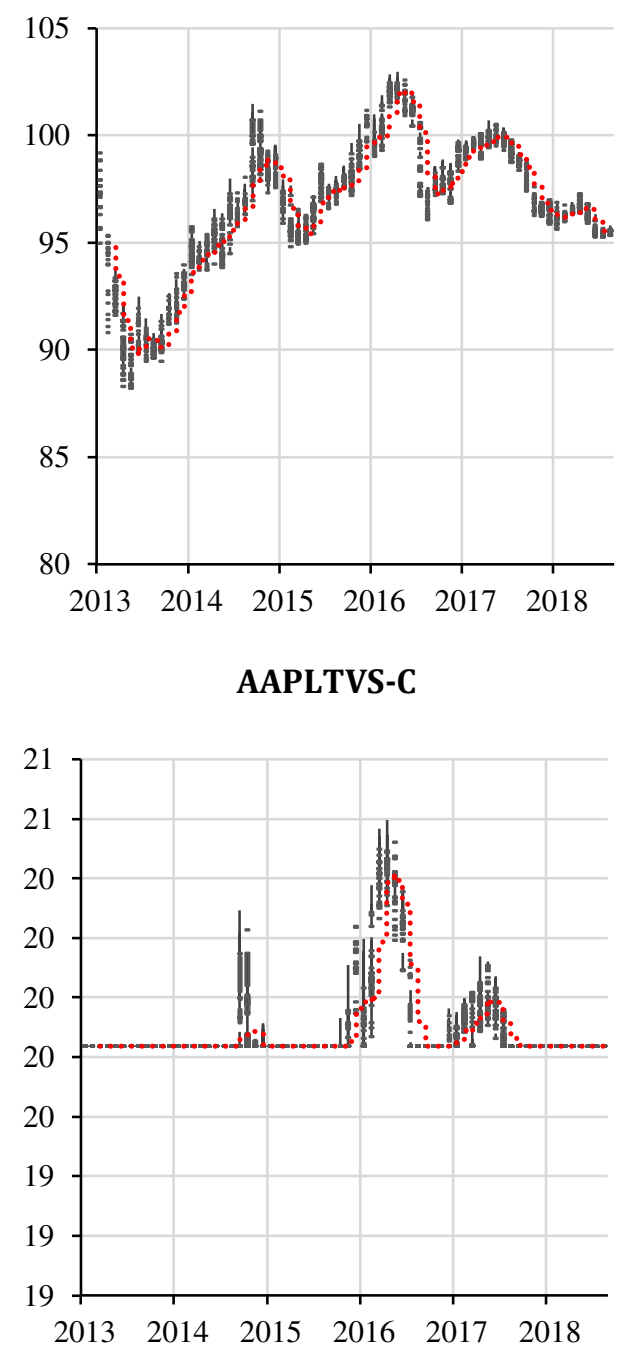

AAPLTVS-A
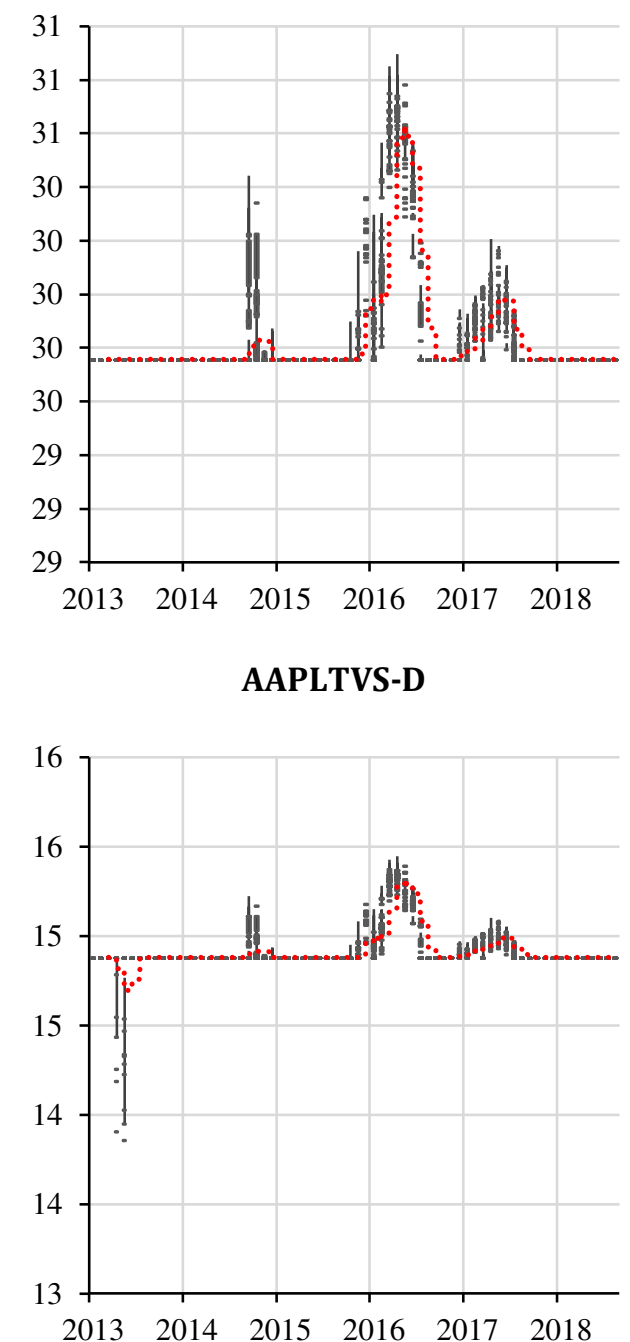

AAPLTVS-B
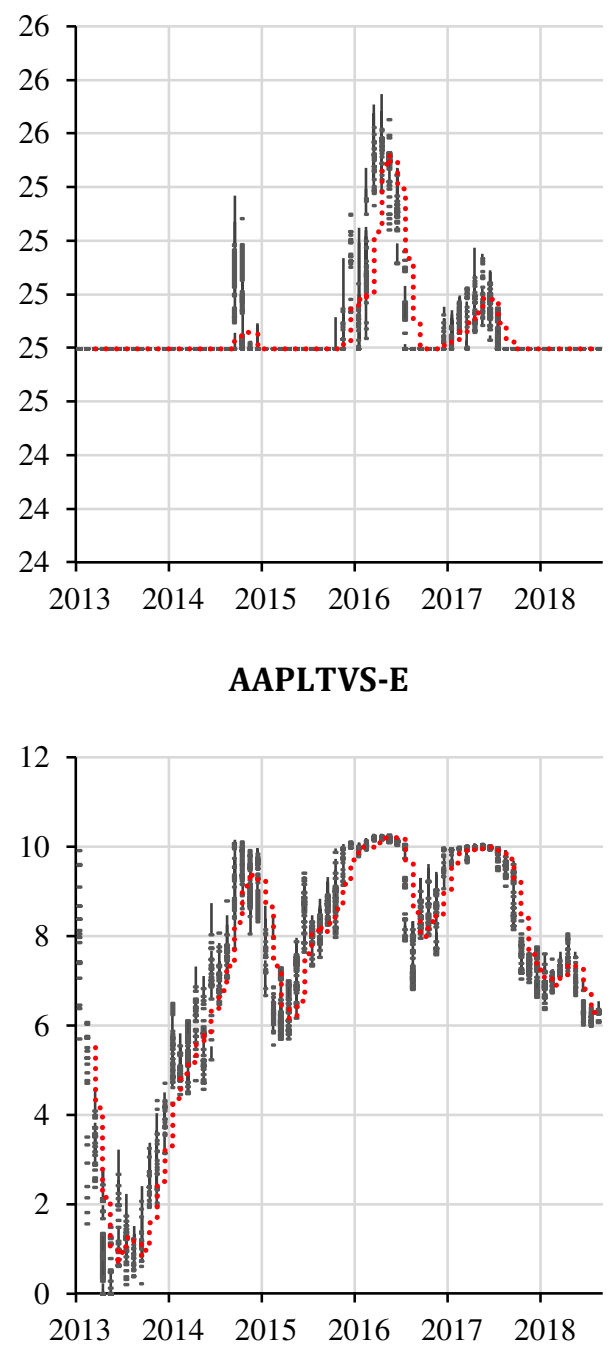

Figure 9.C. Price Candlestick Charts (US\$) and SMA(50). 
US037833AK68

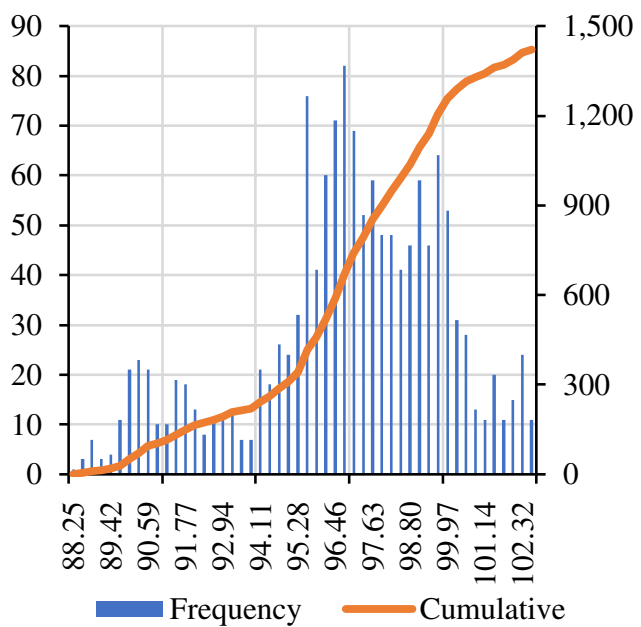

AAPLTVS-C

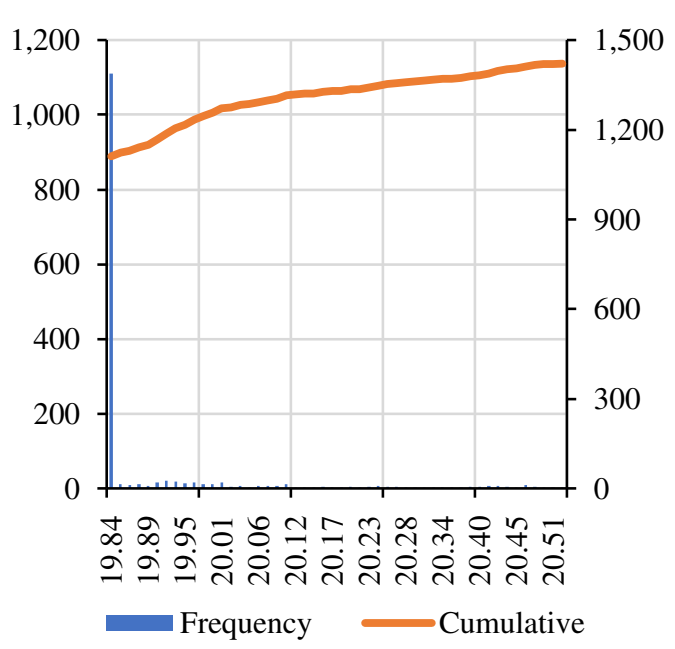

AAPLTVS-A

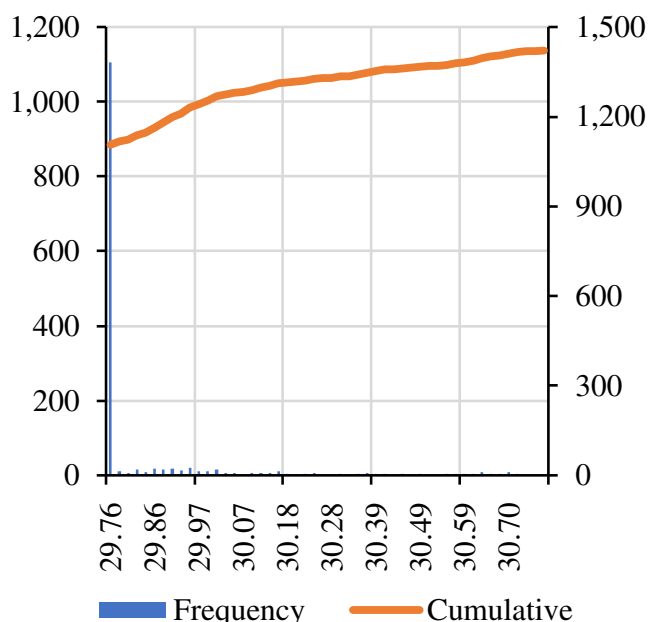

AAPLTVS-D

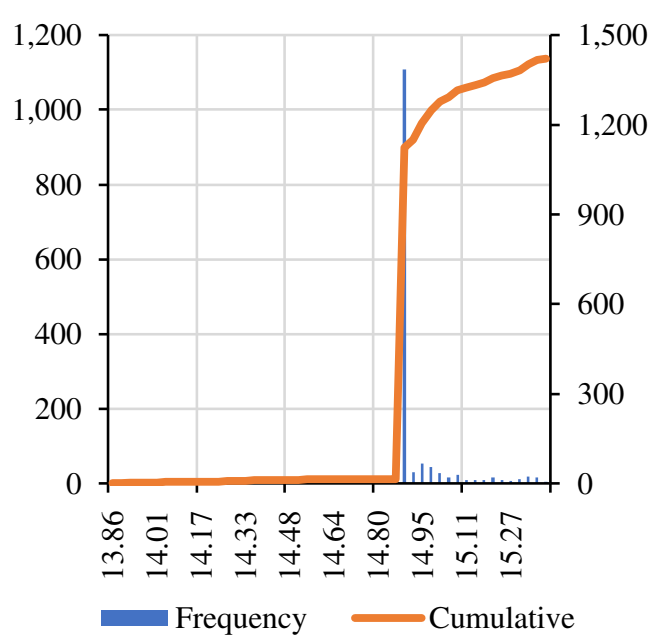

AAPLTVS-B

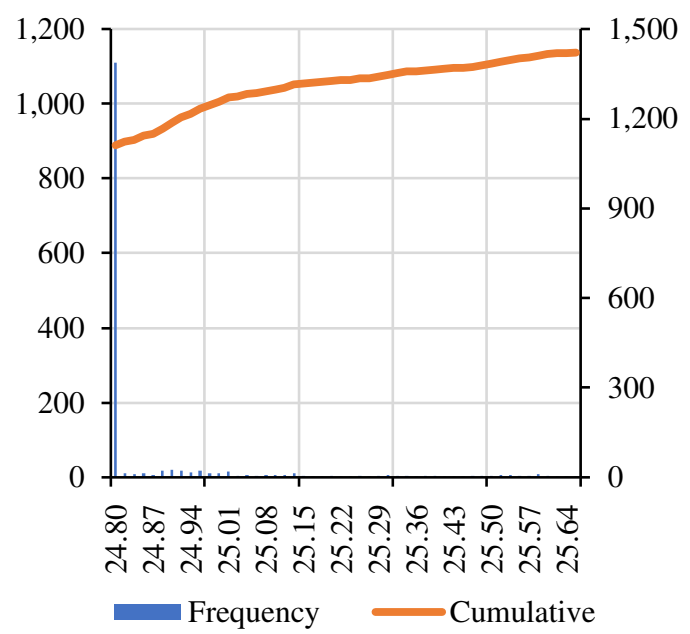

AAPLTVS-E

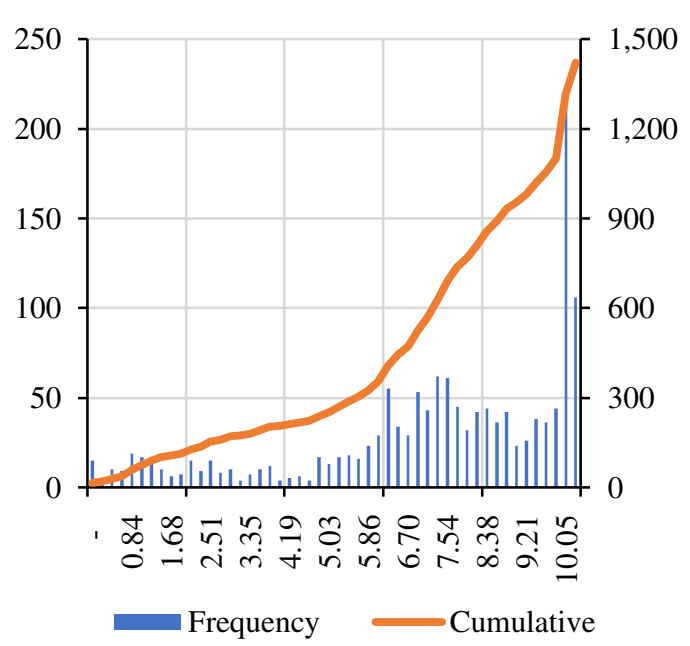

Figure 9.D. Price Distribution Histograms (US\$). 
Table of Statistical Summary for Price

\begin{tabular}{|l|r|r|r|r|r|r|}
\hline & \multicolumn{1}{|c|}{$\begin{array}{c}\text { US037833 } \\
\text { AK68 }\end{array}$} & \multicolumn{1}{c|}{$\begin{array}{c}\text { AAPLTV } \\
\text { S-A }\end{array}$} & \multicolumn{1}{c|}{$\begin{array}{c}\text { AAPLTV } \\
\text { S-B }\end{array}$} & \multicolumn{1}{c|}{$\begin{array}{c}\text { AAPLTV } \\
\text { S-C }\end{array}$} & \multicolumn{1}{c|}{$\begin{array}{c}\text { AAPLTV } \\
\text { S-D }\end{array}$} & \multicolumn{1}{c|}{$\begin{array}{c}\text { AAPLTV } \\
\text { S-E }\end{array}$} \\
\hline Count & $1,421.00$ & $1,421.00$ & $1,421.00$ & $1,421.00$ & $1,421.00$ & $1,421.00$ \\
\hline Mean & 96.69 & 29.84 & 24.86 & 19.89 & 14.91 & 7.19 \\
\hline Median & 96.89 & 29.76 & 24.80 & 19.84 & 14.88 & 7.61 \\
\hline Mode & 96.80 & 29.76 & 24.80 & 19.84 & 14.88 & 0.00 \\
\hline Minimum & 88.25 & 29.76 & 24.80 & 19.84 & 13.86 & 0.00 \\
\hline Maximum & 102.61 & 30.78 & 25.65 & 20.52 & 15.39 & 10.26 \\
\hline Range & 14.36 & 1.03 & 0.86 & 0.68 & 1.53 & 10.26 \\
\hline Sample Variance & 9.48 & 0.04 & 0.03 & 0.02 & 0.02 & 7.61 \\
\hline $\begin{array}{l}\text { Standard } \\
\text { Deviation }\end{array}$ & 3.08 & 0.20 & 0.17 & 0.14 & 0.12 & 2.76 \\
\hline $\begin{array}{l}\text { Mean/ Standard } \\
\text { Deviation }\end{array}$ & 31.41 & 146.19 & 146.83 & 146.83 & 120.56 & 2.60 \\
\hline Standard Error & 0.08 & 0.01 & 0.00 & 0.00 & 0.00 & 0.07 \\
\hline Kurtosis & $(0.01)$ & 7.84 & 7.99 & 7.99 & 17.19 & 0.18 \\
\hline Excess Kurtosis & $(3.01)$ & 4.84 & 4.99 & 4.99 & 14.19 & $(2.82)$ \\
\hline Skewness & $(0.61)$ & 2.91 & 2.94 & 2.94 & $(0.38)$ & $(1.00)$ \\
\hline
\end{tabular}

Price Correlations

\begin{tabular}{lcccccc} 
& $\begin{array}{c}\text { US03783 } \\
\text { 3AK68 }\end{array}$ & $\begin{array}{c}\text { AAPLTV } \\
\text { S-A }\end{array}$ & $\begin{array}{c}\text { AAPLTV } \\
\text { S-B }\end{array}$ & $\begin{array}{c}\text { AAPLTV } \\
\text { S-C }\end{array}$ & $\begin{array}{c}\text { AAPLTV } \\
\text { S-D }\end{array}$ & $\begin{array}{c}\text { AAPLTV } \\
\text { S-E }\end{array}$ \\
$\begin{array}{l}\text { US03783 } \\
\text { 3AK68 }\end{array}$ & 1.00 & 0.57 & 0.57 & 0.57 & 0.61 & 0.98 \\
$\begin{array}{l}\text { AAPLTV } \\
\text { S-A }\end{array}$ & 0.57 & 1.00 & 1.00 & 1.00 & 0.84 & 0.42 \\
$\begin{array}{l}\text { AAPLTV } \\
\text { S-B }\end{array}$ & 0.57 & 1.00 & 1.00 & 1.00 & 0.84 & 0.42 \\
$\begin{array}{l}\text { AAPLTV } \\
\text { S-C }\end{array}$ & 0.57 & 1.00 & 1.00 & 1.00 & 0.84 & 0.42 \\
$\begin{array}{l}\text { AAPLTV } \\
\text { S-D }\end{array}$ & 0.61 & 0.84 & 0.84 & 0.84 & 1.00 & 0.48 \\
$\begin{array}{l}\text { AAPLTV } \\
\text { S-E }\end{array}$ & 0.98 & 0.42 & 0.42 & 0.42 & 0.48 & 1.00 \\
\hline
\end{tabular}

\section{Chart of Statistical Summary for Price}

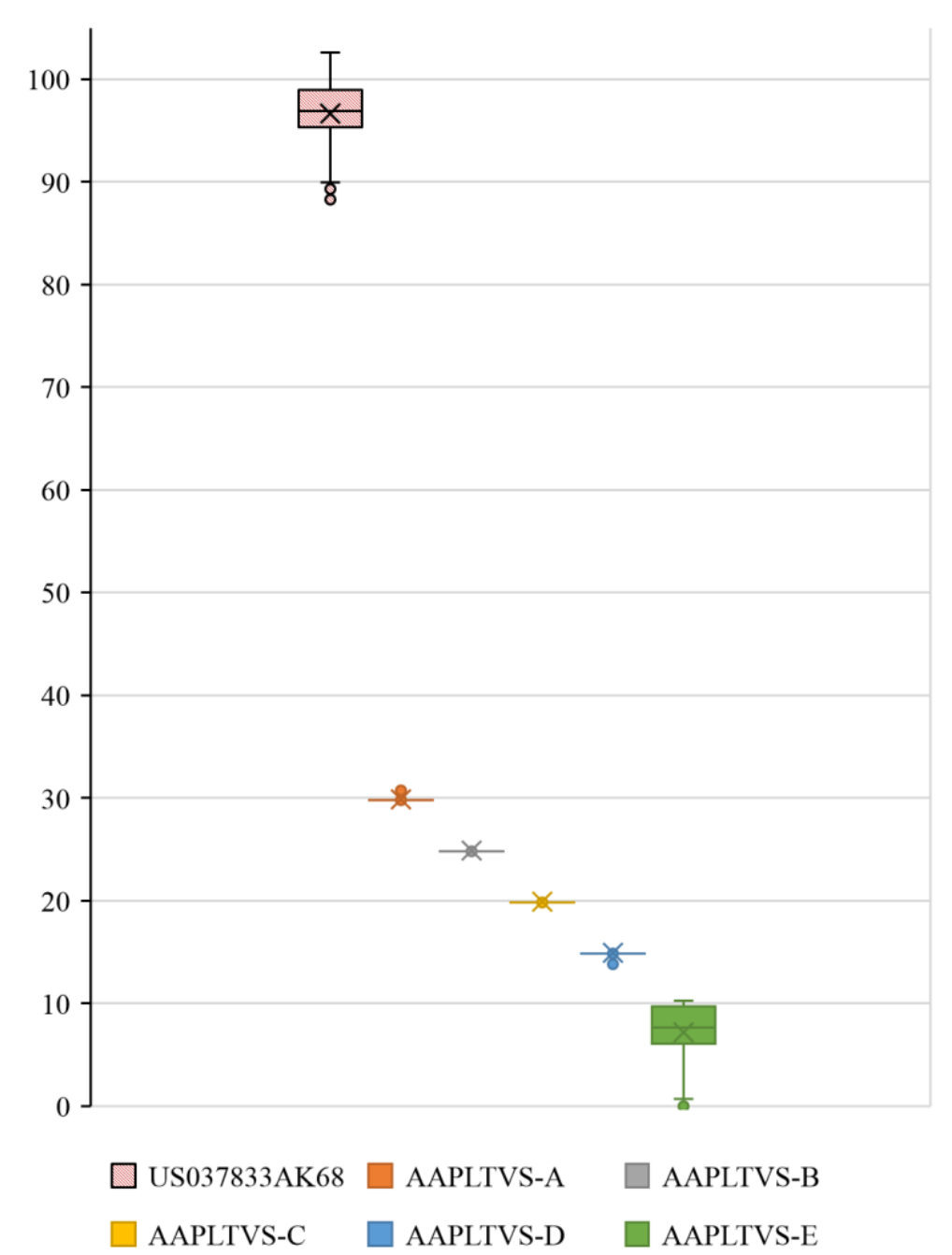

Figure 9.E. Price Statistical Summary (US\$). 
US037833AK68

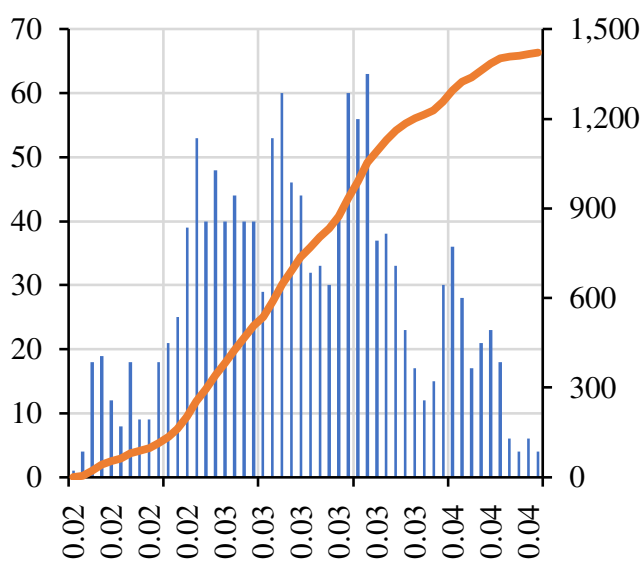

Frequency

AAPLTVS-C

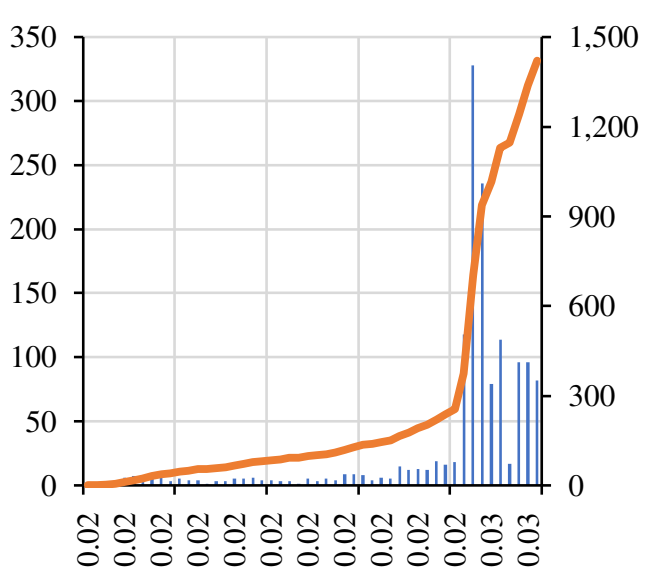

Frequency
AAPLTVS-A

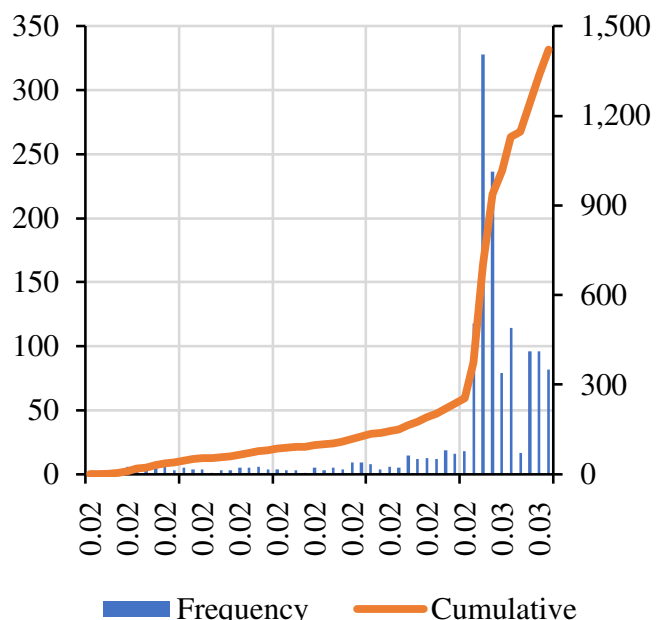

AAPLTVS-D

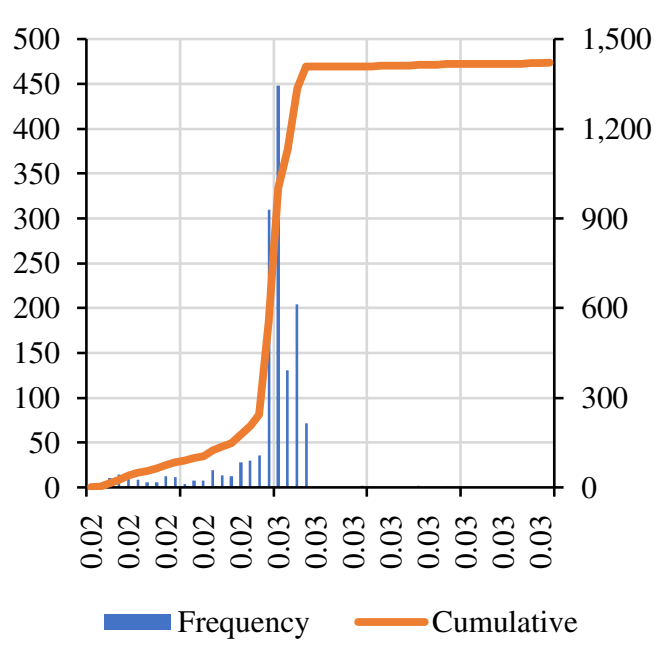

AAPLTVS-B

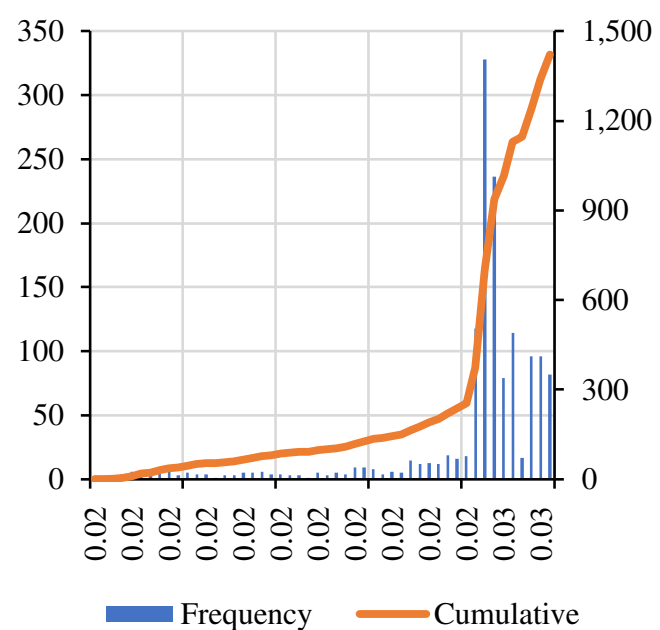

AAPLTVS-E

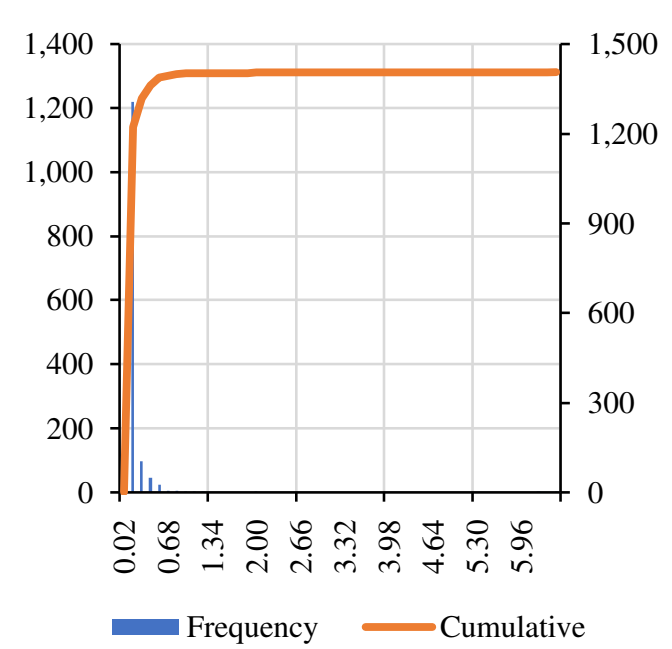

Figure 9.F. Yield-to-Maturity Distribution Histograms (\%). 
Table of Statistical Summary for Yield-to-Maturity

\begin{tabular}{|l|r|r|r|r|r|r|}
\hline & \multicolumn{1}{|c|}{$\begin{array}{c}\text { US037833 } \\
\text { AK68 }\end{array}$} & \multicolumn{1}{c|}{$\begin{array}{c}\text { AAPLTV } \\
\text { S-A }\end{array}$} & \multicolumn{1}{c|}{$\begin{array}{c}\text { AAPLTV } \\
\text { S-B }\end{array}$} & \multicolumn{1}{c|}{$\begin{array}{c}\text { AAPLTV } \\
\text { S-C }\end{array}$} & \multicolumn{1}{c|}{$\begin{array}{c}\text { AAPLTV } \\
\text { S-D }\end{array}$} & \multicolumn{1}{c|}{$\begin{array}{c}\text { AAPLTV } \\
\text { S-E }\end{array}$} \\
\hline Count & $1,421.00$ & $1,421.00$ & $1,421.00$ & $1,421.00$ & $1,421.00$ & $1,406.00$ \\
\hline Mean & 0.03 & 0.02 & 0.02 & 0.02 & 0.02 & 0.11 \\
\hline Median & 0.03 & 0.03 & 0.03 & 0.03 & 0.03 & 0.06 \\
\hline Mode & N/A & N/A & N/A & N/A & N/A & N/A \\
\hline Minimum & 0.02 & 0.02 & 0.02 & 0.02 & 0.02 & 0.02 \\
\hline Maximum & 0.04 & 0.03 & 0.03 & 0.03 & 0.03 & 6.48 \\
\hline Range & 0.02 & 0.01 & 0.01 & 0.01 & 0.01 & 6.46 \\
\hline Sample Variance & 0.00 & 0.00 & 0.00 & 0.00 & 0.00 & 0.07 \\
\hline $\begin{array}{l}\text { Standard } \\
\text { Deviation }\end{array}$ & 0.00 & 0.00 & 0.00 & 0.00 & 0.00 & 0.26 \\
\hline $\begin{array}{l}\text { Mean / Standard } \\
\text { Deviation }\end{array}$ & 6.86 & 22.29 & 22.29 & 22.29 & 20.04 & 0.40 \\
\hline Standard Error & 0.00 & 0.00 & 0.00 & 0.00 & 0.00 & 0.01 \\
\hline Kurtosis & $(0.70)$ & 6.85 & 6.85 & 6.85 & 9.21 & 438.37 \\
\hline Excess Kurtosis & $(3.70)$ & 3.85 & 3.85 & 3.85 & 6.21 & 435.37 \\
\hline Skewness & 0.05 & $(2.61)$ & $(2.61)$ & $(2.61)$ & $(0.99)$ & 19.05 \\
\hline
\end{tabular}

\section{Yield-to-Maturity Correlations}

$\begin{array}{lcccccc} & \begin{array}{c}\text { US03783 } \\ \text { 3AK68 }\end{array} & \begin{array}{c}\text { AAPLTV } \\ \text { S-A }\end{array} & \begin{array}{c}\text { AAPLTV } \\ \text { S-B }\end{array} & \begin{array}{c}\text { AAPLTV } \\ \text { S-C }\end{array} & \begin{array}{c}\text { AAPLTV } \\ \text { S-D }\end{array} & \begin{array}{c}\text { AAPLTV } \\ \text { S-E }\end{array} \\ \begin{array}{l}\text { US03783 } \\ \text { 3AK68 }\end{array} & 1.00 & 0.60 & 0.60 & 0.60 & 0.63 & 0.39 \\ \begin{array}{l}\text { AAPLTV } \\ \text { S-A }\end{array} & 0.60 & 1.00 & 1.00 & 1.00 & 0.90 & 0.08 \\ \begin{array}{l}\text { AAPLTV } \\ \text { S-B }\end{array} & 0.60 & 1.00 & 1.00 & 1.00 & 0.90 & 0.08 \\ \begin{array}{l}\text { AAPLTV } \\ \text { S-C }\end{array} & 0.60 & 1.00 & 1.00 & 1.00 & 0.90 & 0.08 \\ \begin{array}{l}\text { AAPLTV } \\ \text { S-D }\end{array} & 0.63 & 0.90 & 0.90 & 0.90 & 1.00 & 0.08 \\ \begin{array}{l}\text { AAPLTV } \\ \text { S-E }\end{array} & 0.39 & 0.08 & 0.08 & 0.08 & 0.08 & 1.00\end{array}$

Chart of Statistical Summary for Yield-to-Maturity

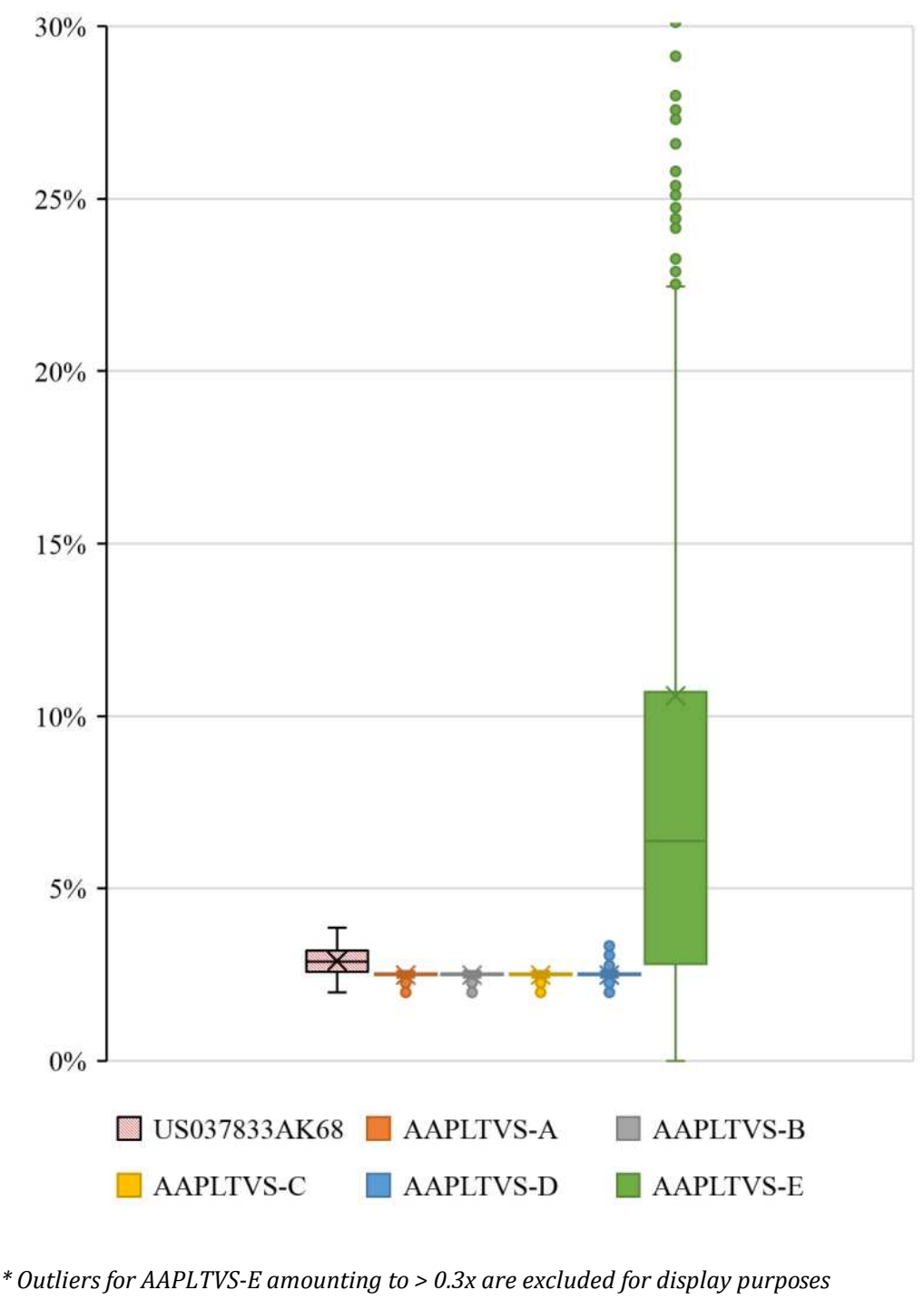

Figure 9.G. YTM Statistical Summary (\%) 


\section{Further Applications}

Previous section displayed potential performance of Tranched Value Securities issued with fixed income and equity instruments as underlying, however, their possible applications are significantly wider than that, as TVS could potentially be issued on any asset, liability, equity, interest rate, exchange rate, market index, notional value or any other instrument, which has an assessible market value or price, with publicly traded securities being the easiest ones to deal with. TVSs can be issued with varying the initial issuance parameters, such as the weight of the value TVS can claim in the underlying. While the higher value share would represent less risk for the potential security buyers, and a smaller value share could significantly improve returns although amplifying the corresponding risks, which all together affect attachment and detachment points in TVS.

In the presented earlier examples, it was assumed that $w_{i} S_{t}$ equals to the minimum value claim $\left(X_{i}\right)$ at the issuance of the security, but the two values can be different, transforming the performance of value shares even further. Furthermore, it was assumed that $w_{i} S_{t}$ and $X_{i}$ are fixed parameters, while they could be floating and be attached either to a specific benchmark, specific rules or events. Moreover, it was previously assumed that TVSs with equity underlying are perpetual in nature, they in fact could have maturity dates, changing equity instrument in some cases to the fixed-income securities. The opposite can be done with TVSs with debt as underlying by rolling the TVS issuance in new debt with the same characteristics as the original one, thus transforming the initial bond into fixed-income equity or perpetual fixed income. Another possible modification of TVS is the issuance with separate groups of underlying. For example, one issue of TVS could have the bond's face value as underlying, while another TVS issue could have bond's coupons as underlying. Same applies to equity and corresponding dividends, which would enhance performance of some value tranches on the expense of others. Also, TVS could be issued with option, forward or swap-like terms, whereas one type forces the execution of value tranche on a specified future date, another one gives a right to execute the contract on or before the specified maturity, and swap forcing the exchange of 
differences in periodic values instead of the notional value exchange. Option-like TVSs can be similar to options in terms of giving a right to buy or sell a specific value share of underlying. Tranched Value Securities can be further be modified and issued on existing TVS (TVS-Squared), making them similar to Credit Default Swaps Squared, where a particular value tranche is backed by a number of specific value tranches in other TVSs.

Also, additional mechanisms could be implemented similar to credit enhancements, that were discussed earlier. Thus, by varying internal and external parameters of tranched value securities, the possibilities for creating new types of instruments are endless, which could potentially satisfy a wide range of market participants with different objectives - be it speculation, long-term investment, hedging operations or any others.

\section{TVS Advantages}

Tranched Value Securities present a new step in financial market innovation with their unique feature of individual asset performance segmentation and transformation, in some cases reaching as far as transformation of the underlying asset class from equity to debt, and vice versa. The most obvious and most important benefits of TVS for investors are diversification within a single asset, and performance modification. That is evident from the presented earlier assessment that showed that various value tranches with the same underlying sometimes exhibit almost no correlation at all, while their return distributions and skewness change forms in some cases. Moreover, mean returns and return ranges get significantly amplified within the junior value tranches and on the contrary perform as fixed income security with senior value tranches, which allows for satisfaction of various risk-return appetites of investor groups all within the same single underlying, without the need for additional issuance of complex derivatives or costly capital market instruments.

Tranched Value Security can be issued virtually with any asset, security or instrument as underlying which is expected to add additional liquidity to the market, which might improve price discovery and transparency of asset pricing, which all together might 
contribute to a more efficient market. Also, TVS instruments can be highly customized allowing for further performance transformation of the underlying assets.

Efficient risk management benefit is another consequence for investors engaging in TVS securities, allowing for risk mitigation, avoidance, acceptance, transference or exploitation virtually to any desirable level by varying the value share of TVS that transforms the amounts of systematic and unsystematic risks that investor is accepting.

Furthermore, TVS allows for greater leverage as investor could potentially use various levels of leverage for various levels of value tranches, increasing or decreasing the desired exposure to the same underlying, while transaction costs could be reduced together with capital commitment in order to engage in transactions, such as shortselling. Which is another benefit provided by TVS as it could potentially allow to short a particular value tranche on the instruments where short positions on the complete underlying were not possible before.

Tranched Value Security issuers can benefit numerous entities, which can be presented in various forms - from corporations to asset managers. Businesses typically raise capital in two forms: by issuing debt, or equity. Within each asset class, there are many different types of securities that can be offered, each having its own unique characteristics. These characteristics are used to divide the risk of business assets among the different types of investors, with their own unique desires for investment maturity, risk-return profile, correlation with other assets, taxation and other parameters. TVS tranches having varying features on their own even within the same underlying, expand the potential reach to varying investor groups, while providing additional capital for the issuing business, as the combined value of value tranches might be greater than the value of the underlying on its own.

For asset managers and financial institutions potential benefits of TVS are similar to the benefits of using Credit Default Obligations (CDOs), such as it allows to reduce exposure to a particular client or industry by reducing the value share in that particular issuance; reduction of risky capital with the subsequent capital infusion; and reduction 
of regulatory capital charges, as by simply selling junior value tranches in a portfolio, institution can cap the downside potential, thereby increasing risk-weighted assets.

Derivative instruments are typically believed to improve market completeness as they improve efficiency of risk allocation, allow for efficient risk transfer to the parties that wish to obtain that risk, and provide investment opportunities that were unavailable before. Tranched Value Securities make an additional step in this regard as they allow for significantly amplified returns of the perceivably most safe assets, such as T-bills, and on the contrary allow for safe returns from the riskiest junk bonds and micro-cap stocks. In these terms, as markets are typically considered to be incomplete as not all participants have equal access to the same information at the same point in time, usually structured derivative products improve market completeness, as issuers use this opportunity to generate additional fees and commissions, while investors expand their investment opportunity set by getting the securities with the desired payment frequency, taxation, liquidity, risk and return profiles, and other parameters. Thus, in this way, structured products, and TVS of no exception, benefit both investors and issuers economically by improving market completeness. As derivative instruments assist in information discovery and price reaction to the new pieces of information, TVS provides a next step in this regard as markets could react to the new positive or negative information more quickly by trading various levels of risk within the same underlying. Moreover, arbitrage trading benefiting from unfair spread between the combined value of TVSs and the underlying would narrower these spreads and ensure that the market prices represent the full currently available information, benefiting the market in price discovery and investors pursuing these opportunities. As a result of TVS issuance where each tranche is treaded as separate security, price revelation could be improved, as market liquidity for TVS could provide a great deal of information about the various levels of risk within the same underlying of the same issuer and about what informed market participants believe various value tranches are worth, which could potentially lead to the phenomena that TVS securities would be leading the price of underlying, instead of the opposite. 


\section{E. Further Work}

Successful launch of Tranched Value Securities requires further work to be done in order to minimize possible risks and misuse cases. As such, proper calibration of the pricing model is required in order to minimize instrument mispricing. Moreover, TVS, similar to any other innovation, requires verification of instrument compliance with applicable securities laws, and regulations. Tax treatment of TVS might also vary case by case in various jurisdictions, therefore, is another important aspect for consideration in further work to be done. Additionally, current analysis assumed perfect adherence to contractual provisions, however in developing markets with inefficient rule of law and capital markets regulations counterparty risk can be a significant issue where the issuers of TVS might decide to hold the value of underlying rather than paying to the investor that wishes to execute TVS position. Therefore, efficient legal base must be established, similar to traditional derivatives to assure successful implementation of TVS.

Currently advancing technology might already support the new instrument, however, in some instances it, together with market infrastructure might be required to be updated or modified to assure proper execution of TVS trades and corresponding obligations. Last, but not the least, among other possible directions of further work, marketing of the instrument to investors and possible involved parties, together with their education on it would be required to assure wide adoption and implementation of TVS.

\section{Conclusions}

Presented here Tranched Value Security instrument is simple enough to be implemented in the current market environment and given the current technological infrastructure, yet is sufficiently powerful to significantly widen investment universe currently available to investors. Analysis showed that TVS considerably transforms performance of the underlying, which can effectively be anything - starting from single financial or real assets, to complex cash flows, derivatives, indices, or other products. 
Tranched Value Security was shown to provide asymmetric payoffs which can satisfy various types of investor preferences without complex packing and repacking of multiple financial instruments, but rather can be implemented on a single security. Employment of TVS even on the most common securities - common stocks and fixed-income bonds can significantly transform performance of underlying. This allows to issue composite securities backed by a single one, as was suggested by Arnoud W. A. Boot and Anjan V. Thakor (September 1993) in order to maximize issuer's profits, be it underlying issuer, or investor holding underlying, and split it up into multiple value tranches which possess various levels of information sensitivity. As was shown above, it allows to amplify risk and return in some cases, and to narrower them in others. Moreover, TVS, similar to other derivatives allows trading the risk of underlying without trading the underlying itself, and create beneficial opportunities for all market participants, that do not exist in their absence, allowing for implementing more efficient trading strategies, and facilitating more effective risk management strategies. While the possible types of TVS securities are limitless with varying parameters, proper valuation models are required, and assessment of such securities in terms of compliance.

Therefore, efficient development and implementation of Tranched Value Securities can be a next step in improving market efficiency, and information discovery of underlying products.

\section{References}

Arnoud W. A. Boot and Anjan V. Thakor. (September 1993). Security Design. The Journal of Finance. 48 (4): 1349-1378.

Christian Felde. (January 2011). A deep dive into the January barometer. Retrieved from Blog of Christian Felde: https://blog.cfelde.com/2011/01/a-deep-dive-into-thejanuary-barometer/.

Dragos Bozdog, Ionut Florescu, Khaldoun Khashanah, and Jim Wang. (October 2018). Rare Events Analysis of High-Frequency Equity Data. Wilmott Journal. 74-81. 
Don M. Chance, PhD, CFA and Don M. Chance, PhD, CFA. (2013). Derivative Markets and Instruments. CFA Institute.

Dr. Helke Waelde. (2013). An overview of innovative financial instruments used to raise funds for international development. 11th Plenary Session of the Leading Group on Innovative Financing. KFW.

Eugene F. Fama and Kenneth R. French. (2008). Dissecting Anomalies. Journal of Finance. 63 (4): 1653-1678.

Gary L. Gastineau and Louis I. Margolis. (1994). The Future of Equity Derivatives: What Lies Ahead? Financial Analysts Journal. CFA Institute. 6-11

Haugen, R. A., \& Lakonishok, J. (1988). The incredible january effect: the stock market's unsolved mystery. Homewood, Illinois: Dow Jones-Irwin.

International Monetary Fund (IMF). (April 2008). GLOBAL FINANCIAL STABILITY REPORT. Containing Systemic Risks and Restoring Financial Soundness. Retrieved from International Monetary

Fund: https://www.imf.org/en/Publications/GFSR/Issues/2016/12/31/ContainingSystemic-Risks-and-Restoring-Financial-Soundness.

International Monetary Fund (IMF). (January 2019). Gross Domestic Product (GDP). Retrieved from International Monetary Fund: https://www.imf.org/external/datamapper/datasets/WEO/1.

Jegadeesh, N, and Titman, S. (2001). Profitability of Momentum Strategies: An evaluation of alternative explanations. Journal of Finance. 56 (2): 699-720.

John Reeves. (May 2009). Warren Buffett's Priceless Investment Advice. MSNBC. Retrieved from https://web.archive.org/web/20090530160842/http:/www.msnbc.msn.com/id/3074 3552.

Katarzyna Jakimowicz, David Osimo, Thomas Mayer, Francesco Mureddu, Ilaria Vigo, Emma Fau. (2017). New financial instruments for innovation as a way to bridge the gaps of EU innovation support. Final Report, European Comission, Directorate-General for Research and Innovation. 
Kenneth R. French. (March 1980). Stock returns and the weekend effect. Journal of Financial Economics. 8 (1): 55-69.

Maberly, Edwin D., and Raylene M. Pierce. (April 2004). Stock Market Efficiency Withstands another Challenge: Solving the "Sell in May/Buy after Halloween" Puzzle". Econ Journal Watch. 1 (1): 29-46.

Michael Simkovic. (2009). Secret Liens and the Financial Crisis of 2008. American Bankruptcy Law Journal.

Oliver Brockhaus. (2016). Equity Derivatives and Hybrids. Markets, Models and Methods. Applied Quantitative Finance. Palgrave Macmillan.

Riddiough, Timothy J. and Thompson, Howard E. (18/04/2012). Déjà Vu All Over Again: Agency, Uncertainty, Leverage and the Panic of 1857. HKIMR Working Paper No.10/2012.

Robert L. Kosowski and Salih N. Neftci. (2015). Principles of Financial Engineering, 3rd Edition. A volume in Academic Press Advanced Finance.

Saad E.W., Prokhorov D.V., and Wunsch D.C. (November 1998). Comparative study of stock trend prediction using time delay, recurrent and probabilistic neural networks. IEEE Transactions on Neural Networks. 9 (6): 1456-1470.

Saeed Moshiri, and Ardeshir Sepehri. (January 2007). Inflation-Growth Profiles Across Countries: Evidence from Developing and Developed Countries. International Review of Applied Economics. 18 (2): 191-207.

Schorin, C. and S. Weinreich. (1998). Collateralized Debt Obligation Handbook. Working Paper, Morgan Stanley Dean Witter, Fixed Income Research.

Teresa Meek. (February 2017). ASU research helps debunk myth of stock market 'weekend effect'. Retrieved from Arizona State University: https://asunow.asu.edu/20170201-discoveries-asu-research-debunks-myth-stockmarket-weekend-effect.

Vinod Kothari. (2006). Securitization. The Financial Instrument of the Future. John Wiley \& Sons (Asia) Pte Ltd. 